Ministry of education and science of Ukraine

Vinnitsa national technical university

O. Burykin, P. Lezhniuk, V. Kulyk, O. Rubanenko, Yu. Malogulko

\title{
OPTIMIZATION OF THE FUNCTIONING OF THE RENEWABLE ENERGY SOURCES IN THE LOCAL ELECTRICAL SYSTEMS
}

Monograph

Vinnitsa

VNTU

2018 
УДК 621.311.24+621.311.1

O-66

The authors:

O. Burykin, P. Lezhniuk, V. Kulyk, O. Rubanenko, Yu. Malogulko

Reviewers:

M. S. Segeda, Doctor of Technical Sciences, Professor

V. M. Kutin, Doctor of Technical Sciences, Professor

Recommended for publication by the Academic Council of the Vinnytsia National Technical University of the Ministry of Education and Science of Ukraine (Minutes № 4 dated November 30, 2017).

Optimization of the functioning of the renewable energy sources O-66 in the local electrical systems: monograph / O. Burykin, P. Lezhniuk, V. Kulyk and others. - Vinnytsia : VNTU, 2018. - 124 p. ISBN 978-966-641-719-3

The monograph considers the problem of the functioning of local power systems with different types of renewable energy sources (RES) in power grids by optimizing their connection schemes, as well as automation of a part of control functions, namely, optimal control of RES regimes, taking into account the peculiarities of their conversion of primary energy and electrical connections. The monograph is intended for specialists in the field of mathematical modeling and optimization of the work of renewable energy sources in distribution electrical networks, and may also be useful for students and graduate students of the appropriate direction.

УДК 621.311.24+621.311.1

ISBN 978-966-641-719-3

(C) O. Burykin, P. Lezhniuk, V. Kulyk, O. Rubanenko, Yu. Malogulko, 2018 


\section{CONTENT}

INTRODUCTION

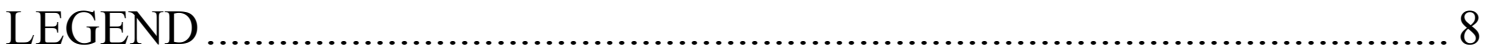

1 OPTIMIZATION PROBLEMS IN ELECTRIC NETWORKS

WITH RENEWABLE ENERGY

1.1 Problems of forming intellectual electric networks

according to Smart Grid concept

1.1.1 Principles of local electric systems with

renewable energy functioning in the Smart Grid concept

1.1.2 Standardization of intellectual local power systems

functioning at their integration into systems of centralized power supply

1.2 Comparative analysis of optimization tasks

for distributed power networks with RE

1.3 Tasks of functioning optimization of renewable energy sources in local electric systems

1.4 Research of methods for optimization renewable energy sources functioning in local electric systems

1.4.1 Optimal reconfiguration of local electric system............... 20

1.4.2 Mathematical model of local electric system

reconfiguration

1.4.3 Method of simple brute force search of edges

at optimal reconfiguration of local electric system

1.4.4 Model of electric network reconfiguration

basing on optimal power flow calculation

1.4.5 Expanded model of electric network

reconfiguration basing on optimal power flow model calculation

1.4.6 Complex approach to reconfiguration

of electric power network.

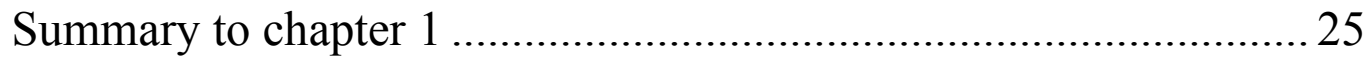

2 OPTIMIZATION OF CONECTION SCHEMES

AND OPERATING MODES FOR RENEWABLE ENERGY

SOURCES IN LOCAL ELECTRIC SYSTEMS

2.1 Problem of calculating optimal established power

in RES in local electric system by complex criteria

2.1.1 Method of calculating optimal established power

of renewable energy sources in local electric system .....

2.1.2 Method of optimization daily generation modes

of renewable energy sources in local electric system

2.1.3 Evaluation of probability of providing normative

power deviation for established reporting period 
2.1.4 Estimation of probability of providing normative electric energy and power losses

2.1.5 Calculation of weight factors of regression equations of complex optimality criterion for local electric system functioning

2.2 Method of defining optimal place of connecting renewable energy sources by criterion of minimal power losses in local electric systems

2.2.1 Mathematical model for estimation of power losses sensitivity in local electric systems to changes of renewable energy sources power generation.

2.2.2 Sensitivity indexes of power losses in edges

of local electric systems to power changes in nodes with renewable energy sources.

2.3 Modelling of optimality conditions for configuring optimality conditions of local electric systems with renewable energy sources by criterion of minimal electric power losses

Summary to chapter 2

3 AUTOMATION OF OPTIMAL CONTROL ON RENEWABLE ENERGY SOURCES IN LOCAL ELECTRIC SYSTEMS

3.1. Algorithm of practical realization of methods for defining optimal power of renewable energy sources in local electric systems.

3.1.1 Algorithm of defining optimal established power

of renewable energy sources in local electric system by complex criterion

3.1.2 Algorithm for optimizing daily generation modes

of renewable sources according to prognosticated loads schedule by complex criterion

3.2 Algorithm of defining optimal connection place

for renewable energy sources in local electric systems .

3.3 Operative control of schemes for power delivery

by renewable energy sources in local electric systems

3.3.1 Way of coordination generation schedules

for renewable energy sources and local electric systems' consumers

3.3.2 Law of optimal control of reconfiguration means

for RES power delivery schemes in local electric systems.

3.3.3 Algorithm of functioning for microprocessor device controlling on RES power delivery scheme in local electric systems 64

3.3.4 Definition of insensibility zone limits for microprocessor controlling device of renewable power sources basing on optimal decisions sensitivity analysis 
3.4 Automated system of control on power delivery scheme

for renewable energy sources in local electric systems

3.4.1 Particularities of hardware implementation a system

of control on power delivery of renewable energy sources

in local electric systems.

3.4.2 Study of functional stability of subsystem

for information exchange in local electric system .................................... 70

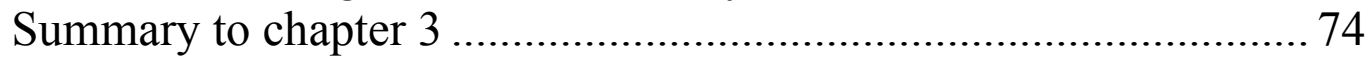

4 OPTIMIZATION OF RENEWABLE ENERGY SOURCES

FUNCTIONING IN LOCAL ELECTRIC SYSTEMS

4.1 Study of efficiency of applying the method

for defining established power of renewable energy

sources by complex criterion

4.1.1 Analysis of LES operation modes on the example

of $10 \mathrm{kV}$ electric networks of Yampilskyi district and

Tsekynivska solar power plant

4.1.2 Calculation of efficiency of using established power

of renewable energy sources by complex criterion in LES

on example of Tsekynivska solar power plant

4.1.3 Defining optimal established power of renewable

energy sources by complex criterion in LES on example

of Tsekynivska solar power plant № 1

4.2 Results of studying efficiency of applying improved

method for defining optimal places of connecting renewable

energy sources in local electric systems

4.3 Results of optimizing daily generation modes

of renewable energy sources and power consumers in local

electric systems on example of Tsekynivska solar power plant

4.4 Estimation of functional stability of subsystem

for information exchange in local electric system ................................. 92

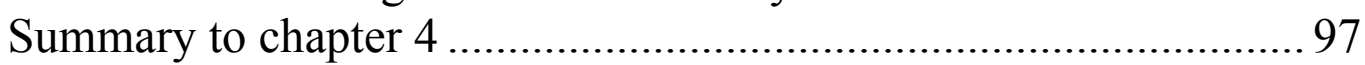

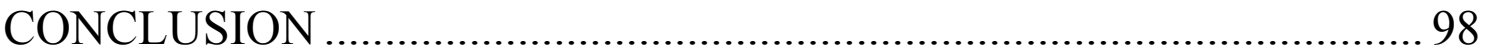

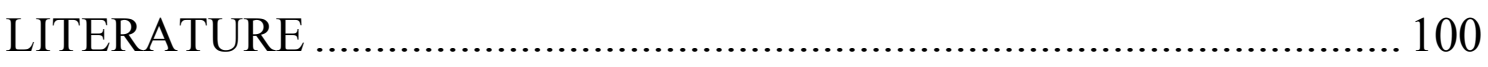

APPENDIX A Analysis of the tasks of distributive electric

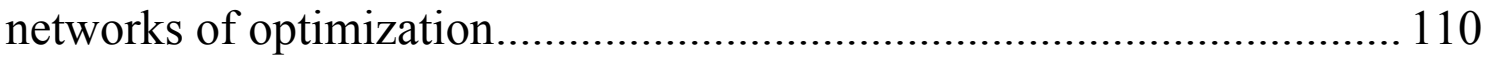

APPENDIX B Results of calculations from the research

of influence Sloboda-Buhanska SPP to the PN modes

$10 \mathrm{kV}$ F-45 substation «Mikhailivka»

APPENDIX C Output file for calculating the F-31 mode of the $110 / 10 \mathrm{kV}$ substation Sloboda-Pidlisivska

APPENDIX D Estimation of functional stability of the

subsystem of information exchange in local electrical systems 


\section{INTRODUCTION}

Modern global trends to decentralize power consumers that are associated with increasing cost of traditional fuel and manifested in the increasing proportion of distributed electricity production from renewable energy sources (RES), lead to complications planning regimes of electric power systems (EPS) and their operational management [1-3]. In addition, the combination of the mentioned above processes with economic power engineering reform - implementation of bilateral agreements - virtually prevent to organize the effective functioning of the EPS without improving their information infrastructure with a gradual transition to the concept of intellectual power networks (Smart Grid) [4-6].

State support for development of renewable energy stimulates research on the design and operation of renewable energy to enhance energy security and reduce the impact of energy on the environment. However, the issue of transportation of electricity produced renewable energy and functioning regional electricity networks (REN) in the new operating conditions are often neglected in the design phase of renewables and place of their accession to power networks (PN).

Lack of research about the design and operation of renewable energy in modern conditions and their impact on modes of electric EM, inconsistency of the specified main equipment to the needs of these sources, lack of information about the typical decisions regarding remedies and automate process electricity production of electricity prevents make informed design decisions during their development, moreover, can't effectively exploit them [7-10]. Thus important is the development of methodical, information and technical support of operation. Important in this regard is the complexity and methodological unity in decision making to improve the performance of renewable energy in their work in electric networks.

In the design scheme of power delivery from the source to the end user raises the need to harmonize their work with the system, of which implemented the central power. That scheme should meet the requirements of reliability for ensure stable power supply and connectivity to provide RES as close to the center of power consumption that will ensure minimum power losses at its transportation. 
Based on this, one can identify a number of important technical aspects of the development of renewable energy in local electric systems, which currently are not sufficiently investigated:

- research and analysis of regulations on the operation of renewable energy sources in the local electric system based on the concept of Smart Grid;

- analysis of the known methods of optimization of electrical networks from renewable energy sources;

- development of methods for determining optimal installed capacity and optimal placement of renewable energy sources in the local electrical system using the integrated optimality criterion;

- development of optimization method daily modes of generating renewable according to predictable schedule loads the local electrical system (LES);

- development of mathematical models of optimum configuration LES conditions and method and optimal control laws schemes issuing power of renewable energy sources;

- development of optimization algorithms installed capacity of renewables and places joining in the local electrical system;

- development of optimization algorithm to daily modes of RES generation according to the predictable schedule loads of LES;

- development of optimal control algorithm of changing configuration scheme for issuing renewable electricity by the criterion of minimum power losses.

Thus, the actual task of optimization of RES in local electric systems solve a problem of design - to determine the optimal installed capacity, and as operational problem - to optimize the daily mode of generating RES and circuits issuance of power electrical energy by local electric networks with RES. This can increase the profitability of energy utilities and power generating companies by improving performance characteristics of electrical equipment in LES. The aim of our work is to improve the efficiency of renewable energy in electrical distribution networks by improving the methods and means of optimizing transport electricity produced. 


\section{LEGEND}

ACS - automatic control system;

AUC - automated control system;

CU - condensing units;

DB - data base;

DES - distributed energy sources;

e.f. - electromotive force;

EPS - electric power system;

ES - electric system;

HPP - hydraulic power plant;

LES - local electric system;

LESR - local electric systems reconfiguration;

OIC - operative-information complex;

PL - power line;

PSPS - pumped storage power station;

PN - power networks;

RE - renewable energy;

REN - region electric network;

SH - small hydro;

SP - software package;

SPP - solar power plant (direct power conversion);

WF $\quad$ - wind farm. 


\section{OPTIMIZATION PROBLEMS IN ELECTRIC NETWORKS WITH RENEWABLE ENERGY}

\subsection{Problems of forming intellectual electric networks according to Smart Grid concept}

Current trends in world power generation industry development are directed on electric networks modernization. Most of the world industrially developed countries comprehend the necessity of increasing the power efficiency in the context of global warming problems. So, they stimulate development of alternative and renewable energy, as well as increase of automatic optimization and control in electric networks, improvement of relay protection facilities etc. [4].

Development of power generation industry set the problem of gradual transition from traditional technologies that expect use of electric networks centralized generating to basically new solution that is directed to wide application of distributed energy sources and active networks able to provide services on transfer, keeping and transformation of electrical power. Active electric systems are able to adapt quickly to variable needs of interested parties - owners, consumers, vendors. They are considered to be the key element of infrastructure of the future "intellectual" power systems. At present all the aspects of creating "intellectual" power systems are viewed within the Smart Grid concept, the most known and popular concept for electric networks modernization [5-6].

Such a concept is characterized by bilateral electrical energy and information streams for creating automated, widely branched distribution grid. Within it, information exchange goes on between communication domains of generating, transfer, distribution and consumption of electric power that are physically presented by systems of production automation and control for each domain [11]. Besides bilateral electrical energy streams and information exchange, this concept provides implementation of current control, protection and functioning optimization of all interacting elements. Those elements include powerful generators and renewable energy sources that are connected with industrial consumers, energystorage units as well as end users using to main and distributed networks.

It is worth to accentuate that Smart Grid is not just new energy technologies, but also modern information and communication technologies for billing, e-commerce, access and administration control in the networks of various scale, data modeling and storage, virtualization, 
computer safety, distributed information computing, collection, processing and transfer real-time [22]. In fact, Smart Grid should be considered not as a single technology, but as a complex approach and methods of creating large-scale «intellectual» enterprises that function on base of new technologic platform and provide a wide range of services with use of information and power technologies.

Specialists think [23] that use of modern management technologies together with wide use of new information and communication technologies will give the possibility to support supply and demand in "intellectual" power systems on the level of a single device. Smart Grid will enable users to take part in power system functioning consciously, at that using assets in power generation industry will improve, economic efficiency will increase, as also quality of electric power and stability of power systems against unendorsed external influence. Finally, transition to "intellectual" power systems will push to development of new types of production and services, and formation of new markets.

\subsubsection{Principles of local electric systems with renewable energy functioning in the Smart Grid concept}

Principles of Smart Grid operation consist in integration and automation of generation, transfer and consumption processes. In general case Smart Grid technologies are understood as a set of software and hardware tools that contribute increase of electric power transfer efficiency. Efficiency is comprehended as:

- decentralization of functions generating and controlling electric energy and information streams in a power system;

- reducing of expenses for arranging power transmission system;

- rapid elimination problem;

- possibility to transfer electric power and information in two directions that is considered an important condition for the concept of distributed power generation industry and use of renewable energy.

Electric network based on Smart Grid concept unites two subsystems:

- electric power transfer subsystem;

- information exchange subsystem.

So, besides conventional power lines, information connections that join all participants of electric power market are introduced. Rough membership of market participants and connection between them is shown on fig. 1.1. 







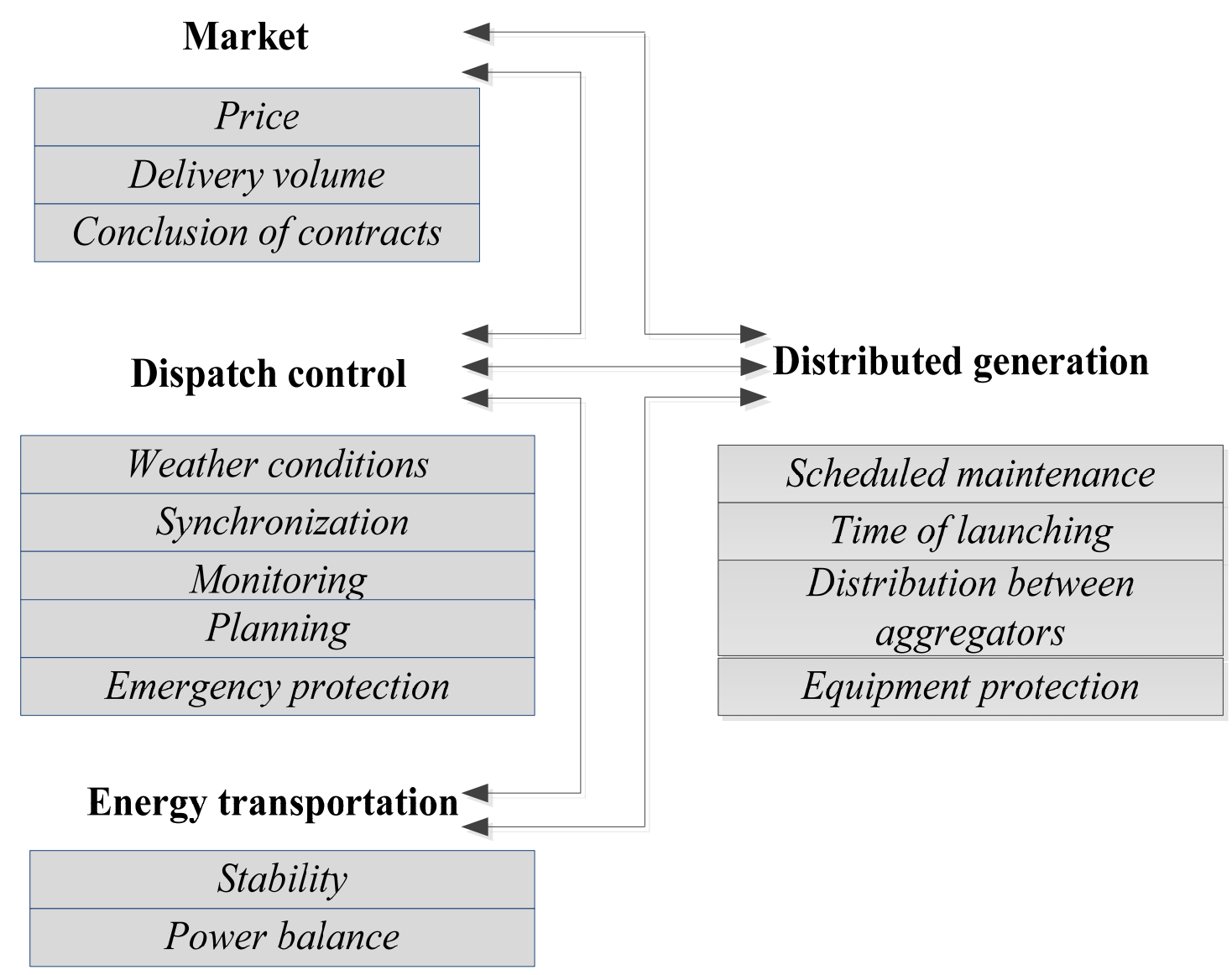

Figure 1.2 - Main functions of separate Smart Grid domains related to power generation due to renewable energy

Domain "Distributed generation" joins power stations, including RE of various types that deliver electric power to distributed electric grids. Its main job is to increase efficiency of electric power production by such sources. Special complexities occur on the way of optimizing wind farms and solar power plants as their modes are defined by stochastic influence of the environment. At this it is almost impossible to store primary energy (as, for example, in case of small HPP). The described domain relates to information streams with domains of control, power market functioning arrangement, and also with energy transportation domain. Information connection with the last one is the most important as the transportation domain functionally fulfills, together with other domains, data collection and processing, equipment protection, operating optimization and other.

Information connections allow to take into consideration operational specialties of different power stations that use RE, especially WF and SPP, where the process of electric power production has a number of technical 
and organizational peculiarities. Information connections with the domain «Market» allow to coordinate tasks of EPS with affirmed delivery volumes of electric power by terms of bilateral contracts, power market conjunction, correcting prices on electric power supplies and other system services.

1.1.2 Standardization of intellectual local power systems functioning at their integration into systems of centralized power supply

Today many world countries has a set of Smart Grid standards for means of relay protection, control and monitoring of main and distributed networks [24-32]. Among them special attention is paid to standards related to connection of renewable energy sources of distributed generation for parallel work with existing electric power systems. These standards are technologically neutral and universal for all types of RE up to $10 \mathrm{MVA}$ and regulate technical specification to electric power systems with renewable sources of generation. Standards include general requirements to RE at normal and emergency modes, requirements to voltage quality indicators, separate and parallel work with electric power system, requirements to connection and synchronization of RE generators, as well as specifications and requirements to design, production, assembling, putting into operation and periodic tests.

There are about hundred standards that relate to Smart Grid. Among them - IEC standards ("Standards for power quality" and "Flicker Standards"), CSA standards (CAN3-C235-83, 107.1/UL1741, C22.2, C.22.3, C22.1), IEEEP2030 standards and other. In complex with these standards, principles of providing interoperability to power technologies, information technologies with elements of power systems, automation of end users and users loading devices are considered. The main standard that regulates RE connection to parallel work is the standard of the Institute of Electrical and Electronics Engineers (IEEE 1547) [33]. The current standard sets up criteria and requirements for connecting RE with EPS. System of IEEE 1547 standards includes a number of documents concerned with different aspects of providing interaction and coherency between distributed resources, integrated to the composition of power systems, and consists of parts:

- IEEE 1547.1 - standard for the general procedure of accordance of connecting RE to a power system.

- IEEE 1547.2 - provides detailed instructions of connection to parallel work. 
- IEEE 1547.3 - requirements to information exchange, RE monitoring and control.

- IEEE 1547.4 - requirements to equipment and its exploitation in separate power systems with RE.

- IEEE 1547.5 - assigned to RE with the power higher than 10 MVA.

- IEEE 1547.6 - practical aspects of connecting RE to distributed grids.

Nowadays the process of connecting to parallel work of RE to Ukraine's power systems does not have any clear branch regulatory guide or standard. That is why growth of RE quantity leads to worsening of technical problems regarding arrangement of their parallel work in power system - providing consistency of operation, quality of electric power, arranging dispatch control, including control of separating RE from power system, synchronizing RE with power system.

Parallel work of RE in power grids is partially regulated by rules of connecting electricity-generating equipment to power grids, approved by regulation of National Energy and Utilities Regulatory Commission dated by 14.12.2005 with changes and attachments dated by 20.09.2007 [34]. The regulation includes just organizational moments of connecting electricitygenerating equipment destined for electric power production. So, technical specifications of connecting RE to power systems are regulated by a number of regulatory documents, all-Union State Standards and Ukraine State Standards. With the aim to verify the possibility to use the experience of foreign countries, it is sufficient to compare technical specifications of IEEE 1547 standard, Germany standards [35], project of requirements of connecting RE in Ukraine [36] and acting all-Union State Standard 1310997 «Quality standard for electric power in the systems of electricity supply of general purpose» [37] that is basic for Ukraine's energetics. Comparative analysis of requirements to quality of electric power according to provided regulatory documents is shown in table 1.1

Comparative analysis shows on appropriateness of solving a complex of tasks on RE functioning optimization in local power systems considering indicators of quality and loss of electric power with further conversion to a single standard. This standard will regulate connection to parallel RE work in Ukraine taking into account the strategy for developing power systems. This will expand opportunities to use RE and users' resources, as well as allow to perform LES functioning optimization taking into consideration improvement of interaction between all system's subjects in real time. 
Table 1.1 - Comparative analysis of electric power quality indicators

\begin{tabular}{|c|c|c|c|c|}
\hline \multirow[b]{2}{*}{ Indicator } & \multicolumn{4}{|c|}{ Specifications according to regulatory document } \\
\hline & 1547 IEEE & $\begin{array}{l}\text { All-Union State } \\
\text { Standard 13109-97 }\end{array}$ & $\begin{array}{l}\text { Project of } \\
\text { requirements to } \\
\text { connection of RE } \\
\text { in Ukraine }\end{array}$ & $\begin{array}{l}\text { Standards } \\
\text { in Germany }\end{array}$ \\
\hline $\begin{array}{l}\text { Frequency } \\
\text { deviation }\end{array}$ & $\begin{array}{l}\quad \text { Allowable } \\
\text { frequency } \\
\text { deviation in RE } \\
\text { should not } \\
\text { exceed the } \\
\text { value from }-0.2 \\
\text { to }+0.5 \mathrm{GHz} \text { in } \\
\text { synchronized } \\
\text { systems. }\end{array}$ & \begin{tabular}{l}
\multicolumn{1}{c}{ Frequency } \\
deviation in \\
synchronized \\
systems of power \\
supply should not \\
exceed $\pm 0.2 \mathrm{GHz}$ \\
in separate systems \\
of power supply \\
deviation makes up \\
$\pm 1 \mathrm{GHz}$.
\end{tabular} & $\begin{array}{l}\text { Frequency } \\
\text { should retain } \\
\text { between } 49.6 \\
\text { (allowable critical } \\
\text { decrease of } \\
\text { frequency) and } \\
50 \mathrm{GHz} \\
\text { (allowable normal } \\
\text { increase of } \\
\text { frequency). }\end{array}$ & $\begin{array}{l}\text { Frequency } \\
\text { should retain } \\
\text { between } 47.5 \\
\text { (allowable } \\
\text { critical } \\
\text { decrease of } \\
\text { frequency) } \\
\text { and } 51.5 \mathrm{GHz} \\
\text { (allowable } \\
\text { normal } \\
\text { increase of } \\
\text { frequency). }\end{array}$ \\
\hline $\begin{array}{l}\text { Harmoni } \\
\text { cs }\end{array}$ & $\begin{array}{l}\quad \text { Maximum } \\
\text { harmonics } \\
\text { component of } \\
\text { current makes } \\
\text { up } 4 \% \text { for odd } \\
\text { harmonics } \\
\mathrm{n}=11 \text {. }\end{array}$ & $\begin{array}{l}\quad \text { Value of } \\
\text { harmonic } \\
\text { component of } \\
\text { current is between } \\
0,2 \text { and } 6 \% \text { of } \\
\text { Unomina } 1 \% \text {. }\end{array}$ & $\begin{array}{l}\quad \text { Value of } \\
\text { harmonic } \\
\text { component of } \\
\text { current is } \\
\text { between } 0.2 \text { and } \\
6 \% \text { of Unomina } \\
1 \% \text {. }\end{array}$ & $\begin{array}{l}\text { Maximal } \\
\text { harmonic } \\
\text { component of } \\
\text { current is } \\
\text { between } \\
0.058-0.04 \% \text {, } \\
\text { for odd } \\
\text { harmonics } \\
0.06-0.18 . \%\end{array}$ \\
\hline $\begin{array}{c}\text { Voltage } \\
\text { fluctuation }\end{array}$ & \begin{tabular}{l}
\multicolumn{1}{c}{ Voltage } \\
fluctuation on \\
RE wires in \\
normal working \\
conditions \\
should not \\
exceed value \\
from -12 \\
to $+10 \%$. \\
\end{tabular} & $\begin{array}{l}\text { Normal } \\
\text { allowable voltage } \\
\text { fluctuation is } \\
\pm 5 \% \text {. Allowable } \\
\text { critical one is } \\
\pm 10 \% \text {. }\end{array}$ & $\begin{array}{l}\text { Normal } \\
\text { allowable voltage } \\
\text { fluctuation is } \\
\pm 5 \% \text {. Allowable } \\
\text { critical one is } \\
\pm 10 \% \text {. }\end{array}$ & $\begin{array}{l}\quad \text { Voltage } \\
\text { fluctuation } \\
\text { within power } \\
\text { grids on RE } \\
\text { wires is not } \\
\text { more than } \\
2 \% \text {. }\end{array}$ \\
\hline
\end{tabular}

\subsection{Comparative analysis of optimization tasks for distributed power networks with $R E$}

A number of optimization tasks for distributed power networks with $\mathrm{RE}$ is solved in engineering practice of different countries. They can be divided into those solved on the stages of developing and exploitation 
(fig. 1.3). Optimization tasks like autonomous work, disposition of commutation equipment and formation of communication network are closely interrelated and almost cannot be solved in modern conditions [38]. RE autonomous work, considering conditional controllability and instability of those energy source, is in fact impossible without a developed communication network. Availability of the last one will allow to get bilateral connection between RE and electric power consumers, according to Smart Grid concept, and regulate modes of power consumption, supporting autonomous work conditions.



Figure 1.3 - Task of optimization of distributed power grids with RE 
Usually mentioned tasks are solved by decomposing to tasks of RE functioning optimization and tasks of PN functioning. Depending on tasks in place, each of them is solved using one of the optimally criterion, such as: minimum power losses [39-40], power quality [41], power supply stability [42], transfer capacity [43-44], rate of voltage recovery [45-46], maximum of power realization [47], maximal financial returns [48], minimal investments [49] etc. Overview of optimization tasks for distributed power networks with RE is given in the attachment $\mathrm{A}$.

When choosing optimally criterion and forming the appropriate mathematical model, it is worth considering that at the same time with the development of distributed generation, economic conditions of electric power functioning as a branch also change, in particular, transition to a new competitive model of wholesale power market - market of bilateral contracts and compensative power market.

In case of power supply implementation by bilateral contracts with involvement of RE, when the last delivers power to electric power grid, necessity to coordinate their work with power system that supplies centralized supply arises. This becomes mandatory when established power of RE in PN makes up a significant part of its total load (for example, $20 \%$ and more). In this case, REN may and should be considered as a local electric system (LES), where tasks of exploring static and dynamic RE stability and other tasks typical for an electric system arise, besides the mentioned ones [38].

Among complex of tasks that arise during the process of introducing $\mathrm{RE}$, it is reasonable to study and solve, first of all, those that influence directly on scales and intensity of RE development, and those that at right solving, together with "green tariffs", will form a solid motivation for investors and power supply countries regarding RE development in Ukraine.

Such a task, in particular, is the task of getting maximum revenue from RE exploitation for their development in condition of reducing electric power losses and improving its quality in LEN, as well as increasing stability of power supply [38]. At this, considering that electric power from RE is transferred by LEN wires simultaneously with electric power of other sources, it is necessary to distinguish the part that relates to transit from RE from total power losses. 


\subsection{Tasks of functioning optimization of renewable energy sources in local electric systems}

To research conditions of RE optimal functioning, optimization tasks (see attachment A) inherent to exploitation of such electric power sources in LES are analyzed. Basing on analysis, list of LES with RE functioning optimization tasks was adapted to specifications of their operation in Ukraine's electric power system.

1. For optimization of RE functioning in normal operating modes of electric power systems, problems of planning organization and operative control of operating modes of such stations with the aim of getting maximum revenue from their exploitation are extremely actual. So, for the present time the most actual task, considering the specifics of providing profitability of RE $[50,52]$, is the problem of optimizing daily modes (on time interval $\left[t_{0} ; t_{k}\right]$ ) of driven energy sources $P_{i}(t), i=1,2 \ldots n$ (for example $\mathrm{SH})$ with consideration of modes of conditionally controllable sources for providing maximum revenue from implementing their electric power in conditions of multistage tariff of power market $\mathrm{c}(t)$ and technical restrictions from the side of separate RE [53]:

$$
\int_{t_{0}}^{t_{k}} \mathrm{c}(t) \sum_{i=1}^{n} P_{i}(t) d t \rightarrow \max
$$

2. In case of RE control in modes related to localization of abnormal situations in a power system, it is reasonable to pass to solving the task of RE mode optimization with the aim of decreasing the dependence of LES with cumulative load $P_{\text {load }}(t)$ from centralized power supply, i.e. minimization of LES load to main supply center $P_{\mathrm{MSC}}(t)[50,53]$ :

$$
\int_{t_{0}}^{t_{k}} P_{\mathrm{MSC}}(t) d t \rightarrow \min
$$

with consideration of balance restriction: $P_{\mathrm{MSC}}(t)+\sum_{i=1}^{n} P_{i}(t)-P_{\mathrm{load}}(t)=0$. 
3. To provide LES stability in the periods of maximum (minimum) consumption or limited carrying capacity of the centralized power supply system, when varying of local generation parameters may lead to breaking restrictions to ES mode parameters, optimization of RE modes is topical, as the goal is to minimize deviations from established centralized graph of cumulative generation at specified restrictions to primary power resources and RE characteristics [50, 53]:

$$
\int_{t_{0}}^{t_{k}} \frac{1}{2}\left(P_{\mathrm{RE}}(t)-\sum_{i=1}^{n} P_{i}(t)\right)^{2} d t \rightarrow \min .
$$

Here predictive information about meteorological parameters that is provided by a proper AUC subsystem should be considered [5].

4. To provide RE profitability, especially topical are the problems of planning organization and operative control of their operation modes with the aim to get maximum revenue from electric power realization $[50,52]$. RE functioning in local electric power system is subject to particular control rules depending on situation. But applying calculus of variations methods combined with criterial method allows to get generalized optimality conditions for optimization tasks that differ just by value of parameters $[50,83]$.

Complex of $n$ controlled RE (on example of SH) and $m$ conditionally controlled wind farms (WF) and SPP is specified. The expected value of their total active power makes up:

$$
M_{V A R}(t)=M_{\mathrm{WF}}\{P(t)\}+M_{\mathrm{SPP}}\{P(t)\} .
$$

It is necessary to find modes of controlled sources (small hydro) $P_{i}(t)$ on time interval $\left[t_{0} ; t_{k}\right]$ that would provide maximum revenue from realization of electric power of all RE complex on electric power market:

$$
\int_{t_{0}}^{t_{k}} \mathrm{c}(t)\left[\sum_{i=1}^{n} P_{i}(t)+M_{V A R}(t)-k_{\mathrm{c}}(t) \cdot \Delta P_{\mathrm{RE}}(t)\right] d t \rightarrow \max ,
$$


where $k_{\mathrm{c}}(t)$ is weight factor determined by correlation of selling tariff for RE $\mathrm{c}(t)$ and cost of power losses for given distribution network $\bigsqcup_{0}$ and depends on conditions of electric power transfer contract;

$\Delta P_{\mathrm{RE}}(t)$ - component of power losses in distribution power networks specified by RE functioning.

In the quality of restrictions, daily flows on each $\mathrm{SH}$ are specified $W_{i}-\int_{t_{0}}^{t_{k}} Q_{i}(t) d t=0$, as well as the balance of flows in cascades. It is also necessary to consider inequality constraint on power of controlled RE $P_{i}^{\min } \leq P_{i}(t) \leq P_{i}^{\max }$, and also on head $H_{i}^{\min } \leq H_{i}(t) \leq H_{i}^{\max }$, herewith limit values $P_{i}\left(t_{0}\right)$ and $P_{i}\left(t_{k}\right)$ are considered to be known.

In fact, optimization task for RE in LES functioning is reduced to providing maximum electric power delivery by controlled sources, independently on power networks and conditionally controlled RE work modes [50]:

$$
\int_{t_{0}}^{t_{k}} \mathrm{c}(t) k_{\mathrm{tr}} \sum_{i=1}^{n} P_{i}(t) d t \rightarrow \max ,
$$

where $k_{t r}$ is the factor that considers revenue diminution for RE due to compensation of losses to transporting electric power by networks.

Analysis of conditions of optimal functioning modes in local electric power renewable sources showed that to reduce electric power losses and improve its quality indicators it is reasonable passing to solving of complex LES scheme optimization task, which provides for implementation of efficient project solutions and introducing systems for operative reconfigurations of RE connection schemes.

\subsection{Research of methods for optimization renewable energy sources functioning in local electric systems}

\subsubsection{Optimal reconfiguration of local electric system}

As it happens that LES is loaded irregularly, it needs correction of power flow that may be executed by proper grid reconfiguration. Reconfiguration is the process of changing LES configuration by changing the position of commutation devices, changing at the same time network 
state. Grid reconfiguration is necessary for losses minimization, load switching from one feeder to another, improving voltage levels and removal of line's abnormal areas. Also, LES reconfiguration is part of power supply system functioning.

LES cause much power losses because of low voltage level in distribution system. The goal of their reconfiguration is finding a radial structure that minimizes power losses in them at normal exploitation conditions. Usually such systems are designed like interconnected networks that during work are assembled as a radial structure. This means that distribution systems are divided to subsystems of radial feeders that consist of a set of normally locked and normally unlocked switchers.

According to graphs theory, LES may be presented by a graph $G$ $(\mathrm{N}, \mathrm{B})$ that consists of multitude nodes $\mathrm{N}$ and a set of edges $\mathrm{B}$. Each node is a power supply node or loading node, while an edge is section of feeder that may be loaded or unloaded. The grid is radial only if feeder's sections form trees where each loading node gets energy uniformly from one power supply node. So, LES reconfiguration problem is finding of a radial structure that minimizes power losses in electric power system, meeting controlling restrictions [54]. In fact, LES reconfiguration may be viewed as the task of detecting the optimal tree for given graph. To solve LES reconfiguration task, many solutions are applied.

In [55-56] combinative optimization of reducing power losses in LES was first suggested. According to combinative nature of the problem, requirements to verification of a big number of reconfigurations for real system's dimension are made. In [57-58] heuristic and modified methods for restoring loading servicing and balancing on feeders are suggested. Functioning conditions are checked using power flow that is figured out by Newton-Raphson modified method. In [59] methods of heuristic reconfiguration based on substituting an edge for reduction power losses and loading balance in a feeder are presented. Beside this, according to these methods, algebraic expressions that allow estimation of loss for given topology are offered. In [60] expert system for solving problems of restoration and reduction power losses in LES is offered, where reconfiguration problems are a combinative problem of non-linear optimization. To find an optimal solution, it's necessary to review all 
potential trees that are formed due to turning on/off switchers that exist in the network.

In [61] it is suggested to study LES reconfiguration (LESR) basing on rule of complex approach. LESR model allows to minimize system's power losses. Rules used for choosing optimal LESR are formed on base of system functioning experience and types of switching edges [62].

\subsubsection{Mathematical model of local electric system reconfiguration}

Mathematical model of LESR may be presented as an expression for current or power determination in an edge [54].

$$
M \inf =\sum_{i=1}^{N L} k_{l} \cdot R_{l} \cdot\left(\frac{P_{l}^{2}+Q_{l}^{2}}{U_{l}^{2}}\right), \quad l \in N L .
$$

At limitations like:

$$
\begin{gathered}
k_{l}\left|P_{l}\right| \leq P_{l_{\max }}, l \in N L ; \\
k_{l}\left|Q_{l}\right| \leq Q_{l_{\max }}, l \in N L ; \\
U_{l_{\min }} \leq U_{i} \leq U_{l_{\max }}, i \in N,
\end{gathered}
$$

when implementing first Kirchhoff's law: $g_{i}(P, k)=0, g_{i}(Q, k)=0$ and considering radial structure $\varphi(k)=0$,

where $P_{l}-$ the real active power in edge 1 ;

$Q_{l}$ - reactive power in edge 1 ;

$R_{l}$ - resistance in edge 1 ;

$V_{l}$ - voltage in node i;

$k_{l}$ - factor that indicates edges topology;

$k_{l}=1$, if 1 edge is locked;

$k_{l}=0$, if 1 edge is unlocked;

$N$ - number of nodes;

$N_{L}$ - number of nodes. 


\subsubsection{Method of simple brute force search of edges at optimal reconfiguration of local electric system}

The main idea of heuristic method of brute force search lies in calculation of changing power losses from a pair of switchers, one of which is switched off and the other is switched on [54]. The goal of given method is reduction of power losses. It advantages are simplicity and easiness of comprehension. Disadvantages:

- end reconfiguration depends on primary reconfiguration;

- solution is a local but not a global optimum;

- much time is wasted for selection and exploitation of each pair of switchers, and also for calculation of proper power flow in radial network.

The given methods use two approximate power flows for radial networks with different accuracy degree. Besides this, methods include offered algebraic expressions that allow to estimate losses for the given topology.

\subsubsection{Model of electric network reconfiguration basing on optimal power flow calculation}

If to substitute complex resistance of all edges in locked network to similar edge with active resistance, then power flow that meets Kirchhoff's laws is called optimal power flow. When power flow in a circuit is optimal, power losses in electric network are also minimal, respectively. So, the main idea of optimal power flow is to unlock the edge in a way to have minimal value of current in the circuit [63].

Advantages of this method:

- end network reconfiguration does not depend on primary network's topology;

- rate of calculations is rather higher than at edges simple brute force method;

- problem of complex combination of switcher's functioning becomes a heuristic problem because of each time unlocking of one switcher.

Disadvantages of the method:

- if there are many unlocked switchers in a network, that means that calculation of optimal power flow includes multitude circuits. Final decision cannot be optimal because of circuits' interference;

- when power flow is calculated due to equivalent current method, it needs calculation of resistance matrix. This leads to load calculation;

- it is necessary to calculate load power flow of locked network two times for each separate switcher operation (before and after its unlocking). 


\subsubsection{Expanded model of electric network reconfiguration basing on optimal power flow model calculation}

Improved model of optimal power flow combines advantages of two heuristic algorithms [57], but it does not include the case of closing of all normally-open switchers but just closing of one switcher and closing of another each time. Besides this, this method focuses on changing losses caused by switcher turning.

Improved model of optimal power flow removes interference between several circuits. Though convergence process is related with primary network, final solutions are stable and not related to order of switching [64]. Necessity to calculate power flow for turning each pair of switchers two times and dependence of convergence process and rate from order of switchers turning are considerable disadvantages.

\subsubsection{Complex approach to reconfiguration of electric power network}

Unlike traditional heuristic method of brute force edge search, method of complex approach joins traditional approach and a set of rules. Rules used for choice of LES optimal reconfiguration are formed basing on exploitation system experience.

In the given method switching of edges is divided into 3 types:

Type $1-$ switching of edges is planned for servicing in short terms according to schedule of equipment' technical servicing;

Type 2 - power exchange at edges switching almost reaches its maximal limits (up to $90 \%$ );

Type 3 - switching of other edges that have sufficient carrying capacity in terms of system's operation.

So, for modified heuristic approach such rules are applied:

a) if switching of edges leads to power losses growth in the system, such edges are not switched off;

b) if switching of edges leads to reduction of power losses but causes system's reload, such edges are not switched on;

c) if an edge relates to abovementioned types and can also lead to reduction of power losses in electric power system, it is necessary to choose the type of edge that will lead to maximal decrease of $\triangle P L_{I}$ power losses.

d) if switching of edges relates to $2^{\text {nd }}$ type and can also lead to reduction of power losses in an electric power system, it is necessary to 
choose the type of edge that will lead to maximum decrease of $\triangle P L_{I I}$ power losses.

e) if switching of edges relates to $3^{\text {rd }}$ type and can also lead to decrease of power losses in an electric power systems, it is necessary to choose the type of edge that will lead to maximum decrease of $\triangle P L_{I I I}$ power losses.

f) for items c) - d) the following formula for determining an edge that will switch is applied:

$$
P I_{s w i}=\frac{W_{i} \cdot \Delta P L_{i}}{W_{I} \cdot \Delta P L_{I}+W_{I I} \cdot \Delta P L_{I I}+W_{I I I} \cdot \Delta P L_{I I I}} \cdot i=I, I I, I I I
$$

where $\triangle P L_{i}$ - change of power losses in system before and after switching the edge; $W$ - weight coefficient of edge switching types differences. Weight coefficients for three types of switching may take on values: $1 ; 0.6$ and 0.3 respectively; $\triangle P L s w_{i}$ - coefficient for i edge switching efficiency. The biggest $\triangle P L s w_{i}$ switches at every circuit switching.

In the result of performed study it was shown that development and introduction of operative optimization way for schemes of RE power delivery to electric networks with the use of analytic optimality conditions by complex criteria that includes power quality parameters and overrated losses, will allow to provide LES normal modes optimality in the process rate taking into account modern specifications to technologic process.

\section{Summary to chapter 1}

To increase technical and economic efficiency of renewable energy sources and distributed electric networks joint exploitation, it is necessary to solve tasks that allow to increase production of energy by RE, decrease electric power losses in distributed electric power systems and raise its quality.

With the aim of renewable energy sources efficient exploitation and their efficient use in electric networks of power systems, it is necessary to study their peculiarities and new features that arise in the result of joint work of these networks in the composition of electric power systems.

It is also necessary to develop a method of detecting optimal established RE power in LES and method of optimizing daily generating modes for renewable energy sources in local electric system. This will 
allow to evaluate real influence of specific RE to parameters of REN mode, including technical and economic indexes of those networks, and define place and role of distributed generation in power supply system.

Basing on above mentioned, it is necessary to:

- develop methods of detecting optimal established power and optimal place of connecting renewable energy sources in local electric system by complex optimality criteria;

- develop method for optimizing daily generation modes of renewable sources regarding prognosticated load schedule of local electric system;

- develop mathematical models for LES configuration optimality conditions, as well as way and law of optimal control of schemes that deliver power from renewable energy sources;

- algorithms for optimization established power and places of RE connection in local electric system, algorithm for optimization of RE generation daily modes according to prognosticated graphic of LES loads and algorithm of optimal control of means for changing configuration schemes of issuing electric power by RE by criteria of minimal power losses.

Solving of above mentioned tasks will allow to develop methods and algorithms of optimization of graphs for combined use in EN of differenttypes RE with consideration of specifications and conditions of centralized supply. 


\section{OPTIMIZATION OF CONECTION SCHEMES AND OPERATING MODES FOR RENEWABLE ENERGY SOURCES IN LOCAL ELECTRIC SYSTEMS}

Problem of RES functioning optimization in local electric systems with the aim to increase revenue, providing qualitative power supply to consumers and decrease of power losses nowadays is still not much studied [7-10]. Important thing here is studying RES influence to LES operating modes, and also considering interference of LES parameters, at the same time.

RES owners are often forced to compensate baselessly overstated normative power losses to electric power market or to third parties. For example, for SH compensation of losses may reach up to $20 \%$ from supplied electric power. This, in its turn, leads to reduction of profitability expected from investments to SH building and restoration.

Studying of RES functioning with the aim to optimize the place of their connection by the criteria of minimal power losses in LES, modeling of mode optimality conditions for LES with RES by complex criteria, as well as developing a mathematical model for evaluation of power losses sensitivity in LES to changes of RES power generation will allow to create conditions for providing efficient LES functioning.

So, in this chapter problems of calculating optimal power of RES in LES and forming optimality conditions of their functioning by complex criteria that considers revenue from electric power sale, its quality and losses for transferring by power networks are solved.

\subsection{Problem of calculating optimal established power in RES in local electric system by complex criteria}

Considering the specifics of providing LES profitability, it's worth solving the problem of calculating the optimal power of conditionally controlled renewable energy sources $P_{j}^{\mathrm{RES}}, j=1,2 \ldots n$ by complex criteria that takes into account conditions of multilevel power market tariff $u_{j}$ and indexes of LES functioning efficiency. As components of optimality criteria for functioning showings of the mentioned above system it's worth using power quality showings and losses for its transfer by LES networks (see item 1.2) to provide maximum revenue from their electric power realization. 
Depending on the goal set, the mentioned problem may be solved as a design problem - to define optimal established power, and as exploitation one - to optimize daily modes of renewable energy sources operation, according to prognosticated LES load schedule.

\subsubsection{Method of calculating optimal established power of} renewable energy sources in local electric system

To solve the problem of calculating optimal established power by complex criteria considering the specifics of providing LES profitability, it's worth using such an expression of total revenue from RES functioning, connected to parallel work in LES:

$$
\mathrm{C}^{\mathrm{RES}}=\sum_{j=1}^{n}\left[\mathrm{z}_{\mathrm{j}} \cdot P_{j}^{R E S} \cdot k_{f_{j}} \cdot T\right]
$$

where $P_{j}^{\mathrm{RES}}$ - established power of RES $j, \mathrm{~kW} ; z_{j}$ - tariff for electric power production by $j$ RES («green tariff»), kop/kW·hour; $k_{\mathrm{f}_{j}}$ - factor of using established power of $j$ RES; $T$ - load schedule duration, hour

Considering (2.1), target function of the problem on choosing optimal established power of renewable energy sources in LES looks like:

$$
\mathrm{F}=\mathrm{C}^{\mathrm{RES}} \cdot e^{-z_{1}} \cdot e^{-z_{2}} \rightarrow \max
$$

with restriction:

$$
\sum_{j=1}^{n} P_{j}^{\mathrm{RES}}-\sum_{g=1}^{m} P_{\mathrm{l}_{g}} \leq P_{\mathrm{lim}}
$$

where $e^{-z_{1}}, e^{-z_{2}}-$ exponential dependencies that determine level of influence of optimality functioning criteria; $z_{1}=k_{1} \cdot\left(1-\bar{P}\left(U \mathrm{y}_{\text {allowable }}, T\right)\right)-$ index of regression equation that considers limitation of revenue from RES functioning by criteria of electric power quality; $z_{2}=k_{2} \cdot\left(1-\bar{P}\left(\Delta W_{\text {allowable }}, T\right)\right)-$ index regression equation that considers limitation of revenue from RES functioning by criteria of electric power losses to its transfer; $k_{1}, k_{2}$ - weight coefficients of regression equation, for correction of fractional optimality criteria influence to optimization results; 
$\bar{P}\left(\mathrm{y}_{\text {allowable }} T\right)$ - probability of providing normative power deviation for established reporting period $T ; \bar{P}\left(\Delta W_{\text {aloowable }}, T\right)$ - probability of providing normative power losses for established reporting period $T ; P_{l_{g}}-$ load power of $g$ consumption node, $g=1,2 \ldots m ; P_{\text {lim }}$ - carrying capacity of LES in electric networks that is limited by the weakest area of the network.

Value of RES optimal established power in conditions of multistage power market tariff $\mathrm{z}_{j}$ and keeping limitations on carrying capacity of power lines and power quality in LES will be the solution for optimization problem (2.2).

So, method of calculating optimal established power of renewable energy sources in a local electric system was suggested, that creates preconditions for increasing functioning efficiency of renewable energy sources in local electric systems at the stage of design. This occurs due taking in consideration limitation of revenue from RES functioning by criteria of electric power quality and criteria of power losses that happen during its transfer, as well as correcting influence of optimality partial criterion to optimization results.

2.1.2 Method of optimization daily generation modes of renewable energy sources in local electric system

Problem of optimization daily modes of renewable energy sources optimization according to prognosticated load schedule of local electric system is shown on fig. 2.1. Array of $n$ controlled RES (on example of SH) and array of conditionally controlled - wind and solar farms, expected value of total revenue from their functioning is:

$$
M_{t}^{\Pi}=\mathrm{c}_{\mathrm{WF}} M_{t}^{\mathrm{WF}}+\bigsqcup_{\mathrm{SPP}} M_{t}^{\mathrm{SPP}} .
$$

where $\amalg_{\mathrm{WF}}$ - tariff on electric power production by $j$ RES, kop/kW·hour; LSPP - tariff on electric power production by $j \mathrm{SPP}, \mathrm{kop} / \mathrm{kW} \cdot \mathrm{hour}$.

Conditionally controlled and instable power sources like WF and SPP in target functions and limitations of optimal control problems are presented by expected value of time dependence of electric power generation $M_{t}^{\mathrm{WF}}, M_{t}^{\mathrm{SPP}}$ for time period $t \in\left[t_{0} ; t_{k}\right]$. 


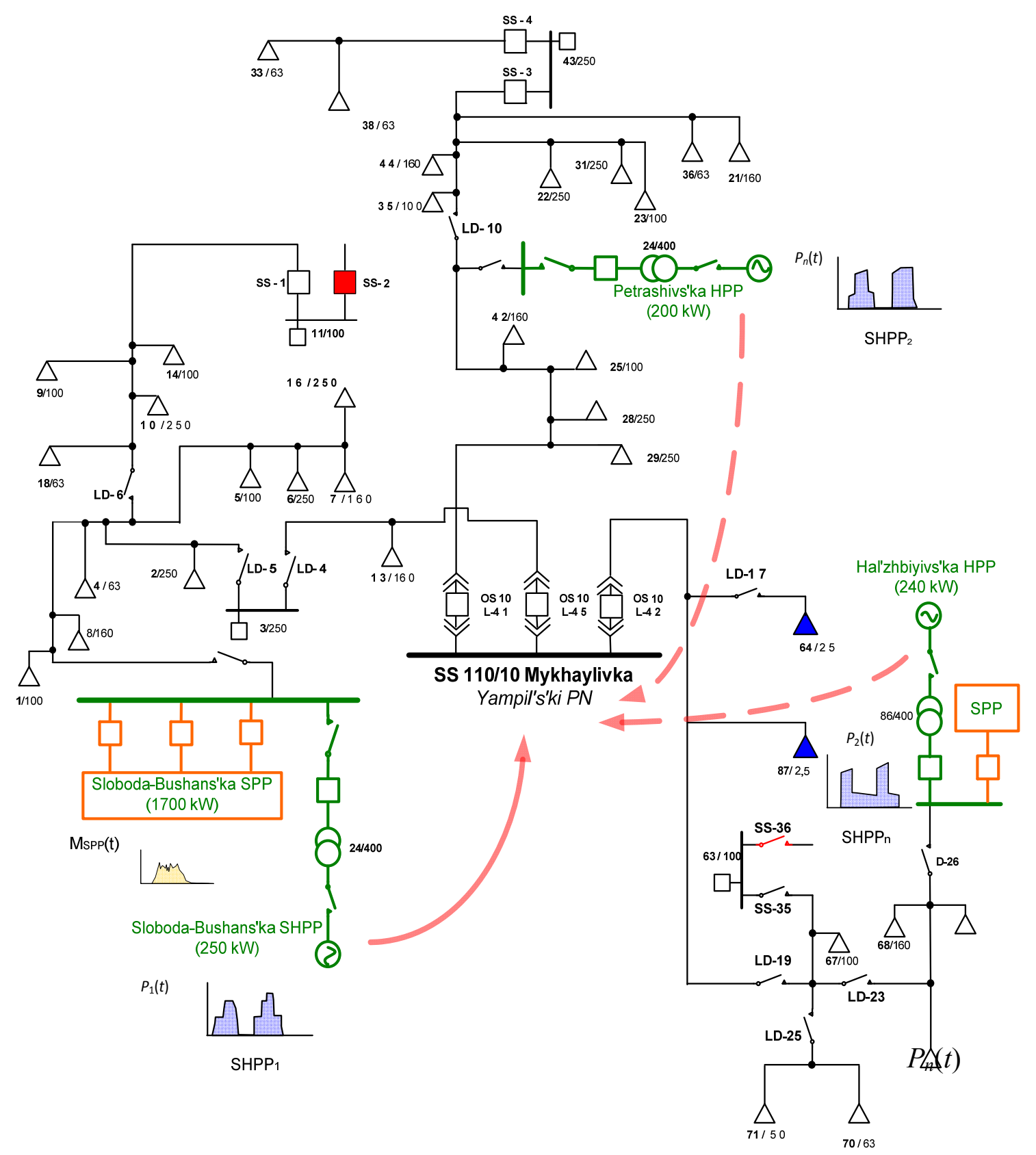

Figure 2.1 - Problem of optimization revenue from RES complex functioning

In the capacity of control variables, SH electric capacities are taken, as they are the less dependent from influence of environment and may alter within rather wide limits not leading to notable losses of energetic potential of primary energy sources. Components of power losses in LES are determined by conditionally controlled RES and small HPP power flows, they are functions from electric capacities of generating last ones and should be considered in target function (2.2) for exploitation problem of daily schedules optimization. 
To solve the mentioned problem (on time period $\left[t_{0} ; t_{k}\right]$ ) of controlled energy sources $P_{j}^{\mathrm{RES}}(t), j=1,2 \ldots n$ (for example, SHPP) considering modes of conditionally controlled sources, the expression (2.1) becomes:

$$
\mathrm{C}^{\mathrm{RES}}(t)=\int_{t_{0}}^{t_{k}}\left[\sum_{j=1}^{n} \mathrm{z}_{j} \cdot P_{j}^{\mathrm{RES}}(t)\right] d t+\sum_{t} M_{\mathrm{C}, t} .
$$

According to (2.5), target function of daily modes optimization problem in renewable energy sources in LES will become:

$$
\mathrm{F}(t)=\mathrm{C}^{\mathrm{RES}}(t) \cdot e^{-z_{1}(t)} \cdot e^{-z_{2}(t)} \rightarrow \max
$$

with limitation:

$$
\sum_{j=1}^{n} P_{j}^{\mathrm{RES}}(t)+M_{t}^{\mathrm{WF}}+M_{t}^{\mathrm{SPP}}-\sum_{g=1}^{m} P_{\mathrm{l}_{g}}(t) \leq P_{\mathrm{lim}}
$$

where $z_{1}(t)=k_{1} \cdot\left(1-\bar{P}\left(U_{\mathrm{y}_{\text {allowable }}}, t\right)\right)$ - index of regression equation that considers limitation of revenue from RES functioning by criteria of electric power quality, at time moment $t ; z_{2}(t)=k_{2} \cdot\left(1-\bar{P}\left(\Delta P_{\text {allowable }}, t\right)\right)-$ index of regression equation that considers limitation of revenue from RES functioning by criteria of power losses on its transfer at time moment $t$; $\bar{P}\left(U_{\mathrm{y}_{\text {allowable }}}, t\right)$ - probability of providing normative deviation of voltage at time moment $t ; \bar{P}\left(\Delta P_{\text {allowable }}, t\right)$ - probability of providing normative power losses at time moment $t$.

Values of optimal generation powers of single RES $P_{j}^{R E S}$ according to prognosticated LES load schedule by complex functioning criterion will be the solution for optimization problem (2.6).

Optimization of daily modes expects involvement of controlled energy sources (for example, SHPP) as balancing for capacity to keep optimal total power of the complex of RES in LES according to (2.6).

To solve problems $(2.2,2.6)$, there is a set of methods and approaches [38-49] that are widely applied in power industry [65] to find numeral solutions appropriate to an array of incoming data (current vector of system's condition). Algorithm realization and examples of solving mentioned tasks is given in next chapters. 


\subsubsection{Evaluation of probability of providing normative power deviation for established reporting period}

Power deviation is characterized by index of fixed power deviation $\delta U_{n}$ [37]. It is the consequence of daily, season and technological changes of users' electric loads, as well as power of compensating devices, regulation of voltage by electric power stations' generators and on power systems' substations, changes in power networks scheme.

Voltage deviation $\delta U$ is the difference between actual $U_{t}$ and nominal $U_{H}$ voltage values in absolute units:

$$
\delta U_{n}=U_{t}-U_{n o m}
$$

or in percent:

$$
\delta U n=\frac{U_{t}-\text { Unom }}{\text { Unom }}
$$

Rules established for it:

- normally admissible and extreme admissible values of established voltage deviation $\delta U_{n}$ on electrical receivers' are equal $\pm 5 \%$ and $\pm 10 \%$ respectively from nominal voltage of electric network;

- normally admissible and extreme admissible values of voltage in points of general connection of power consumers to electric networks with voltage $0,38 \mathrm{kV}$ and more should be established in agreements to use of electric power with consideration of necessity to perform acting standard on electrical receivers' outlets.

Value of average voltage $U_{a v}$ is calculated as result of averaging $N$ observations of power $U_{(I) i}$ for 1 minute time interval (not less than 18 observations per minute):

$$
U \mathrm{a} v=\frac{\sqrt{\sum_{i=1}^{N} U_{i}^{2}}}{N},
$$

where $U_{i}$ - value of voltage $U_{(I) i}$ in i observation.

Quality of electric power meets standard's requirements if all values of established voltage deviation measured during 24 hours are in interval limited by extreme admissible values, but not less than $95 \%$ of measurements for this period are in interval limited by normally admissible values. 
Statistical analysis for providing normative voltage deviation is suggested to be defined by formula for statistical evaluation of probability of technical devices' faultless operation [65]:

$$
\bar{P}(t)=\left[N_{0}-n(t)\right] / N_{0},
$$

where $n(t)$ - number of technical devices that failed for the time t; $N_{0}-$ total number of technical devices that are subject to probation.

Using the expression (2.11) for value of average voltage $U_{y}$ that is within normative deviation, we will get the probability of providing normative voltage deviation:

$$
\bar{P}\left(U_{\text {allowable }}, T\right)=t_{\text {tot }}\left(U \mathrm{a} v_{\min } \leq U \mathrm{a} v_{\text {allowable }} \leq U \mathrm{a} v_{\max }\right) / T,
$$

where $t_{\text {tot }}\left(U \mathrm{a} v_{\min } \leq U \mathrm{a} v_{\text {allowable }} \leq U \mathrm{a} v_{\max }\right)-$ total time when value of average voltage was within admissible limits.

So, using of probability of providing normative voltage deviation as a variable in target function (2.2) and (2.6) will allow to consider index of voltage quality during calculation of optimal value of total revenue from RES exploitation that are connected for parallel work in local electric system.

\subsubsection{Estimation of probability of providing normative electric energy and power losses}

Use of target functions (2.2) and (2.6) expects calculation of probability of providing normative electric energy and power losses. Depending on plentitude of information about element load within electric network for calculation period, to calculate loading electric power losses $\left(\Delta W_{l}\right)$ of distribution networks $10 \mathrm{kV}$ next methods may be used [66]:

- methods where number of hours of greatest losses $\tau$ are used:

$$
\Delta W_{\mathrm{i}}=\Delta P_{\max } \tau
$$

where $\Delta P_{\max }$ - power losses in mode of maximal load of the network;

- methods of average loads that use formula:

$$
\Delta W_{1}=\Delta P_{\mathrm{av}} k_{\mathrm{f}}^{2} T,
$$


where $\Delta P_{a v}$ - power losses in network at average nodes load (or network in whole) for time period $\mathrm{T} ; k_{\mathrm{f}}-$ factor of power or current schedule form.

Values $\tau$ and $k_{\mathrm{f}}$ that characterize power schedule form are defined according to [66]. Number of hours of greatest losses is defined by formula:

$$
\tau=k_{3}^{2} k_{\phi}^{2} T,
$$

where $k_{\mathrm{c}}$ - index of completing the schedule that characterizes relative number of hours of maximal load use. It is defined as:

$$
k_{\mathrm{c}}=\frac{P_{\mathrm{av}}}{P_{\max }},
$$

where $P_{\text {av }}=W / T$ - average value of power for period $T ; W$ - power energy released to consumers for period $T$; $P_{\max }$ - maximal network load.

To define electric power losses by formulas (2.12) or (2.13), it's sufficient to define one of the values $\tau$ or $k_{\mathrm{f}}$. The other one may be defined from connection equation (2.15). Usually $k_{\mathrm{f}}$ is defined at first turn.

In the theory of calculating loads, factor of load schedule form of EN $i$ element is defined by expression [67-68]:

$$
k_{\mathrm{f} j}^{2}=\frac{P_{r m s}^{2}}{P_{\mathrm{m} j}^{2}},
$$

where $P_{\mathrm{r} m s j}, P_{\mathrm{av} j}$ - respectively, mean square and average value of power flow by $j$ edge during calculation period.

In conditions of absence of data about hourly release of electric power to every consumer, $k_{\mathrm{f} j}^{2}$ is calculated just for main feeder's area $10(6) \mathrm{kV} k_{\mathrm{f} \Sigma}^{2}$. Factor value of load schedule form on $j$ feeder's area 10(6) $\mathrm{kV} k_{\mathrm{f} j}^{2}$ takes the value $k_{\mathrm{f} \Sigma}^{2}$. This brings to miscalculation of electric power variable [69] and optimality criterion components losses according to (2.2) and (2.6). 
Especially notable miscalculations are typical for network edges where changes of direction of resulting flows with their negligible average value along a day (fig. 2.2) are observed because of laying on flows of active power to consumers from LES supply center and from renewable energy sources. In such case values $k_{\mathrm{f} j}^{2}$ may exceed several tens (fig. 2.2).

For electric networks edges (PL, transformers), where bidirectional transfer of power is observed due to interchange of power consumption and generation during a day:

$$
\left|P_{\mathrm{av} . j}\right| \leq P_{\mathrm{av} . j}^{C O N} ;\left|P_{\mathrm{av} . j}\right| \leq P_{\mathrm{av} . j}^{R E S},
$$

non-considering of load schedule form factor leads to notable miscalculations of electric power losses reproduction, that eventually may influence negatively on adequacy of taking optimal decisions basing on calculation losses [70].

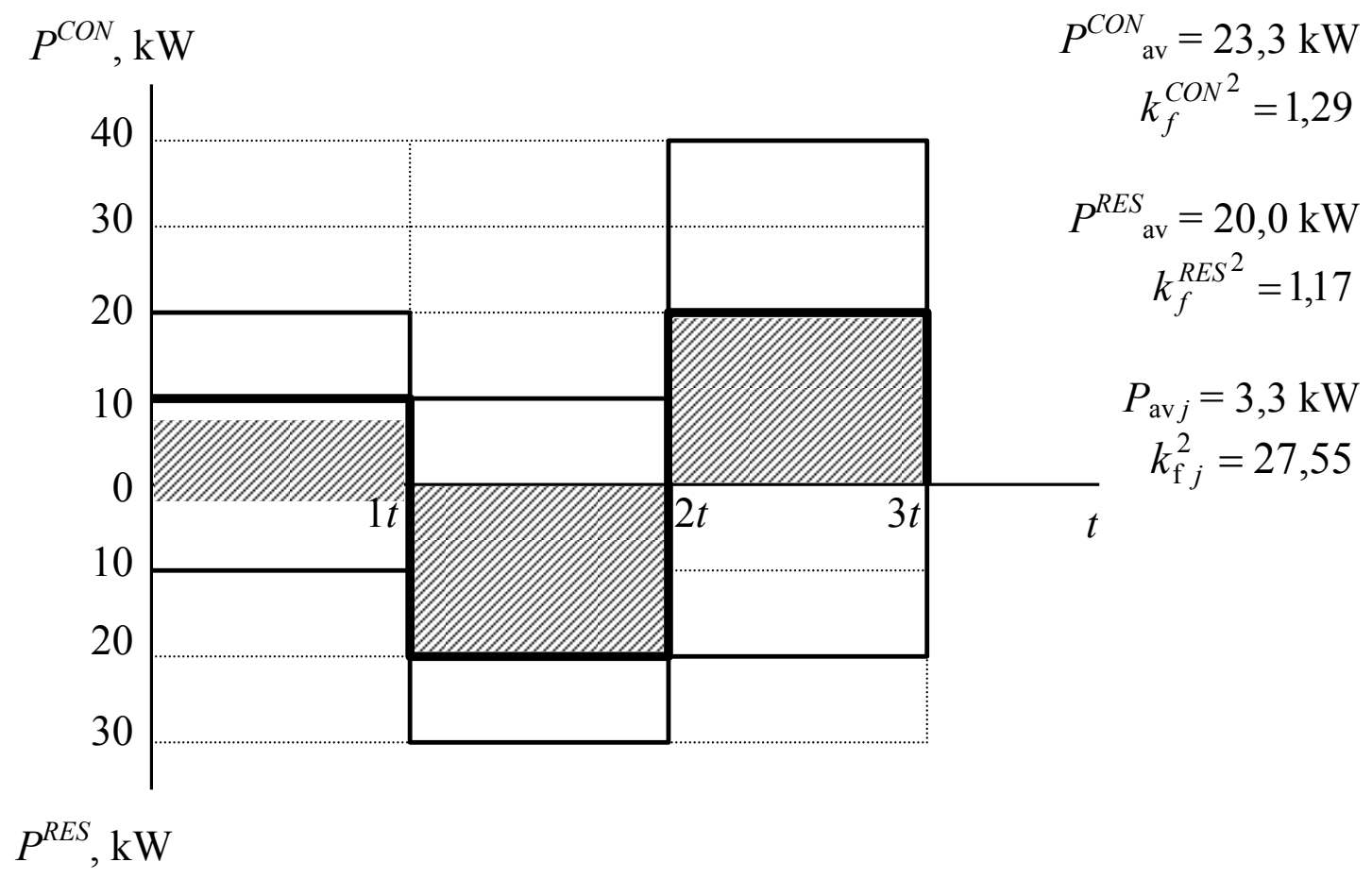

Figure 2.2 - Example of load schedule for LES edge with bidirectional power transfer 
To identify factors of group load schedule forms $k_{\mathrm{f} j}^{\mathrm{CON}^{2}}$, method given at [71-72] is used. For renewable energy sources, defining of schedule forms factors $k_{\mathrm{f}}^{\mathrm{RES}^{2}}$ is made according to data of commercial electric power accountancy. Using measured schedules of RES power release, generation schedules for $\mathrm{j}$ edge of $\mathrm{EN}$ are formed and factors of generation form $k_{\mathrm{f} j}^{\mathrm{RES}^{2}}$ are defined according to them.

Load schedule form factors of $\mathrm{j}$ LES edge that are characterized by bidirectional flows are defined according to [73]. In the quality of input information such values are used: power consumption form factors for each edge of $\mathrm{PN} k_{\mathrm{f} j}^{\mathrm{CON}}{ }^{2}$; average value of consumption $P_{\mathrm{av} . j}^{\mathrm{CON}}$; factor of power generation form by means of RES $k_{\mathrm{f} j}^{\mathrm{RES}}{ }^{2}$ average generation value $P_{\mathrm{av} . j}^{\mathrm{RES}}$.

Expression for calculating factor of schedule form for edge with bidirectional flow load, basing on (2.17), may be presented like [74]:

$$
k_{\mathrm{f} j}^{2} \approx \frac{k_{\mathrm{f} j}^{\mathrm{CON}^{2}} P_{\mathrm{av} . j}^{\mathrm{CON}^{2}}+k_{\mathrm{f} j}^{\mathrm{RES}{ }^{2}} P_{\mathrm{av} . j}^{\mathrm{RES}^{2}}-2 P_{\mathrm{av} . j}^{\mathrm{CON}} P_{\mathrm{av} . j}^{\mathrm{RES}}}{\left[P_{\mathrm{av} . j}^{\mathrm{CON}}-P_{\mathrm{av} . j}^{\mathrm{RES}}\right]^{2}}
$$

So, to define electric power losses for reporting period $T$, it's necessary to have information on typical schedules of daily generation and power consumption for previous periods, as well as quantity of released (consumed) electric power for the same period.

To calculate probability of providing normative deviation of electric power losses in target function (2.2) similar expression was used (2.11):

$$
\bar{P}\left(\Delta W_{\text {allowable }}, T\right)=t_{\text {tot }}\left(\Delta W_{\text {act }} \leq \Delta W_{\text {allowable }}\right) / T \text {, }
$$

where $t_{\text {tot }}\left(\Delta W_{\text {act }} \leq \Delta W_{\text {allowable }}\right)$ - total time when value of electric power losses was within normative deviation; $\Delta W_{\text {act }}-$ actual electric power losses in LES, r.u.; $\Delta W_{\text {allowable }}$ - normative or extreme admissible electric power losses In LES, r.u. 
To define probability of providing normative deviation of power losses in specified moment of time that is used in expression of target function (2.6), (2.19) will look like:

$$
\bar{P}\left(\Delta P_{\text {allowable }}(t)\right)=t_{\text {tot }}\left(\Delta P_{\text {act }} \leq \Delta P_{\text {allowable }}\right) / T,
$$

where $t_{\text {tot }}\left(\Delta P_{\text {act }} \leq \Delta P_{\text {allowable }}\right)$ - total time when value of power losses was within normative deviation; $\Delta P_{\text {act }}-$ actual power losses in LES, r.u.; $\Delta P_{\text {allowable }}$ - normative or extreme admissible power losses in LES, r.u.; $\Delta T$ - discretization interval (information system inquiry).

Value of normative losses of electric energy $\Delta W_{\text {act }}$ and power $\Delta P_{\text {act }}$ are defined according to normative volume of technological expenses at transfer of electric power for II category of consumers and II class of electric networks $(10 \mathrm{kV})$ according to regulation of EUNRC [75] and internal rules of power supply company that are defined for each LES basing on daily generation schedules and network consumption for previous periods.

Use of probability of providing normative deviation of electric power losses $\bar{P}\left(\Delta W_{\text {act }}, T\right)$ as a variable in target function (2.2) will allow to consider the losses factor in electric network during calculation of optimal value of established RES power, joined to parallel work in LES, on stage of introducing new capacities according to problem set in clause 2.1.1.

Exploitation problem (see clause 2.1.2) of optimization daily generation modes of renewable energy according to prognosticated load schedule of LES (2.6) is reasonable to be solved with use of probability of providing normative deviation of power losses for every stage of load schedule.

\subsubsection{Calculation of weight factors of regression equations of complex optimality criterion for local electric system functioning}

Regression dependencies $e^{-k_{1} \cdot\left(1-\bar{P}\left(\text { Uav allowable }_{1} T\right)\right)}, e^{-k_{2} \cdot\left(1-\bar{P}\left(\Delta W_{\text {allowable }}, T\right)\right)}$, suggested in clauses 2.1 and 2.2 are exponential functions. Their power indexes consider limitation of revenue from RES functioning due to inadequate electric power quality and electric power losses to its transfer.

Weight factors of regression equation that define the degree of influence of optimality functioning criteria may be defined with the use of expert evaluation method, use of correlation analysis, graphs method, 
method of extreme and nominal values, methods of regression analysis and other economic and mathematical methods [76-78].

Considering index dependencies in expressions (2.2) and (2.5), it is thought reasonable to use methods of regression analysis [78-80] that consists in analytical finding of weight factors on regression equation basing on statistical information.

According to rules of using electric power [81], in case of supplying electric power that has quality parameters out of indexes limits mentioned in agreement on power supply, the supplier of electric power by regulated tariff is responsible before consumer in the amount of twenty five percent of cost of such power amount. That means, at certain assumption that profit from RES exploitation for indicated time period will make up $75 \%$ from total revenue.

So, value of weight factor $k_{1}$ of regression dependence may be defined for extreme conditions $\bar{P}\left(U_{a v_{\text {allowable }}}, T\right)=0$ and $\bar{P}\left(U_{a v_{\text {allowable }}}, T\right)=1$ from exponential function:

$$
e^{-k_{1} \cdot(1-0)}=0,75 ; \quad k_{1}=-\ln (0,75)=0,288 .
$$

At condition of keeping normative deviation, in other words, in case when $\bar{P}\left(U_{a v}, T\right)=1$, established value of weight factor of regression dependence will not influence on optimization results.

With the aim of compliance testing of attained weight coefficient, a set of calculations was made and accordance between statistical data and offered regression dependence was examined (fig. 2.3). Factor of regression dependence correlation is equal to 0,995 , this testifies about high adequacy of formed mathematical model to statistical data.

Weight coefficient $k_{2}$ is defined with consideration of «Order of calculating payment for transfer of electric energy of own production at electric power supply by non-regulated tariff» [82]. According to [82] volume of technological expenses at electric power transfer in condition of supplying electric power, for example, to consumers of II class (at voltage degree on limits of balance appliance between power producer and power transfer organization $0,4-10 \mathrm{kV}$ ) is defined by formula:

$$
W_{\text {lossIossI }}=\frac{W_{\text {cnII }}}{1-k_{\text {EFNTEEP }}}-W_{\text {conII }}
$$


where $W_{\text {loss IossI }}$ - volume of technological expenses when transferring electric power, MW/hour; $W_{\text {cnII }}$ - volume of consumed electric power by consumers of II class MW/hour; $k_{\text {EFNTEEP }}$ - economic factor of normative technological expenses of electric power to transfer of electric power by networks of II class $\left(k_{\text {EFNTEEP }}=0,1292\right.$ for PJSC «Vinnytsiaoblenergo» [75]).

Performing the analysis of expression (2.21), it's possible to define the rate of normative technological expenses to transfer of electric power in electric network of PJSC «Vinnytsiaoblenergo» by local electric networks for II class of voltage to III - IV quarters of 2013 and I quarter of 2014 that makes up $W_{\text {lossIoss I }}^{*} \approx 15 \%$ from volume of consumed electric power by consumers of II class MW/hour.

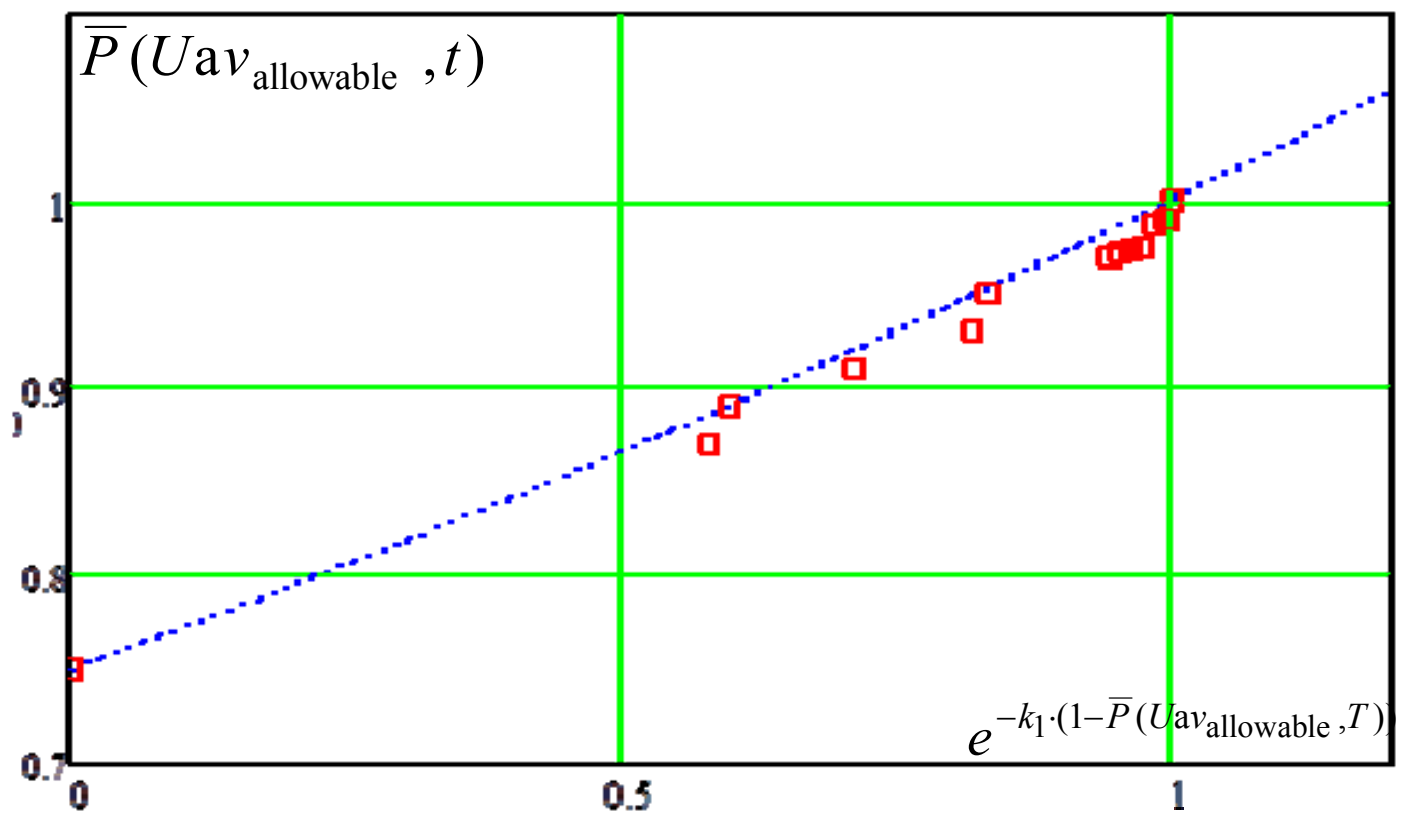

Figure 2.3-Graphic display of observation vector for voltage deviation probability and its exponential dependence

The mentioned economic factor considers losses to transfer, technological expenses, commercial and other types of expenses related to electric power transfer. That is, relative value of actual losses to electric power transfer by LES networks will not exceed $15 \%$, and normed value is regulated for every distribution network by internal normative documents of electric power supply company according to «Methodical 
recommendations for defining technological expenses of electric power in transformers and power lines» [75].

So, value of weight factor $k_{2}$ of regression dependency may be defined for extreme conditions $\bar{P}\left(\Delta W_{\text {allowable }} T\right)=0$ (exceeding of normative technological losses of electric power to transfer of electric power $\left.E_{\text {conII }}^{*}=85 \%\right), \bar{P}\left(\Delta W_{\text {allowable }} T\right)=1$ from exponential function:

$$
e^{-k_{2} \cdot(1-0)}=0,85 ; \quad k_{2}=-\ln (0,85)=0,163 .
$$

Correlation factor of attained exponential dependency with statistical data equal to 0,955 indicates about high adequacy of formed mathematical model to statistics data (fig. 2.4).

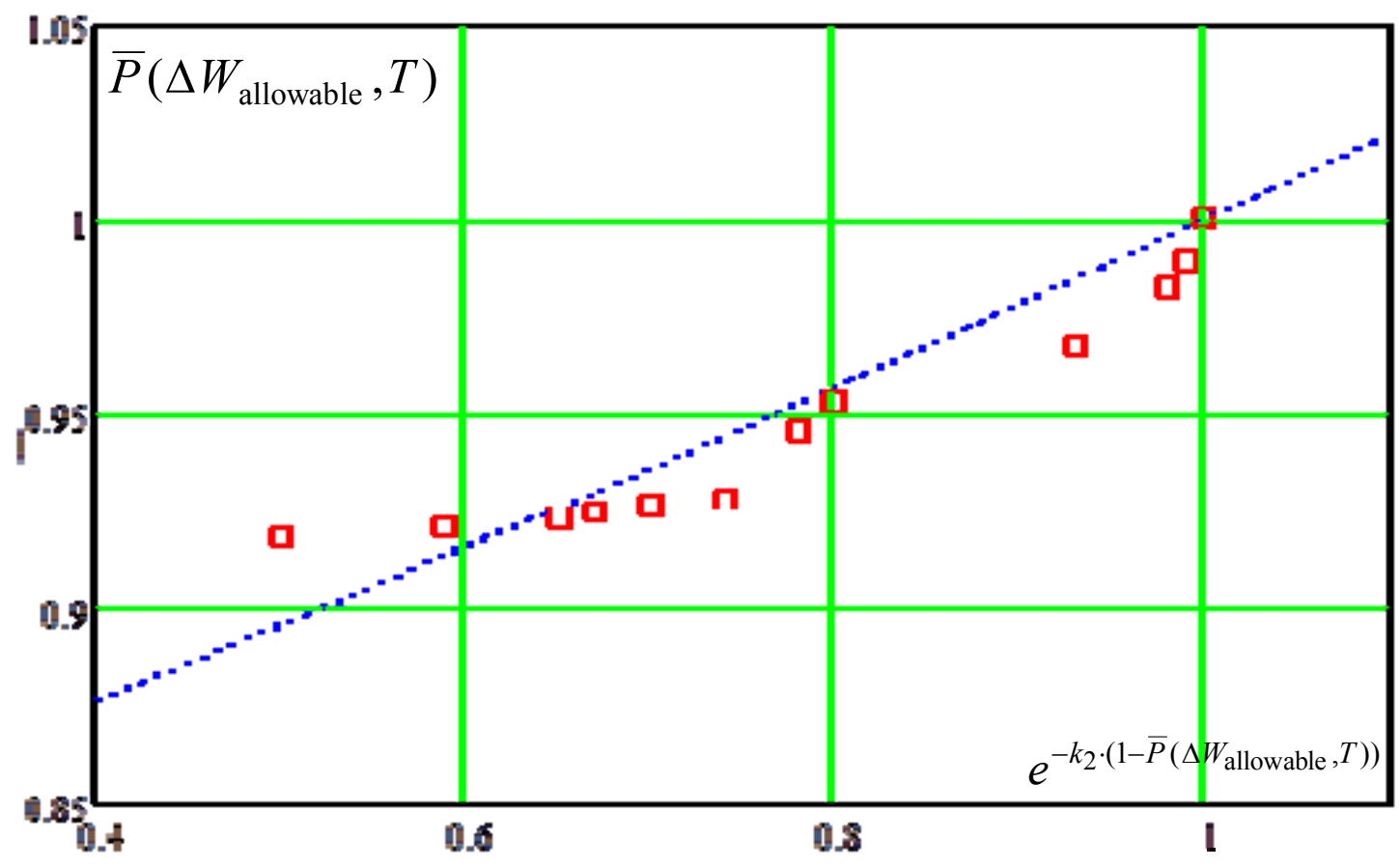

Figure 2.4 - Graphic display of statistical data of power losses normative deviation and suggested exponential dependency

So, to solve established problems of defining optimal established power of RES in LES and optimization of their daily modes, it's necessary to use weight factors $k_{1}=0,288$ and $k_{2}=0,163$. To calculate electric power losses, it's reasonable to consider bidirectional nature of electric power flows during calculation of load schedule form factor, and for algorithm implementation - application of numeral methods for solving optimization problems. 


\subsection{Method of defining optimal place of connecting renewable energy sources by criterion of minimal power losses in local electric systems}

To define optimal place of connecting RES to LES by criterion of minimal power losses, methods that allow to perform calculation as with definitely specified information and with probability-statistical losses estimation [83-84] may be used. But dependency of power losses from RES generation is non-linear that complicates the problem of evaluation of its influence to LES operation mode. So, to consider non-linear dependency of power losses in PN from parameters of its mode, indexes of power losses distribution were used [85].

Row-vector $\dot{\mathbf{T}}_{i}$ consists of indexes that show what part of total losses in edge i makes up power flow over it from each node [85]:

$$
\dot{\mathbf{T}}_{i}=\left(\dot{\mathbf{U}}_{t} \mathbf{M}_{\Sigma i}\right) \widehat{\mathbf{C}}_{i} \dot{\mathbf{U}}_{\text {д }}^{-1}
$$

where $\dot{\mathbf{U}}_{t}-$ transposed vector of voltage in nodes including basis one;

$\mathbf{M}_{\Sigma i}-\mathrm{i}$ column-vector of incidence matrix; $\widehat{\mathbf{C}}_{i}-i$ row-vector of current distribution matrix in nodes $\widehat{\mathbf{J}}$ by edges of LES with RES scheme; $\dot{\mathbf{U}}_{\text {д }}^{-1}$ diagonal inverse matrix of voltage in nodes including basis one.

Basing on [85]:

$$
\Delta \dot{\mathbf{S}}_{\mathrm{B}}=\dot{\mathbf{T}} \cdot \dot{\mathbf{S}}
$$

where $\Delta \dot{\mathbf{S}}_{\mathrm{B}}-$ vector of power losses in scheme edges; $\dot{\mathbf{T}}-$ matrix of power losses distribution indexes in edges of equivalent circuit of distributive EN depending on power in nodes of its circuit where each row consists of (2.31).

According to [85] notice that indexes of losses distribution depend on parameters of equivalent circuit that at certain assumptions may be considered constant, and on voltage values in PN nodes that are defined by load and generation in circuit nodes.

To define optimal place of connecting RES in LES by criterion of minimal power losses with the use if $\mathbf{T}$ matrix, it's necessary to form list of nodes $\theta_{\mathrm{B}}$, on primary stage that may be connected with RES.

On next stage vector of power losses distribution indexes in LES circuit edges is calculated by expression: 


$$
\dot{\mathbf{T}}_{\Sigma}=\dot{\mathbf{T}}^{\mathrm{T}} \cdot \mathbf{n}_{v}
$$

where $\mathbf{n}_{v}$ - unit row-vector that has dimension by number of EN nodes. Vector $\dot{\mathbf{T}}_{\Sigma}$ has dimension by quantity of LES nodes. Each vector element conforms to part of power losses from RES power flow, according to number of column of given element.

Use of suggested index (2.24) allows to define EN node that if connected with RES will provide minimal power losses (maximal decrease of losses), with certain assumption.

With the aim of checking appropriateness if applying index vector of power losses distribution for defining place of RES connection to LES nodes, we perform estimation of sensitivity of power losses and voltage drop in LES to power changes in RES generation.

\subsubsection{Mathematical model for estimation of power losses sensitivity in local electric systems to changes of renewable energy sources power generation}

Local electric system is constantly under influence of external disturbances caused by change of RES operation modes. Changes may appear in LES in one or several points at the same time. Depending on their value, consequences may be characterized by quantitative alterations of mode parameters within admissible changes or qualitative mode alterations, for example, loss of stability [86-88].

Complication of maintenance or introduction of LES mode to admissible area consists in essential difference between parameters reaction to disturbance in its different nodes and edges. Respectively, different action of single regulated devices (RD) to parameters of elements mode and LES subsystems is required. Operation of RD is systematic, so it's necessary to consider change of its parameters as influence not only to single mode parameters but also to general-system features like overall loss of active power in LES, losses from through power flows, distribution of load between several RES or between RES and supply center.

If to assume that indexes of power losses distribution in edges (see clause 2.2.1, 2.2.2) are invariable, power losses in LES will change with alteration of power generated by RES:

$$
\delta \Delta \dot{S}_{\Sigma}^{L E S}=\dot{\mathbf{T}}_{\Sigma} \delta \dot{\mathbf{S}}^{R E S},
$$


where $\delta \dot{\mathbf{S}}^{R E S}=\dot{\mathbf{S}}_{(k)}^{R E S}-\dot{\mathbf{S}}_{(k+1)}^{R E S}-$ column-vector of power changes in nodes with RES at transfer from mode $k$ to $k+1$.

If change of generated power happened just in one RES node $j$ node, than increment of power losses in LES from power changes in node $j$ on $\delta \dot{S}_{j}^{R E S}$ will make up:

$$
\delta \Delta \dot{S}_{j}^{L E S}=\dot{t}_{\Sigma j} \delta \dot{S}_{j}^{R E S}
$$

$3(2.26)$

$$
\dot{t}_{\Sigma j}=\frac{\delta \Delta \dot{S}_{j}^{L E S}}{\delta \dot{S}_{j}^{R E S}} .
$$

From (2.27), conforming to [107-108] follows that $\dot{t}_{\Sigma j}$ is the index of power losses sensitivity in LES to changes of power in node $j$ of RES. As $\dot{\mathbf{T}}_{\Sigma}$ matrix consists of elements of the type $\dot{t}_{\Sigma j}$, it is the sensitivity matrix that establishes connection between power losses increment in LES and power changes in RES nodes.

On practice, sometimes situations happen in LES when only active or reactive power changes in RES. If only active power ( $\delta Q_{j}^{R E S}=0, \quad \delta P_{j}^{R E S} \neq 0$ ) changes in a node, it follows from (2.27) that

$$
\dot{t}_{\Sigma j}=\frac{\delta \Delta P_{j}^{L E S}}{\delta P_{j}^{R E S}}+j \frac{\delta \Delta Q_{j}^{L E S}}{\delta P_{j}^{R E S}} .
$$

In the contrary, if only reactive power changes in a node (source of reactive power switches on or off, $\delta Q_{j}^{R E S} \neq 0, \delta P_{j}^{R E S}=0$ ), than from (2.27) we have that

$$
\dot{t}_{\Sigma j}=\frac{\delta \Delta Q_{j}^{L E S}}{\delta Q_{j}^{R E S}}-j \frac{\delta \Delta P_{j}^{L E S}}{\delta Q_{j}^{R E S}} .
$$

As losses of active power are the optimality criterion for LES normal modes, than firs component from (2.28) and second component from (2.29) are interesting as sensibility factors. Conformably, matrixes of active power losses sensitivity in edges to changes in nodes of active $\mathbf{T}_{\Sigma}^{\prime}$ and reactive $\mathbf{T}_{\Sigma}^{\prime \prime}$ powers are formed. Then active power losses in LES at change of mode in nodes are defined by: 


$$
\delta \Delta P_{\Sigma}=\mathbf{T}_{\Sigma}^{\prime} \delta \mathbf{P} ; \delta \Delta P_{\Sigma}=\mathbf{T}_{\Sigma}^{\prime \prime} \delta \mathbf{Q}
$$

where $\delta \mathbf{P}$ and $\delta \mathbf{Q}$ - changes according to active and reactive powers in LES nodes.

Analyzing the expression (2.40), a conclusion that physical substance of reviewed sensitivity indexes is the ratio of power losses increment in LES to change of generation in nodes may be made. Sensitivity indexes (2.40) in fact are not variable for proportional changes of generation and load in LES, according to load schedules of its daily modes.

Assumption about invariability of sensitivity indexes are based on low $\mathbf{T}_{\Sigma}^{\prime}, \mathbf{T}_{\Sigma}^{\prime \prime}$ sensitivity to voltage changes. To prove such an assumption, it's reasonable to analyze power losses sensitivity in LES edges to voltage in RES nodes.

\subsubsection{Sensitivity indexes of power losses in edges of local electric} systems to power changes in nodes with renewable energy sources

As it's seen from (2.22), values of sensitivity matrix elements $\dot{\mathbf{T}}$ in general case depend on difference of voltages in nodes $\dot{\mathbf{U}}$ with RES and voltage in SC, which in its turn depends on load and LES generation powers.

In this case, at change of power in RES nodes, power losses in LES will change and, on the contrary from (2.26), will be equal to:

$$
\delta \Delta \dot{S}^{L E S}=\dot{\mathbf{T}}_{\Sigma(k)} \dot{\mathbf{S}}_{(k)}^{R E S}-\dot{\mathbf{T}}_{\Sigma(k+1)} \dot{\mathbf{S}}_{(k+1)}^{R E S},
$$

rr, considering that $\dot{\mathbf{S}}_{(k+1)}^{B Д E}=\dot{\mathbf{S}}_{(k)}^{B Д E}+\delta \dot{\mathbf{S}}^{B Д E}$, and $\delta \dot{\mathbf{T}}_{\Sigma(k)}=\dot{\mathbf{T}}_{\Sigma(k)}-\dot{\mathbf{T}}_{\Sigma(k+1)}$,

$$
\delta \Delta \dot{S}^{L E S}=\delta \dot{t}_{\Sigma(k)} \dot{\mathbf{S}}_{(k)}^{R E S}-\dot{t}_{\Sigma(k+1)} \delta \dot{\mathbf{S}}^{R E S},
$$

where $k$ and $(k+1)$ - modes with consideration of power change in nodes.

If changes occurred only in one node $-j$ node, the increment of power losses in LES for power change in $j$ node on $\delta \dot{S}_{j}^{R E S}$ according to (2.25) will be:

$$
\delta \Delta \dot{S}_{j}^{L E S}=\delta \dot{T}_{\Sigma j(k)} \dot{S}_{j(k)}^{R E S}-\dot{T}_{\Sigma j(k+1)} \delta \dot{S}_{j}^{R E S}
$$


With (2.26) ratio of power losses sensitivity in LES to power changes in $j$ node at transfer from mode $k$ to $(k+1)$ with consideration of power change in nodes:

$$
\dot{T}_{\Sigma j(\mathrm{k}+1)}=-\frac{\delta \Delta \dot{S}_{j}^{L E S}}{\delta \dot{S}_{j}^{R E S}}+\frac{\delta \dot{T}_{\Sigma j}}{\delta \dot{S}_{j}^{R E S}} \dot{S}_{j(k)}^{R E S}
$$

Comparing (2.40) and (2.44) we may see that in general, power losses sensitivity in LES to power changes in $j$ node also depends on sensitivity of sensitivity index $\frac{\delta \dot{T}_{\Sigma j}}{\delta \dot{S}_{j}^{R E S}}$ and from values of powers in mode that precedes to changes $\dot{S}_{j(k)}^{R E S}$.

In (2.44) increment of sensitivity factor $\delta \dot{T}_{\Sigma j}$ may be calculated using the expression for defining elements of row-vector of the matrix $\dot{\mathbf{T}}_{\Sigma}$ :

$$
\begin{gathered}
\delta \dot{\mathbf{T}}_{\Sigma j}=\dot{\mathbf{T}}_{\Sigma j(k)}-\dot{\mathbf{T}}_{\Sigma j(k+1)}=\left(\dot{\mathbf{U}}_{t(k)} \mathbf{M}_{\Sigma i}\right) \widehat{\mathbf{C}}_{i}\left(\dot{\mathbf{U}}_{\partial(k)}\right)^{-1} \mathbf{n}_{v}- \\
-\left(\dot{\mathbf{U}}_{t(k+1)} \mathbf{M}_{\Sigma i}\right) \widehat{\mathbf{C}}_{i}\left(\dot{\mathbf{U}}_{\partial(k+1)}\right)^{-1} \mathbf{n}_{v}= \\
=\widehat{\mathbf{C}}_{i}\left(\delta \dot{\mathbf{U}}_{\partial(k)}-\delta \dot{\mathbf{U}}_{\partial(k+1)}\right) \mathbf{n}_{v} .
\end{gathered}
$$

As is seen from (2.45), increment of sensitivity index $\delta \dot{T}_{\Sigma j}$ depends only on values of voltage drops in circuit edges, as matrix of current distribution is constant in conditions of invariable LES circuit parameters and its topology.

According to regulations, admissible value of established voltage deviation $\delta U_{\mathrm{y}}$ [37] on inputs of electrical receivers is equal to $\pm 5 \%$ from nominal power of electric network. So, voltage drop in LES from RES to current distribution point in normal mode should not exceed $5 \%$, so, for each single network edge it will be less than $5 \%$. So, increment of sensitivity index $\delta \dot{T}_{\Sigma j}$ for established power values due to change of voltages in circuit's nodes by regulation means will not exceed $5 \%$. Considering the precision of input data on LES operation modes and nameplate data of electrical equipment for design problems, the mentioned precision is admissible and sufficient for the problem of choosing optimal place of connection RES to LES [91]. 
Connection of RES to a node with the smallest value of row-vector of matrix $\dot{\mathbf{T}}_{\Sigma}$ gives the effect of losses decrease to transportation of electric power in direct proportion to losses distribution index.

So, relative static character of sensitivity indexes allows to numerical procedures of coordinate descent by criterion of minimal power losses.

At certain conditions, connecting of RES may lead to displacement of current distribution point in LES, so, to change of numerical values of power losses indexes $\dot{\mathbf{T}}_{\Sigma}$ in a wider range that requires specification of LES with RES optimality configuration terms by criterion of minimal power losses.

\subsection{Modelling of optimality conditions for configuring optimality conditions of local electric systems with renewable energy sources by criterion of minimal electric power losses}

In case of planning a prospective development of electric networks at conditions of necessity to connect new RES generation capacities, it's worth to pass to solving complex problem of LES reconfiguration scheme with the aim to decrease losses of active power to transfer of electric power and equalization of voltage mode in circuit's node.

Under LES reconfiguration we understand:

- connection of new capacities of RES generation;

- change of RES power delivery scheme by re-distributing it between different LES;

- change of LES operation scheme by re-distributing customers' transformer substations between different LES.

Estimation of the effect from LES reconfiguration to active power losses is possible due to matrix of indexes of power losses distribution (2.23). Mentioned indexes characterize the influence of powers of the indicated node to active power losses in edges of EN equivalent circuit.

As it was shown in subparagraph 2.2.1, elements of the matrix $\dot{\mathbf{T}}_{\Sigma}$ are indexes of power losses sensitivity in LES to changes of power in $j$ node. It characterizes the connection between changes of power in nodes and increment of total power losses in LES circuit. Using the index $\dot{T}_{\Sigma j}=T_{\Sigma j}^{\prime}+j T_{\Sigma j}^{\prime \prime}$, it becomes possible to estimate the change of LES losses due to scheduled reconfiguration.

Using the indexes vector of power losses distribution, the problem of LES with RES reconfiguration by criterion of minimal active power losses 
related to electric power transfer and providing voltage modes in circuit's node may be formulated:

$$
\Delta P=\sum_{j=1}^{n} P_{j}\left(T_{\Sigma j}^{\prime}-T_{\Sigma j}^{\prime \prime} \cdot \operatorname{tg} \varphi_{j}\right)+\Delta P_{\mathrm{SC}}+\Delta P_{\mathrm{CC}} \rightarrow \min
$$

where $P_{j}$ - power of controlled RES or consumer, $j=1,2 \ldots n ; \operatorname{tg} \varphi_{j}-$ expedient index of energy source or consumer power; $\Delta P_{\mathrm{SC}}-$ losses of active power in electric network caused by flows from supply center; $\Delta P_{\mathrm{CC}}$ - losses of active power in electric network caused by flows from conditionally controlled RES; $T_{\Sigma j}^{\prime}$, $T_{\Sigma j}^{\prime \prime}-$ real and imaginary components of distribution factor of active power losses.

Considering balance limitations:

$$
\begin{aligned}
& \sum_{j=1}^{n} P_{j}-P_{\mathrm{SC}}=0 ; \\
& \sum_{j=1}^{n}\left(P_{j} \cdot \operatorname{tg} \varphi_{j}\right)-Q_{\mathrm{SC}}=0,
\end{aligned}
$$

where $P_{Ц ж,}, Q_{ц ж}$ - active and reactive powers that come to network from supply center.

Let's write Lagrangian function for target function (2.46) and balance limitations (2.47). Instead of conditional minimum of target function, we will define the unconstrained one:

$$
\begin{aligned}
& L=\sum_{j=1}^{n} P_{j}\left(T_{\Sigma j}^{\prime}-T_{\Sigma j}^{\prime \prime} \cdot \operatorname{tg} \varphi_{j}\right)+\Delta P_{\mathrm{SC}}+\Delta P_{\mathrm{CC}}+\lambda_{P}\left(\sum_{j=1}^{n} P_{j}-P_{\mathrm{SC}}\right)+ \\
& +\lambda_{Q}\left(\sum_{j=1}^{n}\left(P_{j} \cdot \operatorname{tg} \varphi_{j}\right)-Q_{\mathrm{SC}}\right) \rightarrow \min ,
\end{aligned}
$$

where $\lambda_{P}, \lambda_{Q}$ - undetermined Lagrangian multiplier.

Minimum of Lagrangian function is reached at equality to zero of its partial derivatives by variables $P_{j}$ and $\operatorname{tg} \varphi_{j}$, that is:

$$
\begin{aligned}
& \frac{\partial L}{\partial \operatorname{tg} \varphi_{j}}=-\sum_{j=1}^{n} P_{j} \cdot T_{\Sigma j}^{\prime \prime}+\lambda_{Q} \sum_{j=1}^{n} P_{j}=0 ; \\
& \frac{\partial L}{\partial P_{j}}=T_{\Sigma j}^{\prime}-T_{\Sigma j}^{\prime \prime} \cdot \operatorname{tg} \varphi_{j}+\lambda_{P}+\lambda_{Q} \cdot \operatorname{tg} \varphi_{j}=0 .
\end{aligned}
$$


As it is seen from equations (2.49), the searched solution agrees with equality condition of power losses distribution factors:

$$
T_{\Sigma j}^{\prime}=-\lambda_{P}=\text { idem, } \quad T_{\Sigma j}^{\prime \prime}=\lambda_{Q}=\text { idem }
$$

It is seen from received optimal reconfiguration problem solution that optimal changes in LES with RES functioning mode by mentioned criteria agree to those that approximate factors of power losses distribution to some average-arithmetic value.

So, to choose optimal LES reconfiguration option, it's enough to estimate the level of approximating factors of power losses distribution in each of the offered options.

As suggested factors $\mathbf{T}_{\Sigma}^{\prime}, \mathbf{T}_{\Sigma}^{\prime \prime}$ are multidimensional, they don't give the opportunity of single-valued reconfiguration efficiency estimation without additional conditions. That is, it's necessary to introduce generalized index for choosing an option by reducing vectors $\mathbf{T}_{\Sigma}^{\prime}, \mathbf{T}_{\Sigma}^{\prime \prime}$ to the form of number. Only in this case possibility of unbiased estimation of close options is provided.

In correspondence to physical contents, vectors $\mathbf{T}_{\Sigma}^{\prime}, \mathbf{T}_{\Sigma}^{\prime \prime}$ may be reviewed as functional metric multitudes $\left\{\mathbf{T}_{\Sigma}^{\prime}\right\},\left\{\mathbf{T}_{\Sigma}^{\prime \prime}\right\}$ that answer to axioms of metric space [92]. Each multitude is a set of coordinates of $n$ measurable vector of total power losses in basis of LES node powers that are defined to appropriate development option. So, lengths of losses vectors $d P^{\prime}, d P^{\prime \prime}$ according to [92] may be defined by expressions:

$$
d P^{\prime}=\left|\mathbf{T}_{\Sigma}^{\prime}\right|=\left[\sqrt{\sum_{j=1}^{n} T_{\Sigma j}^{\prime 2}}\right] ; \quad d P^{\prime \prime}=\left|\mathbf{T}_{\Sigma}^{\prime \prime}\right|=\left[\sqrt{\sum_{j=1}^{n} T_{\Sigma j}^{\prime \prime 2}}\right] .
$$

So, lengths of vectors $d P^{\prime}, d P^{\prime \prime}$ are measured in relative units, have physical contents of modules of relative losses components $\Delta P$ from flows of active and reactive powers and may be used as indicator of influence of parameters of a single node or edge to level of electric network mode optimality in whole.

Graphically, essence of suggested index on example of electric network with three nodes is shown on fig. 2.5. It is seen from fig. 2.5 that increment of module $d P^{\prime}$ may arise as consequence of proportional growth of single losses sensitivity factors $T_{\Sigma j}^{\prime}$, or as the result of essential increment of single components. This meets the character of power losses changes in electric networks, so, the suggested factor characterizes changes 
of losses during electric power transfer. Similar conclusions may be made according to component conformity $\left|\mathbf{T}_{\Sigma}^{\prime \prime}\right|$.

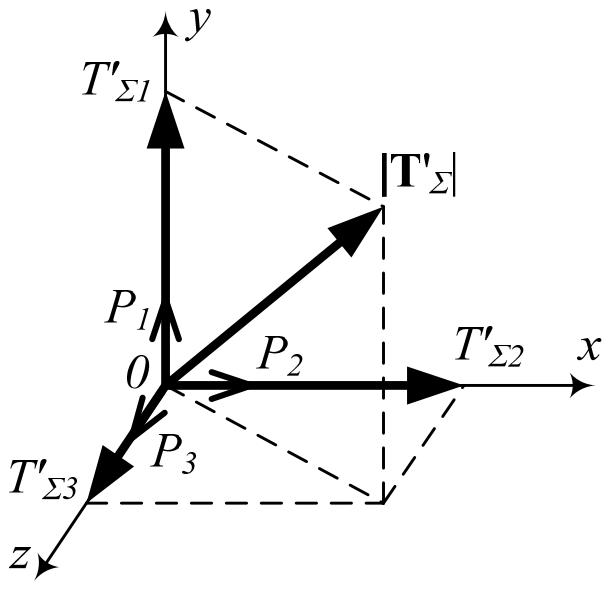

a)



b)

Figure 2.5 - Schedule of modules for indexes vectors of power losses distribution $\left|\mathbf{T}_{\Sigma}^{\prime}\right|$ by orthogonal basis for case of value-close (a) and essentially different (b) components

So, $d P^{\prime}, d P^{\prime \prime}$ are generalized efficiency indexes what allow to compare LES reconfiguration options when used, as well as choose optimal ones in clear manner, by comparing single numerical values (2.51).

\section{Summary to chapter 2}

1. From the results of theoretical studies and practical calculations regarding RES influence to EN operation modes it was found out that the problem of defining optimal power of renewable energy sources in local electric systems is reasonable to be solved by complex criterion that considers revenue from RES functioning, electric power quality factors and losses to its transfer by LES networks. When defining the index of electric power quality, it's worth using the probability of providing normative deviation of voltage and electric power losses for specified report period. This allows to minimize possible disadvantages of design solutions and improve the efficiency of LES functioning.

2. It was shown that using of provided approach to define optimal established power of renewable energy sources allows to increase the efficiency of local electric systems operation by limiting established RES power, optimal with consideration of electric power quality and power losses, on the stage of design. 
3. Suggested method of defining optimal place of RES connection by criterion of minimal power losses in LES allows to estimate sensitivity of total power losses in LES as criterion of optimality of its modes and power losses in single edges of electric networks to change of generation in RES nodes.

4. Analysis of sensitivity indexes of power losses distribution shown that for design solutions, supposition on stability of indexes losses sensitivity at voltage alteration in EN circuit's nodes is admissible. So, application of the offered method for defining optimal place of RES connection allows to define optimal nodes for introducing RES capacities for wide range of LES exploitation modes and RES in it still on the stage of choosing option of design solutions.

5. Obtained analytical optimality conditions of active and reactive loads allow to solve the problem of defining optimal place of RES connection or LES reconfiguration by criterion of minimal power losses in it without the decrease of power generation companies profitability. The suggested generalized indexes of LES with RES reconfiguration efficiency that have physical substance of relative losses components increment from flows of, respectively, active and reactive powers, may be used as quality indicator of parameters influence of a single node or edge to LES optimality mode. Using of generalized efficiency indexes allows to compare LES reconfiguration options and choose the optimal one in clear manner. 


\section{AUTOMATION OF OPTIMAL CONTROL ON RENEWABLE ENERGY SOURCES IN LOCAL ELECTRIC SYSTEMS}

Providing of RES functioning optimization process in local electric systems in modern conditions supposes use of automated control systems in the context of increasing the quality of production and distribution of electric power with use of Smart Grid technologies and standards (see item 1.1). This not only accelerates and simplifies this process but also create conditions for building modern integrated control systems. Adaptive automated control systems (AACS) mostly satisfy such requirements as they allow to support the appropriate quality of technological process in conditions of incomplete or imperfect primary information on its parameters and influences of the environment. The last one is especially important for RES exploitation in local electric systems. Use of such systems requires improvement and development of technical, information support and software.

So, the algorithmization of developed RES functioning optimization methods in local electric systems will allow to use them in the system of automated control (SAC) on LES modes and increase the efficiency of their functioning optimization process.

The present chapter is devoted to development of algorithms for defining optimal established power of renewable energy sources, defining optimal place of RES connection and optimization of daily modes of renewable energy sources generation in local electric system with the use of methods developed and described above. Rules and algorithms of optimal control on means for power delivery reconfiguration schemes basing on Smart Grid concept for using in SAC my LES with RES modes are suggested.

\subsection{Algorithm of practical realization of methods for defining optimal power of renewable energy sources in local electric systems}

\subsubsection{Algorithm of defining optimal established power of} renewable energy sources in local electric system by complex criterion

In subparagraph 2.1.1 method of defining optimal established power of RES in LES by complex criterion of quality and electric power losses factors with consideration of specificity of providing LES profitability was presented. Algorithm of using the method is given o fig. 3.1. 


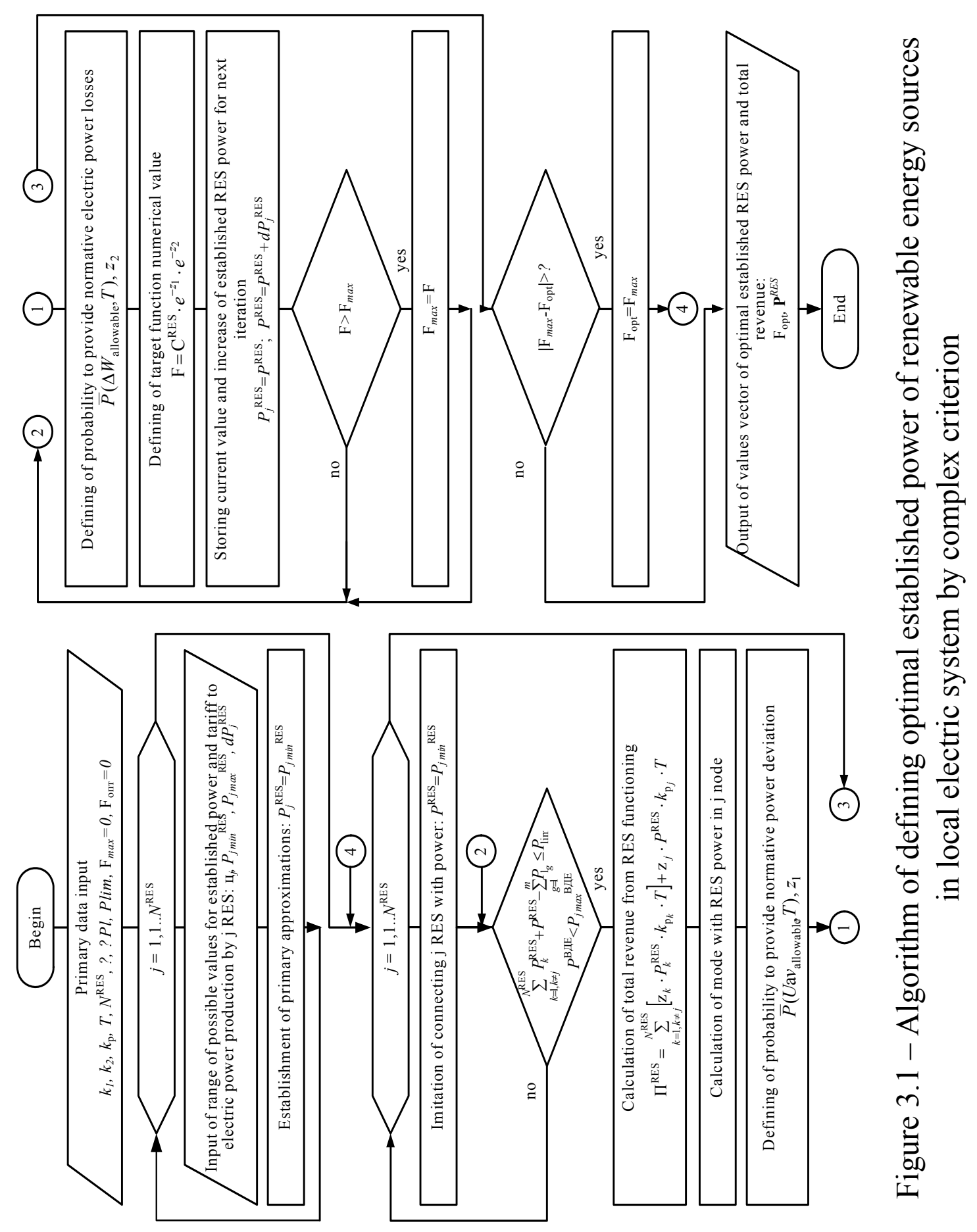


According to the algorithm, input of primary data is moved to the beginning of the algorithm as the present stage doesn't require computations. In the quality of primary data introduction of weight indexes of regression dependency $k_{1}$ and $k_{2}$, index of established power $k_{\mathrm{p}}$ consumption, duration of loads schedule $T$, quantity of planned RES connections $N^{\mathrm{RES}}$ total LES load power $\Sigma P_{l}$, extreme power of main feeder's area $P_{\text {lim }}$ and primary approximations of target function $\mathrm{F}_{\max }=0$, $\mathrm{F}_{\mathrm{op}}=0$, as well as precision of iteration calculation $\xi$.

On the second stage, introduction of the range of established power $P_{j \min }{ }^{\mathrm{RES}}, P_{j \max }{ }^{\mathrm{RES}}$ possible values, step of coordinate descent $d P_{j}^{\mathrm{RES}}$ and tariff to electric power production for each RES $\Perp_{j}$, where $j=1,1 . . N^{\mathrm{RES}}$ is provided. Primary approximations of optimal established RES power are considered to meet minimal values from possible range $P_{j}^{\mathrm{RES}}=P_{j \min }{ }^{\mathrm{RES}}$. On the next stage of the algorithm, imitation to RES with established power $P^{\mathrm{RES}}$ that changes in the range from $P_{j \min }^{\mathrm{RES}}$ to $P_{j \max }^{\mathrm{RES}}$ with the pitch $d P_{j}^{\mathrm{RES}}$ is executed cyclically.

If the connected power does not contradict the limitations of LES carrying capacity on active power $\sum_{k=1, k \neq j}^{N_{\mathrm{RES}}} P_{k}^{\mathrm{RES}}+P^{\mathrm{RES}}-\sum_{g=1}^{m} P_{1_{g}} \leq P_{\text {lim }}$, total revenue $\mathrm{C}^{\mathrm{RES}}$ from RES functioning with power $P^{\mathrm{RES}}$ is calculated.

With the aim to maintain quality and electric power losses indexes, mode with RES with established power $P^{\mathrm{RES}}$ in current connection place $j$ with duration of loads schedule $T$ is calculated. For the present period, basing on the results of imitation calculations, probability to provide normative deviation of electric power losses and voltage is defined, as well as factors of regression dependency to be used in target function $\mathrm{F}(t)=\mathrm{C}^{\mathrm{REE}}(t) \cdot e^{-z_{1}(t)} \cdot e^{-z_{2}(t)} \rightarrow \max (2.6)$.

On the next stage, calculation of target function $\mathrm{F}$ numerical value is performed, it's value is limited according to complex criterion. If the obtained value $\mathrm{F}$ is bigger than initial $\mathrm{F}_{\max }$ or the value $\mathrm{F}_{\max }$, obtained on the previous stage, re-assignment of maximal target function value $\mathrm{F}_{\max }=\mathrm{F}$ is performed, and the primary approximation of established power of $j$ connection is assigned a value equal to established power: $\left(P_{j}^{\mathrm{RES}}=P^{\mathrm{RES}}\right)$.

Then, step-by-step increment of established power $P^{\mathrm{RES}}$ is repeated until condition $P^{R E S}<P_{j \max } R E S$ is satisfied, or until breaker of LES carrying capacity limitation is reached. So, for $j$ connection, optimal established power is defined by maximum value of target function $\mathrm{F}$. 
When $P^{\text {ВДE }}$ will exceed $P_{j \max }{ }^{R E S}$, then similar calculation for the next RES connection place is performed until $j<N^{\mathrm{RES}}$.

After the calculation of possible target function values, for all possible values of established power meeting of condition of termination optimal established power $\left|\mathrm{F}_{\text {max }}-\mathrm{F}_{\text {opt }}\right|>\xi$ search iteration process is checked, where on the first stage $\mathrm{F}_{\text {опт }}=0$. So, in general case the algorithm expects performing at least 2 iterations.

If the condition of termination search iteration process of optimal established power is satisfied, the received results are displayed and prepared for analysis is form of optimal established power values $\mathbf{P}^{\mathrm{RES}}$ and the corresponding target function value $\mathrm{F}_{\mathrm{opt}}$,

Results obtained basing on the developed method and algorithm allow to perform qualitative and numerical estimation of optimal established RES in LES power with consideration of quality and electric power losses indexes for specified load duration schedule $T$ and customers load in typical LES mode.

\subsubsection{Algorithm for optimizing daily generation modes of renewable sources according to prognosticated loads schedule by complex criterion}

In the algorithm provided hereinbefore, to define optimal established power, time interval $T$ is used, equal to duration of load schedule for the wished period. During designing, seasonal or annual load schedules are usually used, this makes impossible application of the mentioned algorithm for optimization of renewable sources generation daily modes.

With the aim to optimize renewable sources generation daily modes according to prognosticated load schedule by complex criterion, in the present paper algorithm of defining optimal generation power of controlled RES for lapse of time $t \in\left[t_{0} ; t_{\mathrm{k}}\right]$ is developed, that is reasonable for operative control (fig. 3.2). As in subparagraph 3.1.1, input of primary data is moved to the beginning of algorithm, as the present stage does not require calculations. In the quality of primary data, introduction of weight indexes of regression dependency $k_{1}$ and $k_{2}$, time interval for optimization $\Delta t$ and primary approximation of target function $\mathrm{F}_{\max }=0$ are expected.

Quantity of controlled RES $N^{\mathrm{B} Д \mathrm{E}}$, total power of LES load $\Sigma P_{\text {l, }}$, extreme power of main feeder area $P_{\text {lim }}$, range of regulation controlled RES $P_{j \min }{ }^{\mathrm{RES}}, P_{j \max }^{\mathrm{RES}}, d P_{j}^{\mathrm{BLE}}$, as well as tariff to production of electric power $\mathrm{L}_{j}$ are red from base of LES operative-information complex (OIC) in the quality of adjusting parameters. 


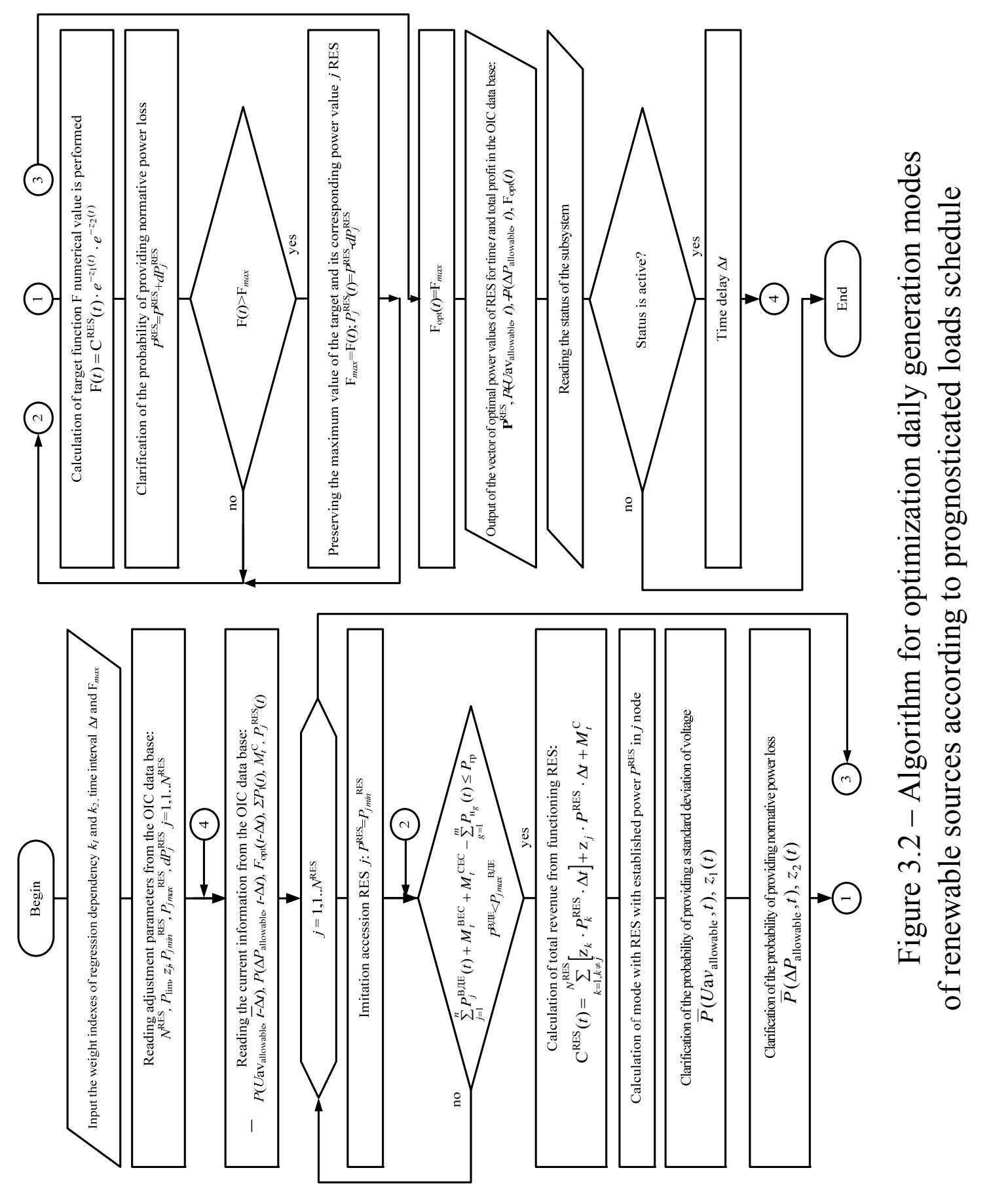


In the quality of primary approximations current values of controlled RES power $P_{j}^{\text {RES }}$, expected value of total revenue from functioning for current time $M_{t}^{\mathrm{C}}$, as well as information for the previous period $\Delta t$, that is: probability of providing normative deviation of power $\bar{P}\left(\Delta P_{\text {allowable }}, t-\Delta t\right)$ and voltages $\operatorname{losses} \bar{P}\left(U \mathrm{y}_{\text {allowable }}, t-\Delta t\right)$ value of target function $\mathrm{F}_{\mathrm{opt}}(t-\Delta t)$, that are red from data base of operativeinformation complex OIK.

On the next stage of algorithm, cyclically, by quantity $N^{\mathrm{RES}}$, imitation of generation controlled RES of power $P^{\mathrm{RES}}$ is performed, that are changed in the range from $P_{j \min }{ }^{\mathrm{RES}}$ to $P_{j \max }{ }^{\mathrm{RES}}$ with pitch $d P_{j}^{\mathrm{RES}}$.

If connected power doesn't contradict limitations of LES carrying capacity on active power $\sum_{j=1}^{n} P_{j}^{\mathrm{RES}}(t)+M_{t}^{\mathrm{WF}}+M_{t}^{\mathrm{SPP}}-\sum_{g=1}^{m} P_{1_{g}}(t) \leq P_{\lim }$ for current time period, total revenue $\mathrm{C}^{\mathrm{RES}}$ from RES functioning with power $P^{\mathrm{RES}}$ is calculated.

With the aim to adhere quality and electric power losses factors, mode with power $P^{\mathrm{RES}}$ of controlled RES in current connection place $j$ is calculated. Basing on the results of mode calculation, probability of providing normative deviation of electric power losses and voltage are specified, as well as factors of exponential dependency for use in target function $\mathrm{F}(t)=\mathrm{C}^{\mathrm{RES}}(t) \cdot e^{-z_{1}(t)} \cdot e^{-z_{2}(t)}$.

On the next stage calculation of numerical value of target function $\mathrm{F}$ for time moment $t$ is performed, its value is limited according to complex criterion. If the received value $\mathrm{F}(t)$ is bigger than primary approximation $\mathrm{F}_{\max }$ or value $\mathrm{F}_{\max }$ obtained on the previous stage, re-attribution of maximal target function value $\mathrm{F}_{\max }=\mathrm{F}(t)$ is executed and primary approximation of established power of $j$ connection is attributed equal to current value of established power $P_{j}^{\mathrm{RES}}=P^{\mathrm{RES}}$. Than step-by-step increment of established power $P^{\mathrm{RES}}$ is repeated until condition $P^{R E S}<P_{j \max }{ }^{R E S}$ is satisfied or LES carrying capacity breach happens. So, for $j$ connection optimal established power by maximal value of target function $\mathrm{F}(t)$ is defined.

When $P^{R E S}$ will exceed $P_{j \max }{ }^{R E S}$, than similar cycle stage for next controlled RES is performed until $j<N^{\mathrm{RES}}$.

Definition of optimal powers of controlled RES is performed by one algorithm turn, this relates to necessity of operative control for optimization time interval $\Delta t$. 
Results of calculations on optimization powers of controlled RES are stored in database of LES operative-informational complex for further use during next algorithm execution.

After information withdrawal to OIC database, status verification of subsystem for calculating optimal power values of controlled RES is performed to optimize daily modes of generating renewable sources by reading the appropriate flag from database. In case if subsystem's status is active, the algorithm provides time delay $\Delta t$ equal to mode optimization time interval. Otherwise, subsystems for calculating optimal power values of controlled RES terminate their work, and launch of subsystem is performed by operator's request. Results obtained basing on developed method and algorithm allows to perform optimal powers calculation for controlled RES with consideration of expected value of generation conditionally-controlled RES, for moment of time $t$. Obtained values of optimal power are read from database by subsystem of controlled RES automated management that function in local electric system.

\subsection{Algorithm of defining optimal connection place for renewable energy sources in local electric systems}

Suggested methods of defining optimal RES connection place has their advantages and disadvantages, so, their joint application is considered to be the most efficient one. At this, there are possibilities to provide conditions of the most efficient application for each of methods. That's why the problem of defining criterion of passage from one method to another is an important problem. One of those criteria is considered to be exceed of optimal RES power $P^{R E S}$ of total LES consumption load $\Sigma P_{1}$. Optimal RES connection place with specified established power, for example, calculated by developed algorithm (see subparagraph 3.1.1) is defined by criterion of minimal electric power losses.

If optimal established RES power doesn't exceed total LES consumers load power $\Sigma P_{1}$, then optimal connection place is chosen by criterion of minimum indexes of power losses distribution. This is explained by fact that optimal RES power calculated by algorithm shown on fig. 3.1 smaller than total LES load power, than point of power flow will be between supply center (tie-station $110 / 10 \mathrm{kV}$ ) and connected RES, that 
is in the middle of local electric network. As sensitivity analysis performed in subparagraphs 2.2.1-2.2.2 shown, at such conditions power losses distribution factors are invariable for broad range of exploitation modes of local electric system and RES in it.

In other case, when $P^{R E S}>\Sigma P_{1}$, optimal connection place is defined by minimum criterion of generalized efficiency index $d P^{\prime}$ from flows of active power, as connection of such RES power will lead to displacement of power flow point in LES, this leads to change of numerical factors of power losses distribution in a wider range and requires definition of optimality conditions for local electric system with RES by criterion of minimal power losses. So, summarizing the described above, algorithm block-scheme of defining optimal RES connection place is developed, what is shown on fig. 3.3. The algorithm expects input of primary data of LES typical mode for creating calculation model and forming list of nodes $\theta_{\mathrm{B}}$ available for RES connection.

The next stage of algorithm provides calculation of LES typical mode without planned connections of renewable energy sources. Basing on the results of typical mode calculating, matrix of indexes for power losses distribution is calculated by expression (2.22) and verification of condition $P^{R E S}<\Sigma P$ is performed. To choose optimal connection place, row-vector of power losses distribution factors in LES circuit edges from nodes load is calculated as sum of all elements of transposed matrix $\mathbf{T}$ by columns. Element with minimal value that belongs to list of $\theta_{\mathrm{B}}$ nodes available for RES connection is chosen from the obtained vector. Number of this element corresponds to number of optimal connection node.

In this case set of calculations of established modes by quantity of nodes $\theta_{\mathrm{B}}$ available for RES connection is performed. Minimal value $d P^{\prime}$ has a corresponding optimal RES connection place with the power $P^{B Д E}$. For each of calculated modes, generalized efficiency index $d P^{\prime}$ from active power flows is calculated: $d P^{\prime}=\left|\mathbf{T}_{\Sigma}^{\prime}\right|=\left[\sqrt{\sum_{j=1}^{n} T_{\Sigma j}^{\prime 2}}\right]$.

So, comparison of LES reconfiguration ways by connecting new RES capacities is realized algorithmically by criterion of minimum of generalized efficiency index in clear manner. Obtained results are displayed and algorithm work finishes. 


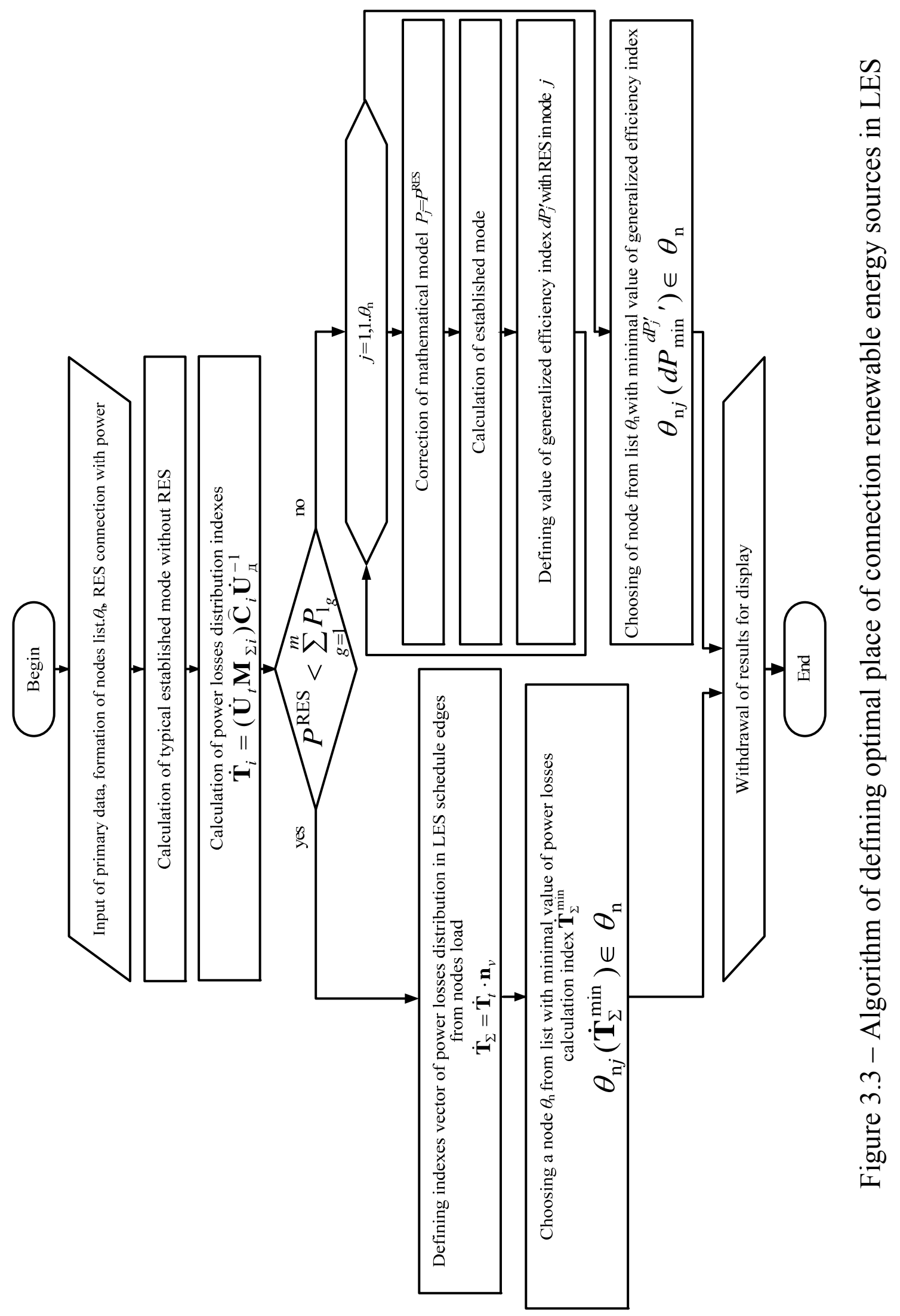


Application of such a method allows to get the solution almost independent from PM mode changes and provides decrease of electric power losses and increase of voltage quality for totality of LES probable modes.

\subsection{Operative control of schemes for power delivery by renewable energy sources in local electric systems}

\subsubsection{Way of coordination generation schedules for renewable energy sources and local electric systems' consumers}

To provide efficient work of conditionally-controlled RES, for example, solar plants, it is necessary to consider their influence to reliability of customers power supply and quality of electric power delivered to consumers. This is a rather complex problem, considering probabilistic character of such sources' modes of work.

Probabilistic character of generation often rather complicates organization of operative control on local electric systems modes in consequence of impossibility to follow the specified schedule of power issue by conditionally-controlled RES.

Typical structure of solar power plant is shown on fig. 3.4. Delivery of power is made through invertors connected in parallels, on tires system $0,4 \mathrm{kV}$. Such a connection method allows to control power delivery modes of single invertors only die to solar energy under-exploitation that is inexpedient from the point of view of exploitation profitability.

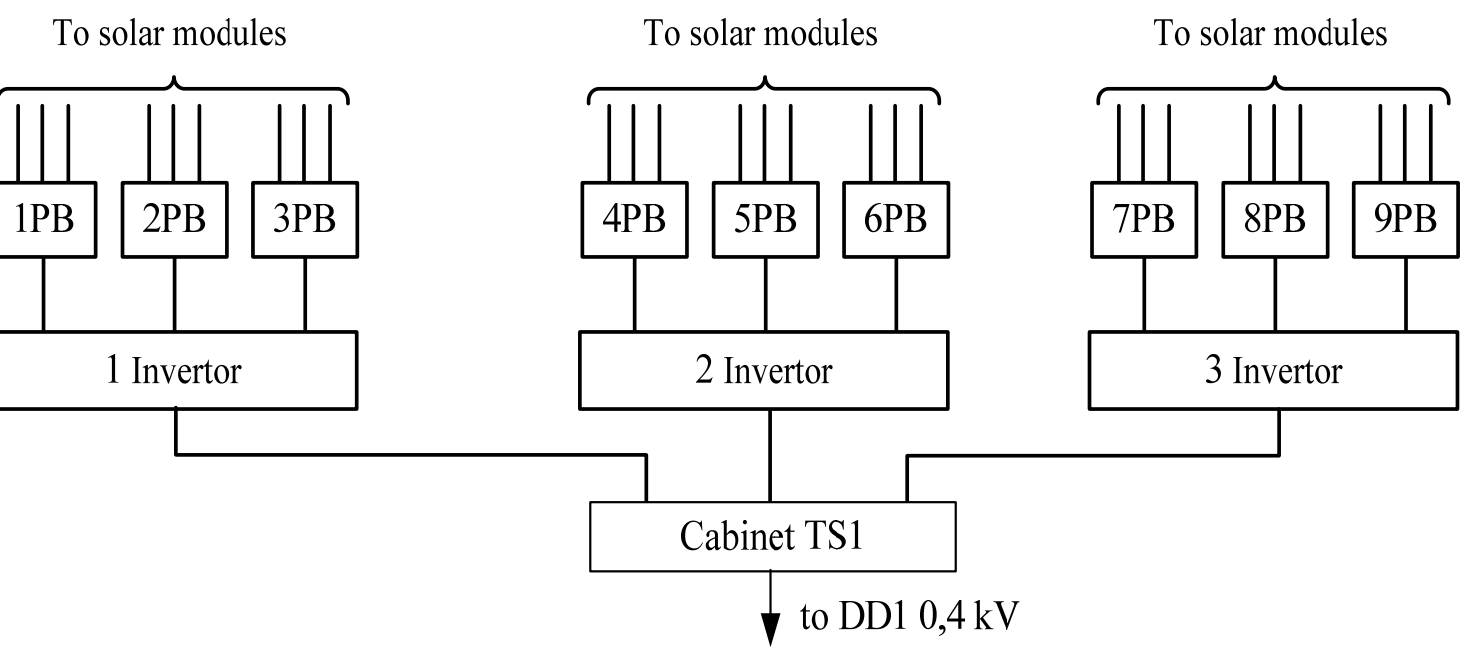

Fig 3.4 - Main scheme of solar power plant electric connections 
Growing of volumes of RES increasing power in single connection points leads to impossibility to deliver electric power without worsening its quality [50,53]. With the aim of solving this problem, owners of power sources are forced to invest money to building of additional power lines and in fact, distribute generated electric power of one electric power station between LES feeders [83].

Due to this, structural schemes of such electric power stations acquire the form shown on fig. 3.5.
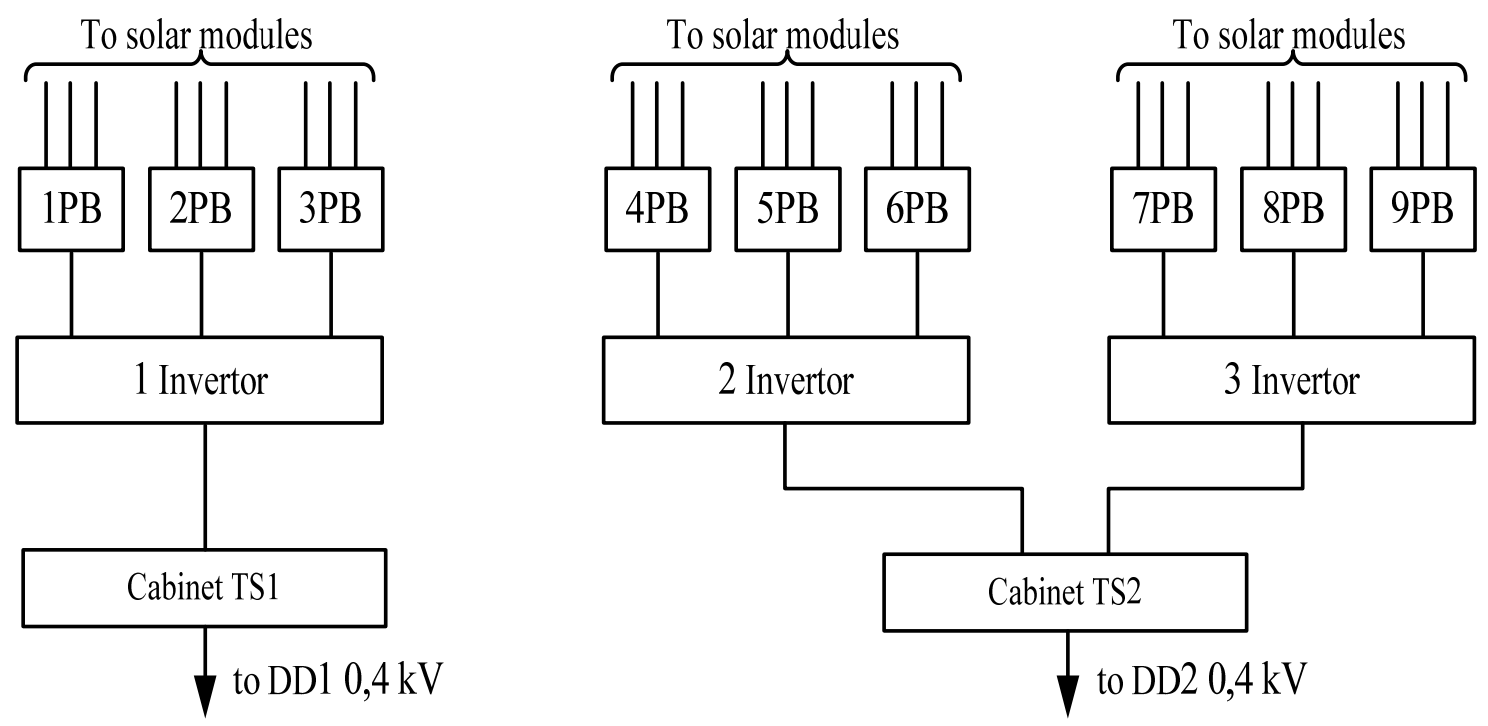

Figure 3.5 - Main scheme of electric connections of solar electric power station with reserved scheme of power delivery

To agree schedule of SPP generation with local electric power consumption, in this paper, method of operative correction of invertors connection scheme is suggested, that is, changes of power issue to EM. Depending on current SPP power and customers load to regulated tires system, a number of invertors able to provide consumption in LES with adherence quality indexes and minimal electric power losses are connected. Excess of produced electric power is delivered directly to supply center that is connected to another non-regulated tires system (TS) with a separate feeder. To implement the method, use of electronic keys of appropriate power or controlled commutation equipment $0,4 \mathrm{kV}$ installed in power box (PB) is provided. Besides this, it's necessary to install automatic devices of reverse power (ADRP) (fig.3.6). 
To solar modules

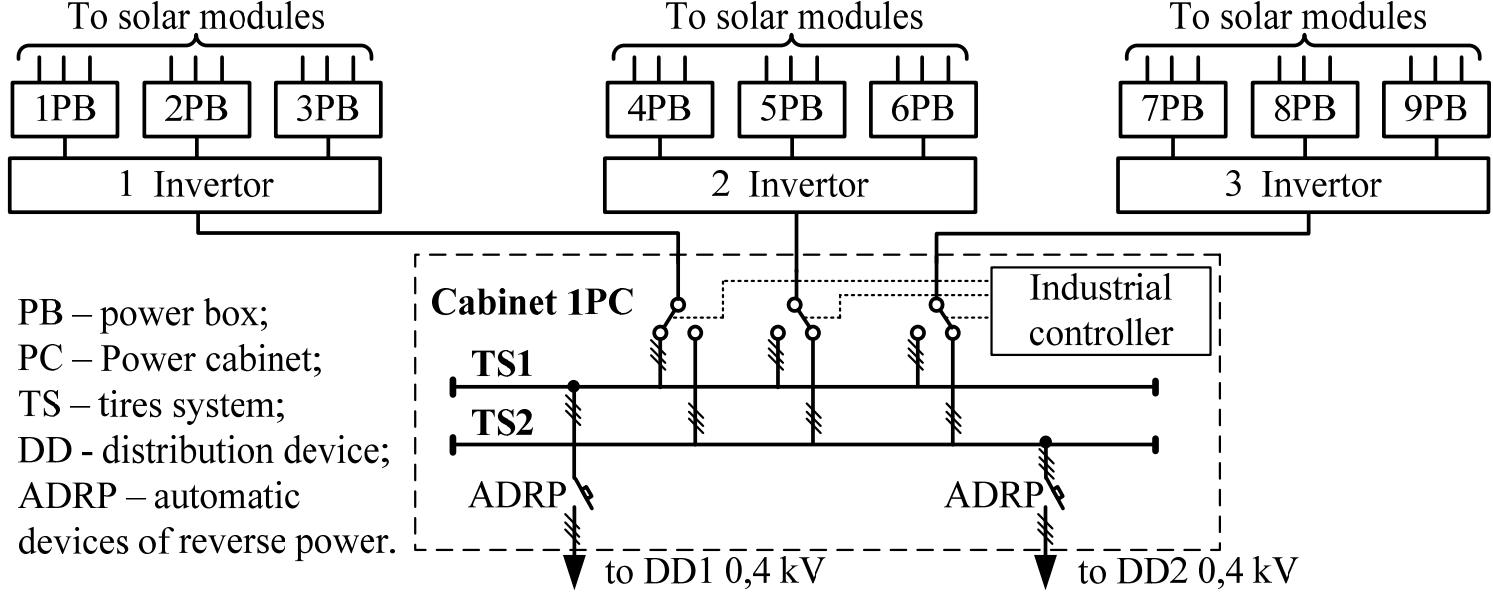

Figure 3.6 - Main scheme of connections for solar power plant with reserved and controlled power issue connections

Structure scheme of solar power plant presented on fig. 3.6 will allow to coordinate operatively schedules of power delivery on one of the tires systems with local load due to automatic power re-distribution from invertors outputs between sections of electric power station tires. For this, microprocessor device of local ACS and channel of connection with LES operative-information complex, used to read current values of optimal RES power from database (see subparagraph 3.1.2).

By such scheme of connecting electric power station, possibility of work in one tire section in basic mode is provided - according to schedule of local electric power consumption. For second tires section connected directly with supply substation of distribution power networks, excess of electric power generated by solar power plant not conformed with local power consumption will be delivered.

Application of the suggested method of coordinating schedules of conditionally-controlled RES with local electric power consumption will allow to increase reliability of electric power system functioning, improve indexes of electric power quality and will give a possibility of operative control on operation modes for dispersed generation without decreasing its profitability.

\subsubsection{Law of optimal control of reconfiguration means for RES power delivery schemes in local electric systems}

To increase efficiency of RES functioning by means of reducing electric power losses in power network, it's is suggested to measure current on high voltage tires of solar power plant and depending on optimal power 
value defined by algorithm of optimization for daily generation modes in RES (see subparagraph 3.1.2), change the number of invertors $N$ connected to first or second tires system (see fig. 3.6) to support voltage in tires of in the area of admissible values.

In concordance with the presented foundation and to implement the suggested way of coordinating SPP generation schedules with local electric power consumption, the law of optimal control of system's commutation devices in reconfiguration system for their power issue looks like (3.1), similar to [93]:

$$
\begin{aligned}
& \Delta i(t)=K_{1}\left[\left(I(t)-I_{\text {oper }}\right)-K_{2}\left(U(t)-U_{\text {oper }}\right)\right\rfloor \\
& N= \begin{cases}n(t)+1, \quad \text { if } \quad\left\{\begin{array}{l}
\Delta i(t) \leq i_{\mathrm{low}} ; \\
\Delta i\left(t-\tau_{\mathrm{s}}\right) \leq i_{\text {low }} \\
U(t) \leq U_{\mathrm{max}} \\
n(t), \quad \text { when } \quad
\end{array}\right. \\
\frac{i_{\mathrm{low}}<\Delta i(t)<i_{\mathrm{up}}}{d t} \leq 0 ; \\
n(t)+1 \leq n_{\mathrm{max}} \\
n(t)-1, \quad \text { if } \quad\left\{\begin{array}{l}
\Delta i(t) \geq i_{\mathrm{up}} \\
\Delta i\left(t-\tau_{\mathrm{s}}\right) \geq i_{\mathrm{up}} \\
U(t) \geq U \text { min } \\
\frac{d I_{\mathrm{env}}}{d t} \geq 0 ; \\
n(t)-1 \geq 0 ;
\end{array}\right.\end{cases}
\end{aligned}
$$

where $N$ - number of invertors connected to regulated tires system; $\Delta i(t)-$ current deviation from optimal value with consideration of voltage change on RES tires; $i_{\text {low }}, i_{\text {up }}$ - limits of insensibility zone, lower and upper, respectively; $I_{\text {oper }}-$ current operative value that corresponds to optimal RES power and is corrected depending on LES modes parameters, release price etc.; $U_{\text {oper }}$ - voltage operative value on RES tires equal to nominal voltage or another value if RES takes part in LES voltage regulation; $I(t), U(t), n(t)$ - measure of current and voltage, number of reversers switched on in moment of time $t ; K_{1}$-amplification factor that determines sensitivity of regulator to current deviation; $K_{2}$ - equivalent conductivity recalculation of 
voltage deviation from operative value to equivalent current deviation from optimal that provides system's reaction to voltage exceeding in case when current corresponds to optimality area; $I_{\text {env }}$ - envelope of summary current of reversers $I(t) ; \tau_{s}$ - time of signal delay; $t$ - moment of time regulation is made for; $n_{\max }-$ maximal number of reversers that may be switched on to regulated tires system.

Every additional invertor will be switched on to tires regulated system if current deviation $\Delta i(t)$ will be smaller than lower limit of insensibility zone $\left(\Delta i(t)=-6 \mathrm{~A}\right.$, a $\left.i_{\text {low }}=-5 \mathrm{~A}\right)$, voltage lower than maximal, number of degrees does not exceed maximal value, and measured RES current has a trend to decrease. And otherwise, if current deviation $\Delta i(t)$ will be higher than upper insensibility zone $\left(\Delta i(t)=+6 \mathrm{~A}\right.$, and $\left.i_{\mathrm{up}}=+5 \mathrm{~A}\right)$, power is higher that maximal, number of degrees is not smaller than minimal value, and measured RES current will have a trend to increase, reverser switching from regulated to non-regulated tires system will be performed.

\subsubsection{Algorithm of functioning for microprocessor device controlling on RES power delivery scheme in local electric systems}

To provide possibility of performing automatic control on configuration of RES power delivery scheme and coordination of controlling influences with operative control, functioning algorithm of microprocessor device (MD) of group control on SPP invertors was developed (fig. 3.7), that works according to law of on reconfiguration means for RES power delivery schemes in local electric systems (3.1).

On the beginning of algorithm work initialization, reading and overwriting of internal registers, testing of general blocks, check of connection with OIC and regulation means are performed.

Reading of adjusting parameters is performed from database of LES operative-information complex. In the quality of adjusting parameters, limits of voltage regulation $U_{\max }, U_{\min }$ on RES substation tires are used, as well as maximal number of regulated tire reversers $n_{\max }$, limits of insensibility zone $i_{\text {low }}, i_{\text {up. }}$, time of signal delay $\tau_{\text {s }}$, weight factors $K_{1}$ and $K_{2}$.

After reading adjusting data from OIC database, status check for subsystem of automatic control on RES power delivery scheme configuration is performed by reading of the appropriate flag from data base. In case if system's status is active, the algorithm provides reading of LES mode parameters $I(t)$ and $U(t)$ for current moment of time $t$. Also, number of reversers connected to regulated tires system $n(t)$ and operative 
value on current $I_{\text {oper }}$ and voltage $U_{\text {oper }}$ for RES substation tires is red from database. In other case, subsystem terminates its work and its launch is performed by operator's request.

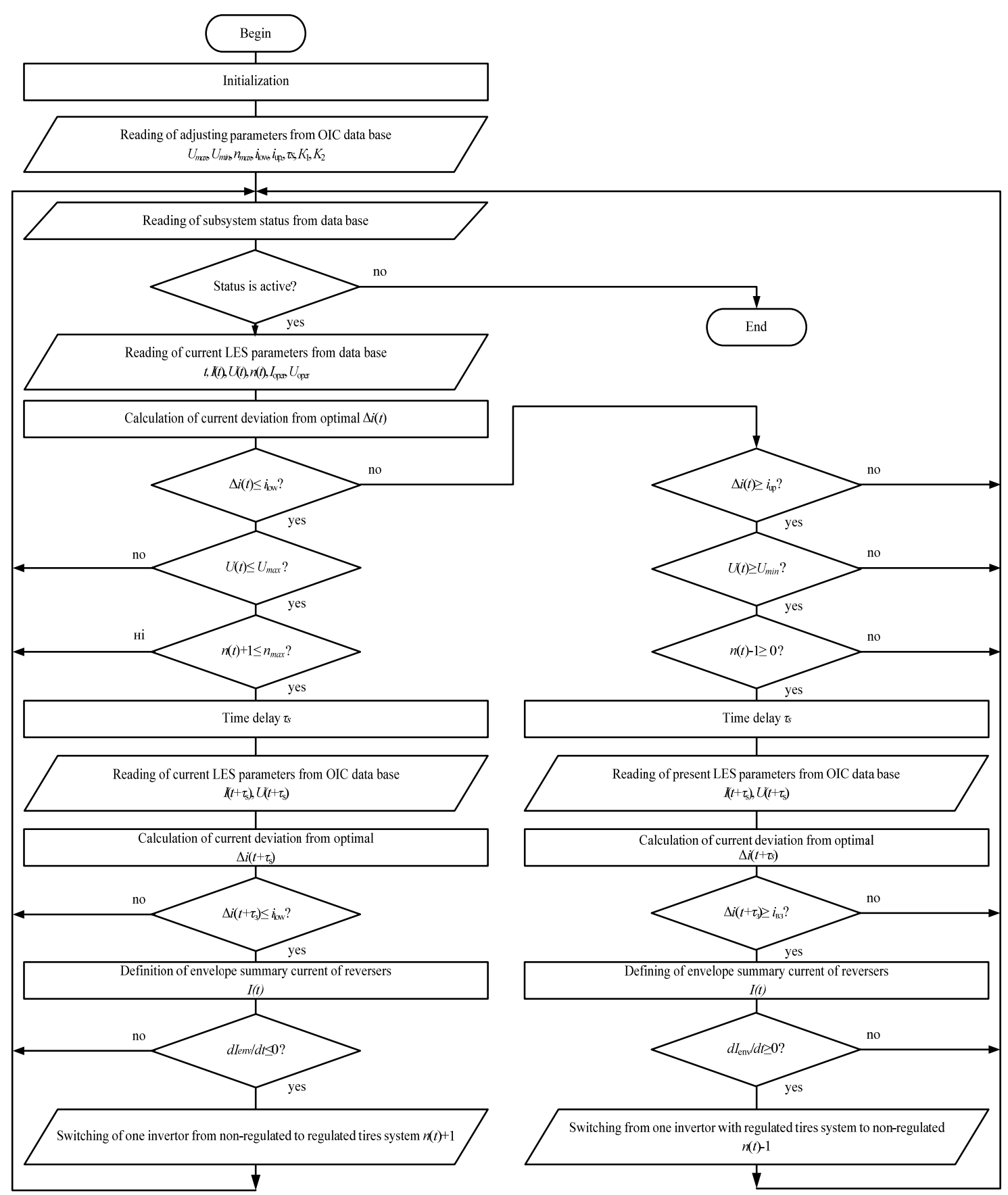

Figure 3.7 - Algorithm of microprocessor device functioning

On the next stage calculation of current deviation from optimal value is performed by expression: 


$$
\Delta i(t)=K_{1}\left\lfloor\left(I(t)-I_{\text {oper }}\right)-K_{2}\left(U(t)-U_{\text {oper }}\right)\right\rfloor .
$$

The obtained value is compared with lower $i_{\text {los }}$ (upper $i_{\text {up }}$ ) insensibility zone. If the deviation is considerable, in other words the condition is executed, check of possibility to perform reversers switching between tires and check of keeping current voltage within normal limits is performed.

For time delay equal to signal time delay $\tau_{\mathrm{s}}$ of information transfer subsystem, current deviation from optimal value is compared with insensibility zones limits. If deviation exceeds insensibility zone, envelope of summary current of invertors and its derivative $d I_{\text {env }} / d t$ are calculated. Depending on derivative sign $d I_{\text {env }} / d t$, signal about increase or decrease of reversers number connected to regulated SPP TS is passed.

\subsubsection{Definition of insensibility zone limits for microprocessor} controlling device of renewable power sources basing on optimal decisions sensitivity analysis

Using of algorithm of functioning for microprocessor device controlling RES power delivery schemes in local electric systems shown in fig. 3.7 supposes availability of microprocessor device adjusting parameters in OIC data base. Calculated adjusting parameters allow to establish the necessary insensibility area in MD that decreases the number of switchings when applied and increases stability of controlling system.

For the task of decreasing additional power losses caused by flows from RES in local electric system by means of automatic control, the problem of defining possible area of arguments varying (summary current of reversers connected to regulated tires system) that are optimized arises, at specified deviation of target function (revenue from RES exploitation with consideration of complex criterion (2.6)) from its optimal value [94].

It is possible to define target function deviation from its previously defined optimum in case of varying arguments close to their optimal value by solving the direct problem of optimal solutions sensitivity [94-96]. Possibility to define area's limits provide solution for inverse problem of sensitivity.

As it is known [96,97], optimality criteria in mathematical models of the problems of operative control on EPS normal modes may be defined just by numerical methods and don't have analytical expression. With the aim to get analytical dependence of controlling criterion from parameters 
of regulating devices, it's possible to use approximation of statistical data by selected criterion [98]. It's worth to build such an analytical dependence in relative units, when value of parameters of regulating devices and quality indexes for optimal mode are taken as a basis [98].

With the aim to get a set of statistical data, to build a dependence $\mathrm{F}_{*}=\mathrm{f}\left(I_{*}\right)$ in analytical form, computing experiment on computer is effectuated. At this, all model's parameters are fixed (for example, on optimal values), except one examined for sensitivity [99]. As the result, necessary approximation data are accumulated.

In this case approximation data are summary current of reversers connected to regulated tires system and the results of calculating target function value (2.6) in local electric system that is performed by algorithm showed on fig. 3.2. Basing on obtained data, dependences $\mathrm{F}_{*}=\mathrm{f}\left(I_{*}\right)$ are formed and search for approximation formula in form of binominal posynomial is performed [100].

$$
\mathrm{F}_{*}=a \cdot I_{*}^{\alpha}+b \cdot I_{*}^{\beta},
$$

where $\mathrm{F}_{*}=\mathrm{F} / \mathrm{F}_{0}, I_{*}=I / I_{0}$ - relative values of target function and summary current of reversers connected to regulated tires system; F, $I, \mathrm{~F}_{0}, I_{0}$ - current and basis values of quality criterion of control and summary current of invertors connected to regulated tires system; $a, b, \alpha, \beta$ - constants that form nature of dependence and measure of influence $I_{*}$ to value $\mathrm{F}$ *

Limits of insensibility area if microprocessor device $i_{\mathrm{H} .3}$ and $i_{\mathrm{B} .3}$ (fig. 3.7) that correspond to specified value of insensibility area of optimality criterion $\delta Ц_{*}$ are defined by such expressions [93]:

$$
i_{\text {low }}=\left[\frac{-\left(1+\delta \mathrm{F}_{*}\right) \beta}{a(\alpha-\beta)}\right]^{1 / \alpha} ; \quad i_{u p}=\left[\frac{\left(1+\delta F_{*}\right) \alpha}{b(\alpha-\beta)}\right]^{1 / \beta} \text {. }
$$

Due to formulas (3.3) area of admissible deviations of total current of reversers connected to regulated tires system from its optimal value is defined (fig. 3.7).

If current deviation from optimal value is within the interval $i_{\text {low }} \div$ $i_{\text {up }}$, the change of invertors number connected to regulated tires system is inexpedient. Otherwise $I_{*}$ should be changed to value sufficient for its introduction to optimality area. 


\subsection{Automated system of control on power delivery scheme for renewable energy sources in local electric systems}

3.4.1 Particularities of hardware implementation a system of control on power delivery of renewable energy sources in local electric systems

To realize complex of problems of optimal RES control in local electric systems, the necessary condition is providing of centralized control of an object in real time. But this condition cannot be provided because of spatial distribution of controlled object and limited security of communication channels between them and dispatching center [101-103]. Based on this, automated control system (ACS) with necessary list of controlling functions may be built as centralized system of operative control with decentralization of real time functions due to use of local ASC.

Considering structural and hardware complexity of such system in combination with rather hard financial restrictions regarding design, implementation and further support, ACS should be built on principles of hierarchical structure of control with selecting three levels:

- first level - dispatching center of centralized control;

- second level - «supporting» controlled RES that are functionally subordinated to first level and realize control of renewable sources of third level, retransmitting commands or correcting adjusting parameters that come from higher level;

- third level - renewable sources equipped with means of local automated control with minimal necessary intellectualization and maximal autonomy of functioning that perform commands and implement laws of control from higher hierarchical levels adapting them to local conditions.

Such structure allows to decrease costs to hardware and software realization of ACS.

According to above presented structure and suggested way of coordinating schedules of SPP generation with local electric power consumption, peculiarities of hardware implementation of SPP automated controlling system are shown on fig. 3.8. On fig. 3.8, interconnection between subsystem of information exchange at computation-dispatching center (CDC) of local electric system (first level) and sun power plant ACS (third level) of automated controlling system. 


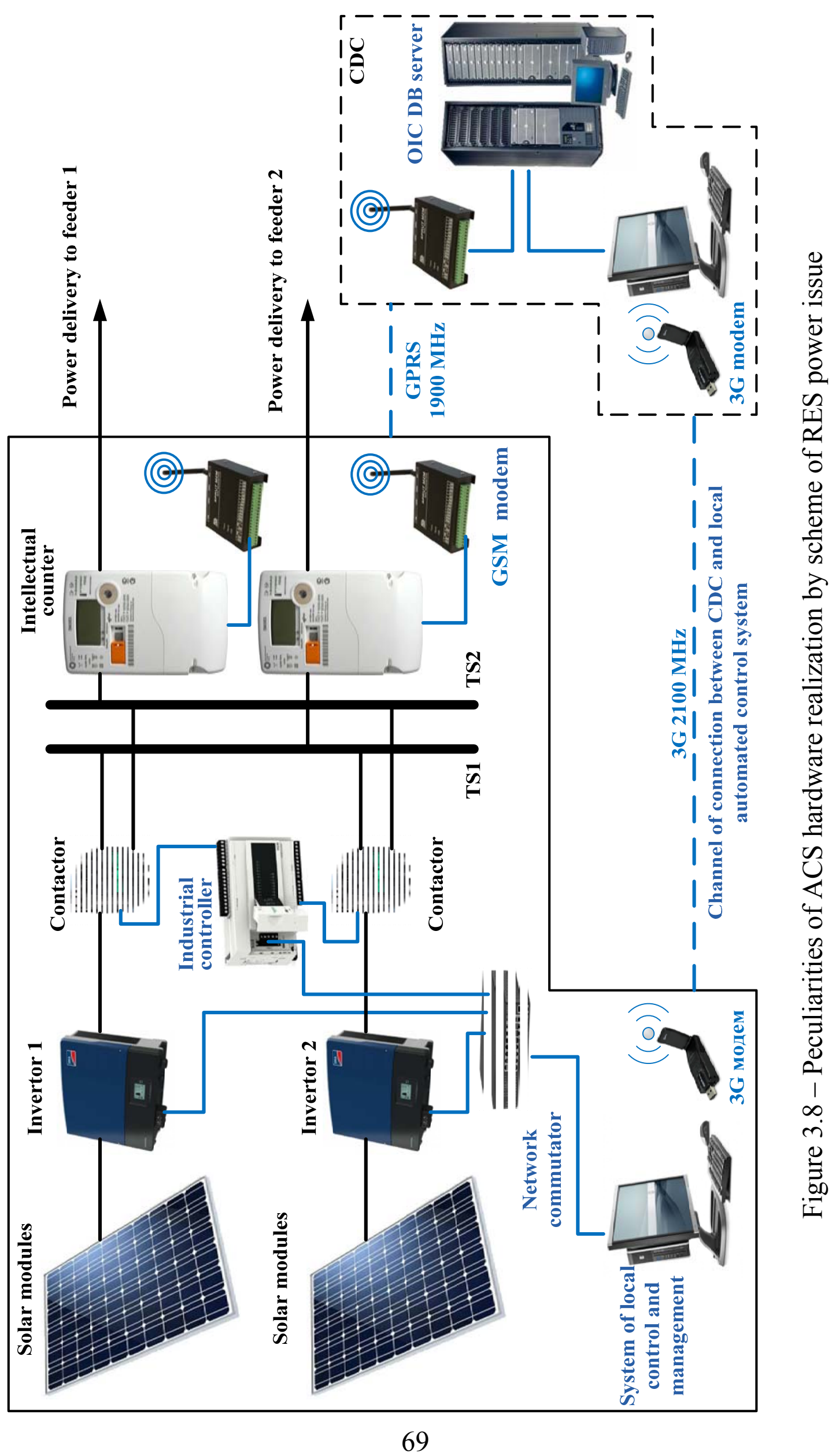


According to suggested way of operative correction of scheme for power delivery to PN, hardware realization supposes use of controlled commutation devices (contractors) that has nameplate data which depends on reversers' nominal power installed on SPP.

Control of commutation devices is made with industrial controller that functions accordingly to algorithm shown on fig. 3.7 by the law of control (3.1).

Industrial controller compares information about actual values of power and current on SPP tires with the value of optimal power calculated by algorithm on the fig. 3.2 and stored in database of CDC operativeinformation complex. Information on actual current and power values on controlled tires system is red from data base of operative-information complex and communication reversers' outputs.

Depending on the results of algorithm work, a number of reversers able to provide consumption from LES with maintaining all quality and minimal power losses factors is connected to regulated tires system. Excess of produced electric power is delivered to non-regulated tires system.

Using showed hardware implementation of automated control system will allow improving the existing system with means of discrete control. This will allow increasing functioning efficiency of local electric system and improve electric power quality factors, and will give the possibility of operative control over modes of work for distributed generation without worsening their profitability.

So, the suggested SPP automated control system (fig. 3.8) is based on Smart Grid functioning principles that lie in notable integration and automation of generation, transfer and consumption processes. Information connections with intellectual measuring and controlling equipment, as well as with OIC database, allow to consider exploitation peculiarities of distributed renewable energy sources and local electric system on the level of dispatching control.

\subsubsection{Study of functional stability of subsystem for information exchange in local electric system}

Structure of hardware realization of automated control system for RES power delivery in local electric systems suggested on fig. 3.8 consists on totality of interdependent and inter-acting hardware and software means of transfer, storing and processing of digital information connected by communication connections and aimed for solving a wide class problems regarding RES work modes control and management. 
In modern conditions providing the function of information exchange subsystem in RES control automated system is urgent. Functional stability is the feature of a complex technical system that characterizes possibility to continue performing a definite volume of functions, maybe with deterioration, during influence of internal and external destabilizing factors.

To solve this problem, it's necessary to provide collection, processing and analysis of information with automatic identification of emergency situation that is arising, and formation of recommendations on actions in conditions of such a situation.

Providing functional stability of any complex technical system is made due to excessiveness of different types: structural, hardware, time, informational etc. Means directed to providing or increasing level of functional stability, at first turn, provide improvement of fail-safety and viability characteristics, but not certainly safety factors of single constituent elements and articles, as well as tactics and technical system's characteristics [104].

One of the reasons of functional instability of complex technical systems in emergency situations is insufficient preparedness of computing system for recognition and actions in unexpected conditions. This manifests as non-considering all the set of situations in computation system. One of the signs may be first received signal on LES mode or RES work breach, or spatial-time structure of definite specific cases, or absence of algorithms for denial identification, also restriction of actions at parry of emergency situation.

Functioning of ACS on RES power delivery scheme with the aim of identifying an emergency situation supposes performing of operations listed below.

1. Detection of non-conformity of factual functioning parameters to specified parameters;

2. Detection of the most probable group the denial belongs to;

3. Reproduction of full pattern of expected denial;

4. Performing of active information perceiving based on waystandard for exact identification of situation.

For this, system encounters specified requirements of possibility to transfer information from any node to any another one. With that, continuing of functioning, possibly with quality reduction, during influence of destabilizing factors requires detection and use of excessiveness in 
system's structure. That's why it's worth to restrict with study of ACS information exchange subsystem for RES power delivery scheme.

To define excessiveness of suggested accomplishment of reverse problem, i.e. synthesis of excessive structure with specified features of functional stability and cost of system's construction and exploitation.

It is suggested to calculate level of functional stability for system of ACS data transfer for RES power delivery scheme by generalized probabilistic factor $F_{\mathrm{ACS}}$ that is calculated as convolution of connectivity probabilities matrix:

$$
\begin{gathered}
P_{3 B}=\left[\begin{array}{ccccc}
0 & P_{12} & P_{13} & \ldots & P_{1 n} \\
P_{21} & 0 & P_{23} & \ldots & P_{2 n} \\
\cdot & \cdot & \cdot & . & \cdot \\
P_{n 1} & P_{n 2} & P_{n 3} & \ldots & 0
\end{array}\right] ; \\
F_{A C K}=F\left(P_{3 B}\right)=\sum_{i=1}^{n} \sum_{j=1, j \neq i}^{n} w_{i j} \cdot P_{i j},
\end{gathered}
$$

where $n$-number of commutation nodes in subsystem of ASC information exchange for RES power delivery scheme; $P_{i j}$ - probability of connectivity between nodes $v_{i}$ and $v_{j} ; w_{i j}$ - weight factors of connection lines that depend on specified intensity of information transfer $\rho_{i j}$ between nodes $v_{i}$ and $v_{j}$ :

$$
w_{i j}=\left\{\begin{array}{l}
2, \text { при } \rho_{i j} \geq \mathrm{M}[\rho] ; \\
1, \text { при } 0,1 \mathrm{M}[\rho] \leq \rho_{i j} \leq \mathrm{M}[\rho] ; \\
1 / 2, \text { при } \rho_{i j}<0,1 \mathrm{M}[\rho] .
\end{array}\right.
$$

Expected value of specified information transfer intensity $\mathrm{M}[\rho]$ in system of ACS data transfer for RES power delivery scheme is defined based on the following dependency:

$$
\mathrm{M}[\rho]=\frac{1}{n(n-1)} \sum_{i=1}^{n} \sum_{j=1, j \neq i}^{n} \rho_{i j}
$$

Probability of connectivity $P_{i j}$ is defined basing on next primary data:

1) structure of ACS data transfer system for RES power delivery scheme specified by connections matrix $A_{3 B}$;

2) coefficient of information transfer readiness $K_{\ulcorner i j}$ by connection line $l_{i j}$. 
So, the problem of synthesis functionally stable subsystem of ACS information exchange for RES power delivery scheme may be formulated in such a way:

Define: Optimal structure of graph $\mathrm{G} \xi(\mathrm{V}, \mathrm{E}), \xi=1,2, \ldots, \mathrm{N}$, that meets requirements:

$$
F_{A C S}=f\left(P_{i j}\right) \rightarrow \max
$$

at limitations:

$$
\begin{gathered}
C_{\xi}=\sum_{i} \sum_{j} C_{i j}\left(l_{i j}, \rho_{i j}, h_{i j}\right) \leq C_{\text {allowable }} ; i, j=1,2, \ldots, \mathrm{N} ; \\
\chi(\mathrm{G}) \geq 2 ; \quad \lambda(\mathrm{G}) \geq 2 ; \quad \mathrm{G}_{0}(\mathrm{~V}, \mathrm{E}) \subseteq \mathrm{G}_{\xi}(\mathrm{V}, \mathrm{E}) .
\end{gathered}
$$

In the suggested approach to optimization of ACS information exchange subsystem's structure for RES power delivery scheme optimization by criterion of maximal index of functional stability at restrictions on system's cost is offered. Such problem setting in practical sense is interpreted as attempt to get system's structure that would resist to external and internal destabilizing factors due to founded excessiveness.

Index ${ }_{\xi}$ in (3.7) supposes detection of several structures for specified $\operatorname{cost} \mathrm{C}_{\text {allowable }}$ for optimization and augmentation of system's structure.

For possibility to reach result in the paper, decision relating to several one-criterion optimization problems with specified values $\mathrm{C}_{\text {allowable }}$ was taken as calculations of multi-criterion problem on graphs is almost impossible.

Suppositions:

1. Searched structures $\mathrm{G}_{\xi}(\mathrm{V}, \mathrm{E}), \xi=1,2, \ldots, 5$ should not has many-fold edges.

2. Searched structures don't have forbidden connection lines. We'll suppose that from any node $v_{i}$ to any node $v_{j}$ it is possible to stretch a connection line $e_{i j}\left(v_{i}, v_{j}\right)$ that has length $l_{\mathrm{ij}}$ and expenses cost $C_{i j}$ to capital investments and exploitation of connection lines.

3. Carrying capacity of separate information transfer channel is taken $\rho_{i j}>h_{i j}$, where $h_{i j}$ - intensity of information exchange between nodes $v_{i} \mathrm{i} v_{j}$. 
4. Cost of capital investments and exploitation of any structure $\mathrm{G}_{\xi}(\mathrm{V}, \mathrm{E})$ is calculate basing on known empirical dependencies.

5. Weight factors $w_{i j}$ in expression (3.4) at calculation of generalized index of functional stability $F_{\mathrm{ACS}}$ have subjective character and should be defined basing on method of expert values after rating of different directions of data transfer by importance.

Analysis of values of generalized index of functional stability allows to compare different system's structures. Higher is $F_{\mathrm{ACS}}\left(P_{i j}\right)$, more "protected" is the system from different failures, denials and damages due to structural excessiveness.

Decrease of values $K_{\Gamma}$ leads to extenuation of requirements to physical channels of information transfer but requires bigger expenses to building of additional connection lines for providing functional stability of distributed automated control system.

In its turn, index $K_{\Gamma}$ itself reflects both physical nature of connection channel (cable, radio, fiber optics etc.), and complex of measures regarding provision of necessary viability (reliability) of this channel. That's why another way to increase functional stability is to increase values of every single index $K_{\mathrm{r}}$ for each separate connection line. It's obvious that complex of measures on increasing viability (reliability) will also influence on channel cost that in conclusion will lead to necessity to solve a new problem of choosing rational variant of improving ACS information exchange subsystem for RES power delivery scheme.

\section{Summary to chapter 3}

Problems of defining optimal established power and optimization of daily generation modes of renewable sources generation are reasonable to be solved separately as problems of design and exploitation for specified local electric system with aim to get maximal effect in it. In concordance with this, algorithm realization of mentioned problems should be performed for each electric network that is being optimized.

The suggested algorithm of defining optimal established power of renewable energy sources in local electric system by complex criterion allows to solve the problem of defining optimal power of conditionally controlled renewable sources on the stage if design with consideration of electric power quality indexes. Violation of the last ones puts away the obtained solution from optimal one. 
The developed algorithm of daily generation modes accordingly to prognosticated load schedule by complex criterion allows to solve the problem of keeping maximal power of conditionally controlled renewable sources during their exploitation with consideration of electric power quality indexes. Use of the present algorithm in ACS on RES power issue scheme allows to define optimal values of power on tires of energy source and use them during optimal control.

Use of combined algorithm of defining optimal connection place for renewable energy sources in local electric systems allows to get a solution that is almost independent from PN mode changes, decreases electric power losses and increases quality of power for totality of LES probable modes.

Algorithmic implementation of developed way of optimal control on scheme of invertors connection, i.e. change of power delivery scheme to $\mathrm{PN}$ is used to coordinate schedules of SPP generation with local power consumption in ACS on RES power delivery scheme. So, according to developed way, algorithm of functioning for microprocessor device that controls RES power delivery scheme in local electric systems was suggested.

The suggested way of hardware implementation of automated control system on RES power delivery scheme in local electric systems is based on Smart Grid functioning principles that consist in notable integration and automation of generation, transfer and consumption processes. The new approach to defining indexes and criteria for estimation functional stability of ASC information exchange subsystem for RES power delivery scheme uses in complex way the principle decomposition of the procedure that provides functional stability to more simple stages and uses method of calculating generalized index of functional stability as convolution of structure connectivity matrix. The used indexes and criteria allow to evaluate and compare different structures of subsystem for information exchange in automate control system 


\section{OPTIMIZATION OF RENEWABLE ENERGY SOURCES FUNCTIONING IN LOCAL ELECTRIC SYSTEMS}

In previous chapters a set of methods and algorithms that allow to solve RES functioning optimization problem in local electric systems on the stage of their design and exploitation was suggested. In the present chapter a set of practical calculations that confirm adequacy of suggested methods and functional ability of algorithms was performed. Calculations were made on examples of $10 \mathrm{kV}$ electric networks of Yampilskyi district. The mentioned networks were selected based on such reflections. From one side, they are used for power delivery of considerable number of divers RES that have commensurable power or where power exceeds PN load. From the other side, Tsekynivska solar power plant is situated in Yampilskyi district; it delivers power to two single feeders at the same time, at this, one of them functions without intermediary power take-off and this gives the possibility to investigate efficiency of the suggested optimization method for daily generation modes.

Efficiency and adequacy of developed methods and algorithms may be shown by means of calculating experiment. In this chapter functional ability and efficiency of methods and algorithms suggested in the paper are shown on examples of real renewable sources and distribution networks. Practical calculations on defining optimal established RES power by complex criterion that considers quality and power losses indexes are made. Efficiency of applying the improved method for defining optimal RES connection places in local electric systems is studied. Optimization of daily generation modes of Tsekynivska solar power plant and power consumers in electric networks of Yampilskyi district is performed.

According to the suggested ACS structure on RES power delivery scheme in local electric system, functional stability of information exchange subsystem and possibility to provide its functional stability by way of connection lines reservation is studied.

\subsection{Study of efficiency of applying the method for defining established power of renewable energy sources by complex criterion}

\subsubsection{Analysis of LES operation modes on the example of $10 \mathrm{kV}$ electric networks of Yampilskyi district and Tsekynivska solar power plant}

Calculations of efficiency from using established RES power in distributed PN are made on example of Tsekynivska solar power plant 
situated in electric networks of Yampilskyi district. Main characteristics of the plant:

- put in service - 28.12.2011;

- established power:

Tsekynivska SPP № 1: 1,43 MW;

Tsekynivska SPP № 2: 1,43 MW;

Tsekynivska SPP № 3: 0,25 MW;

Electric circuit of the plant is shown on fig. 4.1-4.2. Tsekynivska SPP delivers electric power directly to electric network $10 \mathrm{kV}$ through feeders F-31 and F-35 of substation 35/10 kV «Sloboda Pidlisivska». The connection scheme is shown on fig. 4.3. For connection of SPP with feeder F-35 on voltage $10 \mathrm{kV}$ overhead transmission line $12 \mathrm{~km}$ long is used, realized with wire AS-70.

Length of SS 35/10 «Sloboda Pidlisivska» f.№ 31 makes up 21,3 km. The feeder contains: 40 nodes, 18 transforming substations; 8 breakers, one of which is normally switched off, 2 switches, one solar power plant Tsekynivska SPP № 1 with the power 1,430 MW.

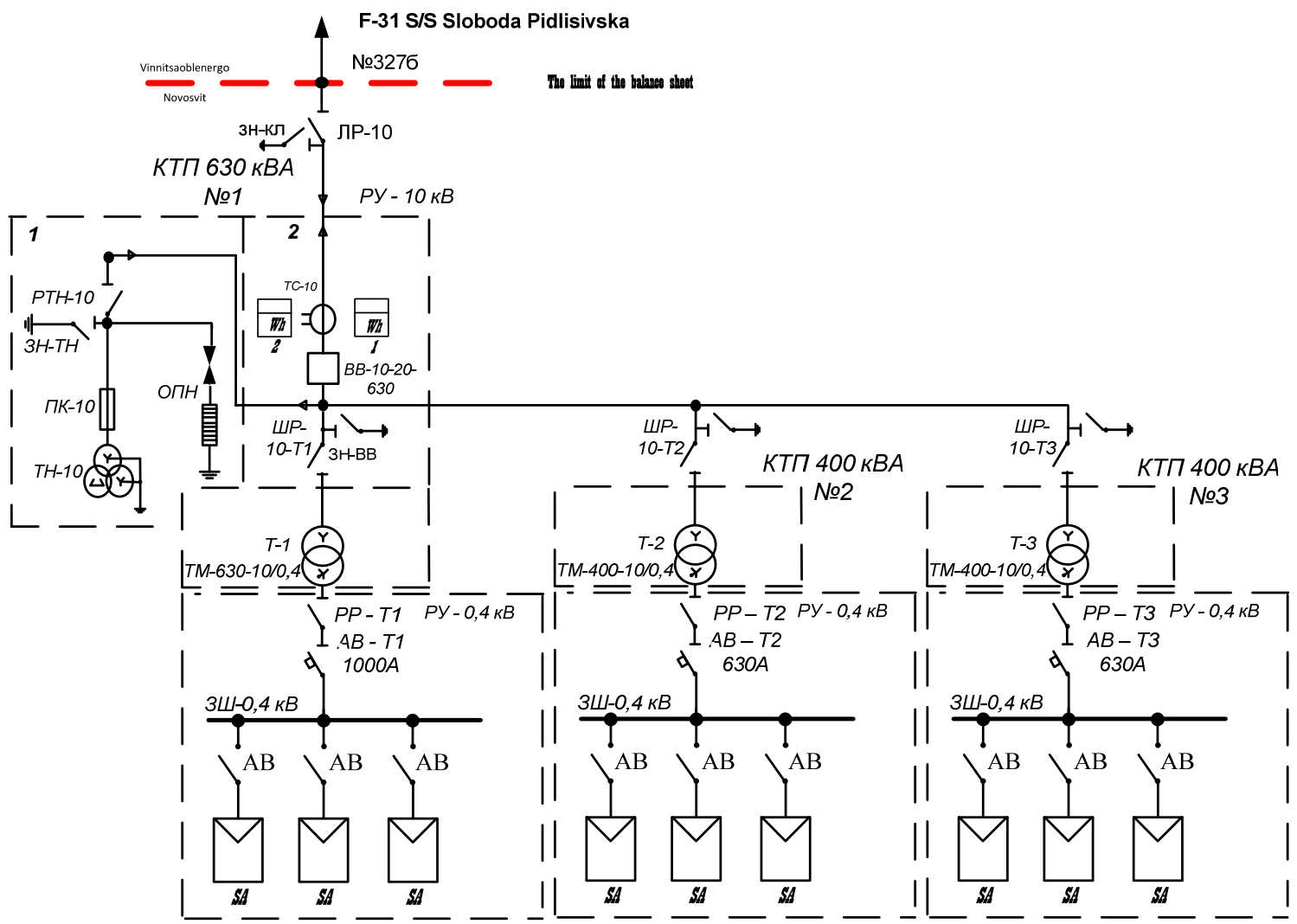

Figure 4.1 - Scheme of electric connection of Tsekynivska SPP № 1 FEA «Novosvit» 




$\stackrel{\infty}{\sim}$ 


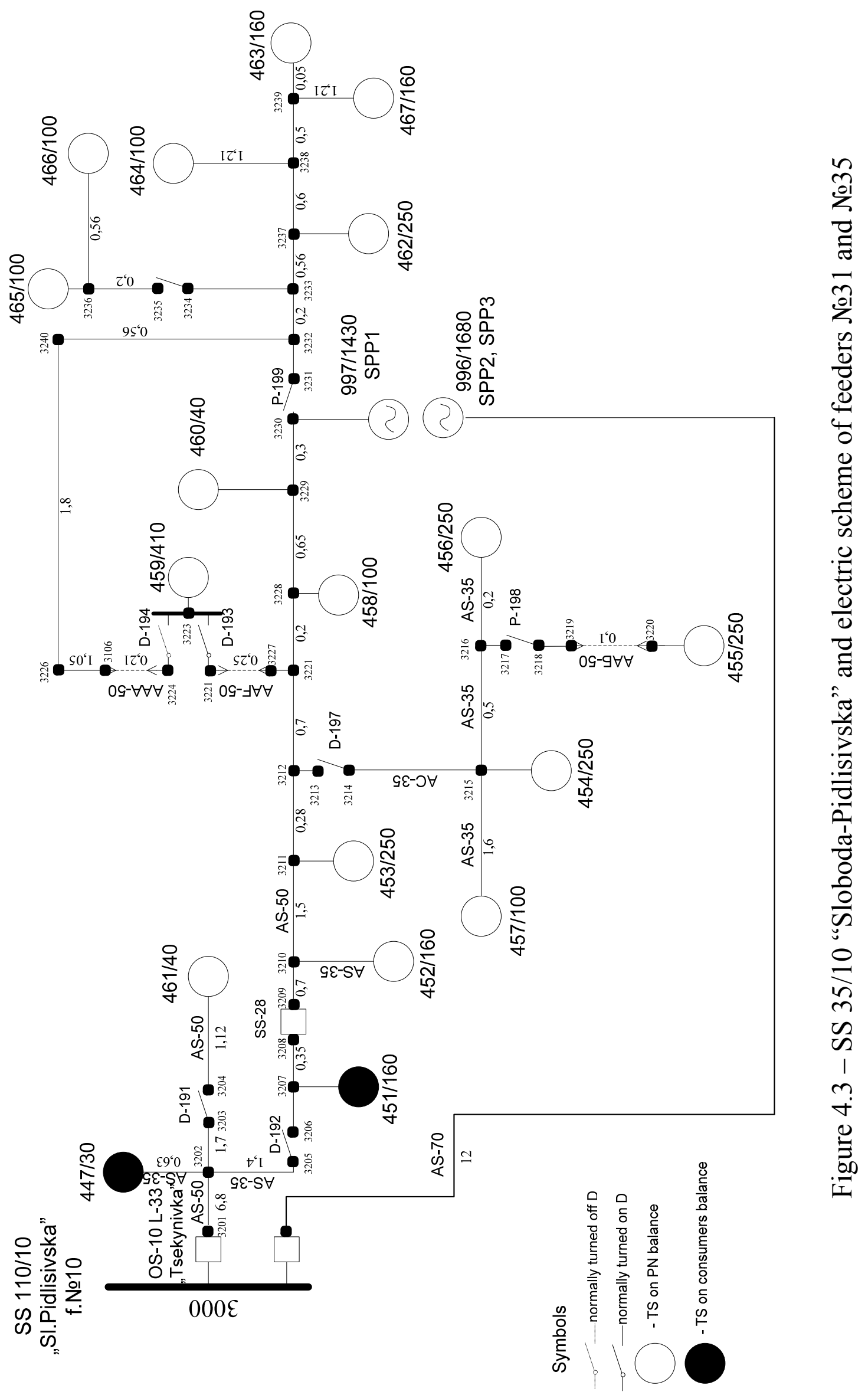


Input data on $10 \mathrm{kV}$ distribution network that receives power from Tsekynivska SPP №1 delivered through feeder F-31 to substation $35 / 10 \mathrm{kV}$ «Sloboda-Pidlisivska» is provided on attachment A. Modes are analyzed according to loads schedules for typical SPP operation modes to study influence of SPP to network's modes of operation. Correlation of power delivery schedules of Tsekynivska SPP №1, № 2 and № 3 and load to feeder $\Phi-31$ for mode of maximum loads are shown in figure 4.4-4.5. Analyzing load graphics shown on fig. 4.4, it is seen that load of feeder F-31 in mode of maximum load exceeds admissible generation power connected to this feeder, at the same time part of generation power is passed to wires of substation 35/10 «Sloboda-Pidlisivska» directly by feeder F-35. Check of optimality of such distribution needs solution of problem of optimization scheme for RES connection to electric network.

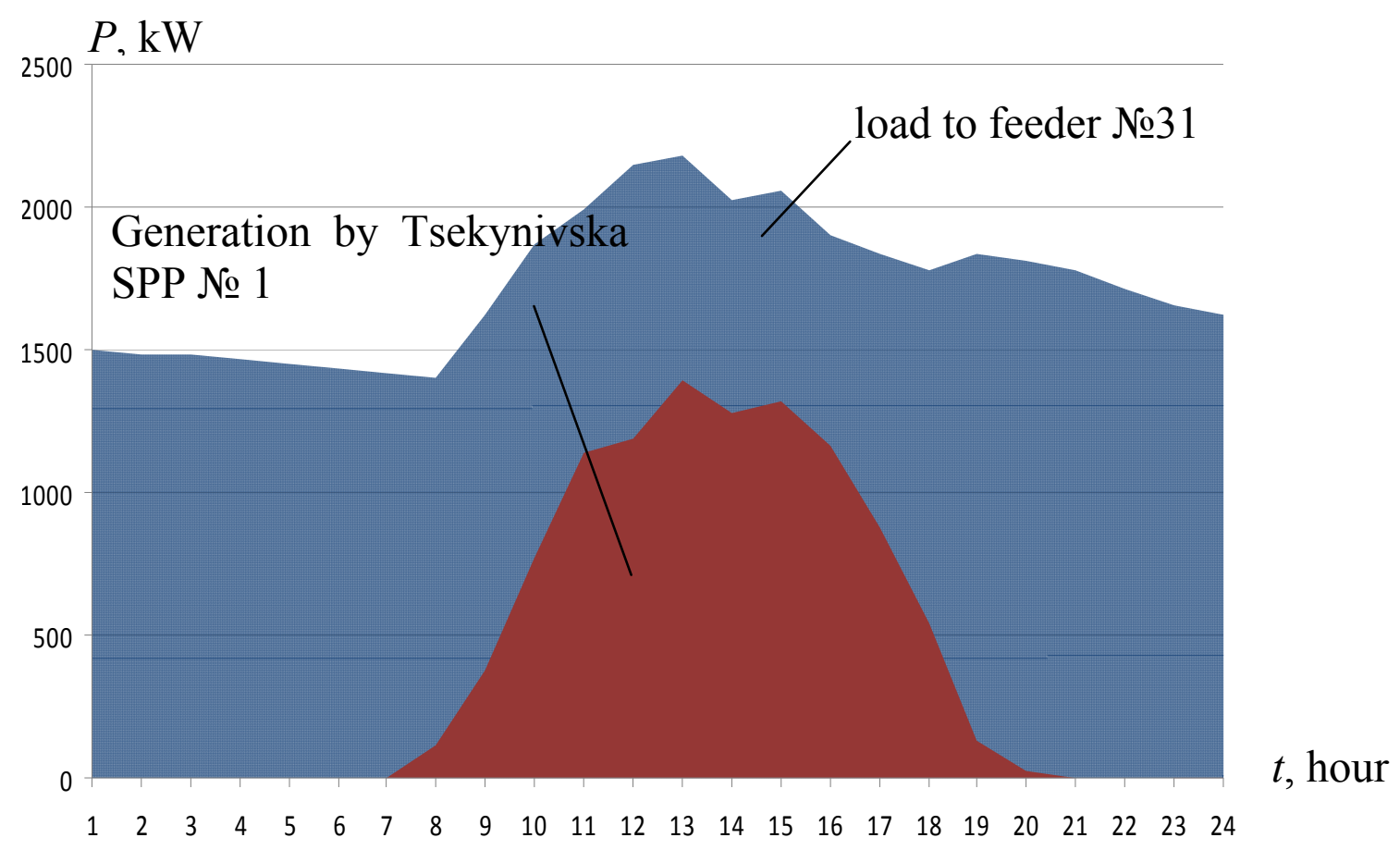

Figure 4.4 - Correlation of graphics of power delivery by Tsekynivska SPP № 1 and load to SS 35/10 «Sloboda Pidlisivska» feeder № 31 in mode of maximum load 


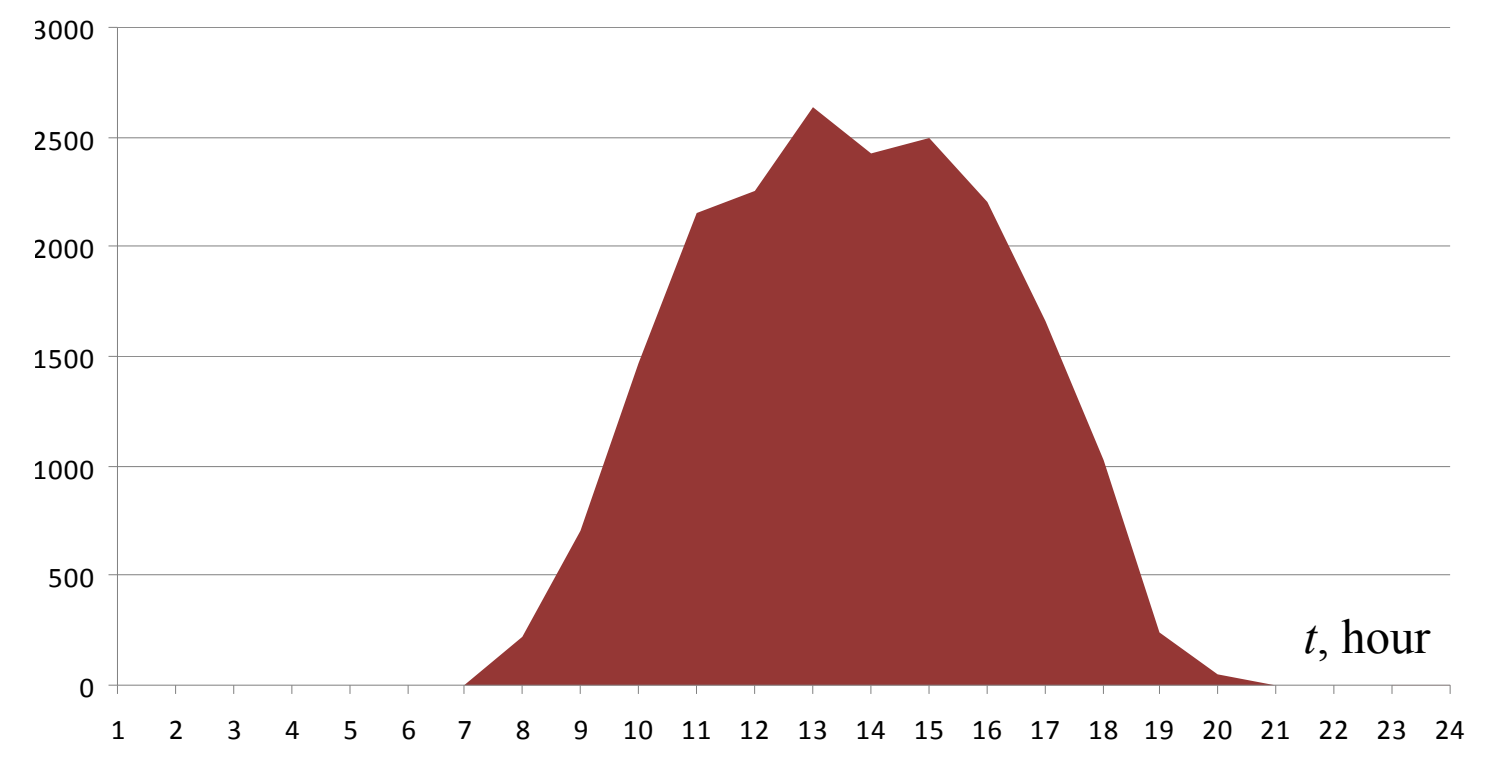

Figure 4.5 - Graphic of power delivery by Tsekynivska SPP № 2,3 in mode of maximum loads

4.1.2 Calculation of efficiency of using established power of renewable energy sources by complex criterion in LES on example of Tsekynivska solar power plant

Calculation was made by method shown in subparagraphs 2.1 , and parameters for calculation of target function values (2.2) were calculated by means of software for analysis of power losses and formation of energysaving measures in distributed electric networks with distribution generation «VTRATY-10/0,4 (RES)».

For analysis of efficiency of use established power of renewable energy sources by complex criterion, load graphics of typical feeders F-31 and F-35 mode were used, what is shown on fig. 4.6-4.7.

Powers of Tsekynivska SPP № 2 and № 3 are issued to feeder № 35 of substation 35/10 «Sloboda-Pidlisivska» with no intermediary selection, that's why graphic of feeder's loads on fig. 4.7 gets negative values.

Input of information on substations (fig. 4.8) is made by establishing of average value of current in feeder's head, as well as information on parameters of electric network's scheme, wires, breakers, that gave the possibility to count total losses on substations and separately on feeders (attachment B). 


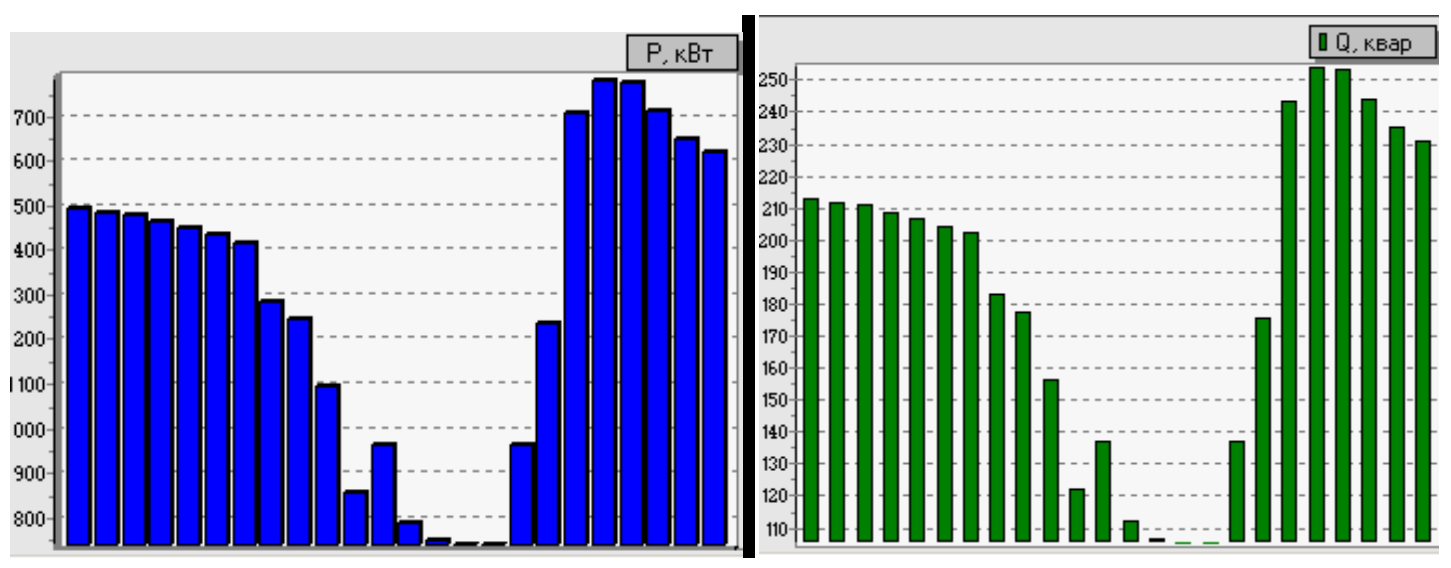

Figure 4.6 - Daily load graphics on active and reactive power of feeder № 31 SS 35/10 «Sloboda-Pidlisivska»



Figure 4.7 - Daily load graphics on active and reactive power of feeder № 35 SS 35/10 «Sloboda-Pidlisivska»



Figure 4.8 - Information on substations in program «VTRATY-10/0,4 (RES)» 
During the process of calculation, information on load current in main feeder's area is changed automatically, according to load graphics (see fig. 4.6-4.7)

For typical LES mode, probabilities of providing normative power losses and providing normative power deviation were calculated. Results of calculation by program complex «VTRATY-10/0,4 (RES)» are shown on fig. 4.9-4.12.

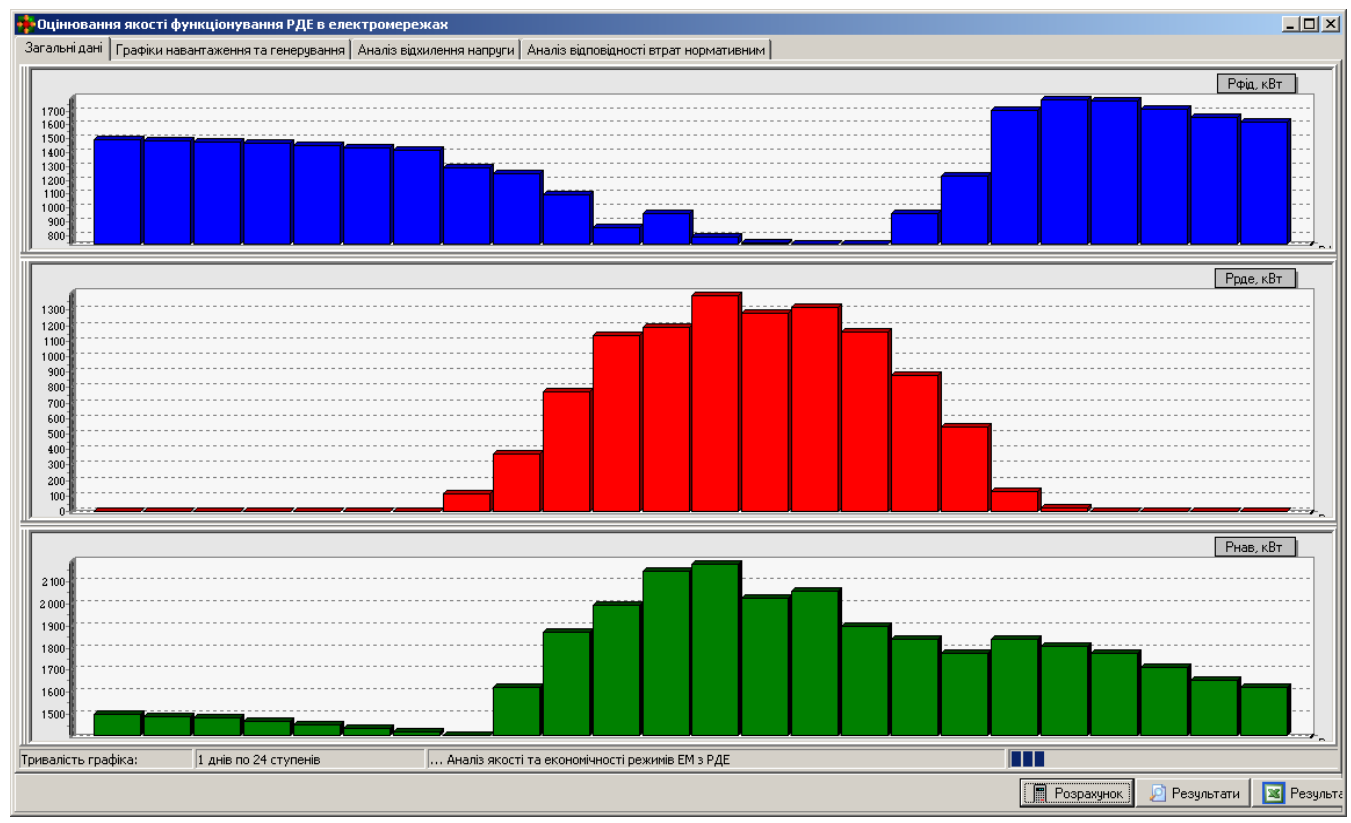

Figure 4.9 - Information for calculation on SS 35/10 «Sloboda-Pidlisivska» feeder № 31

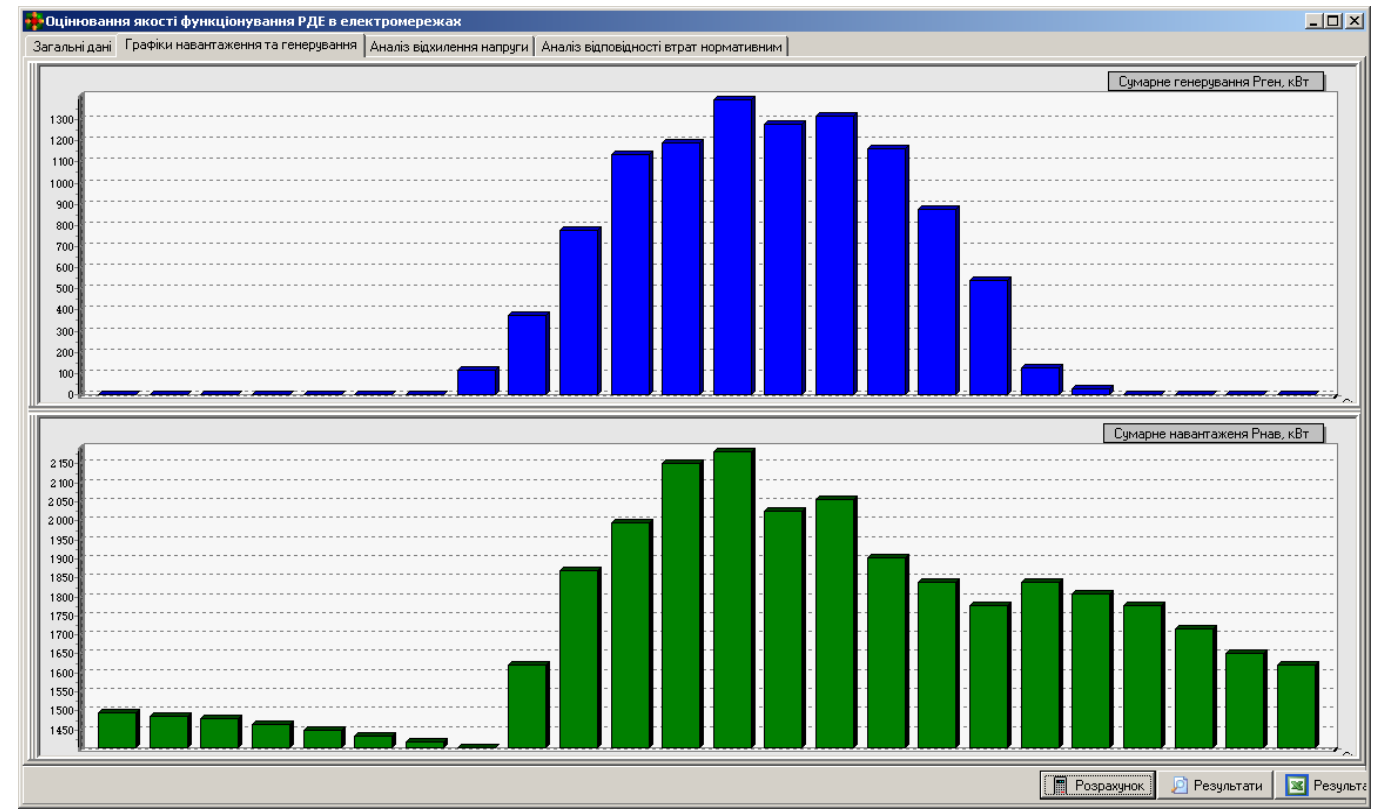

Figure 4.10 - Generation and load graphics on SS 35/10 «Sloboda-Pidlisivska» feeder № 31 

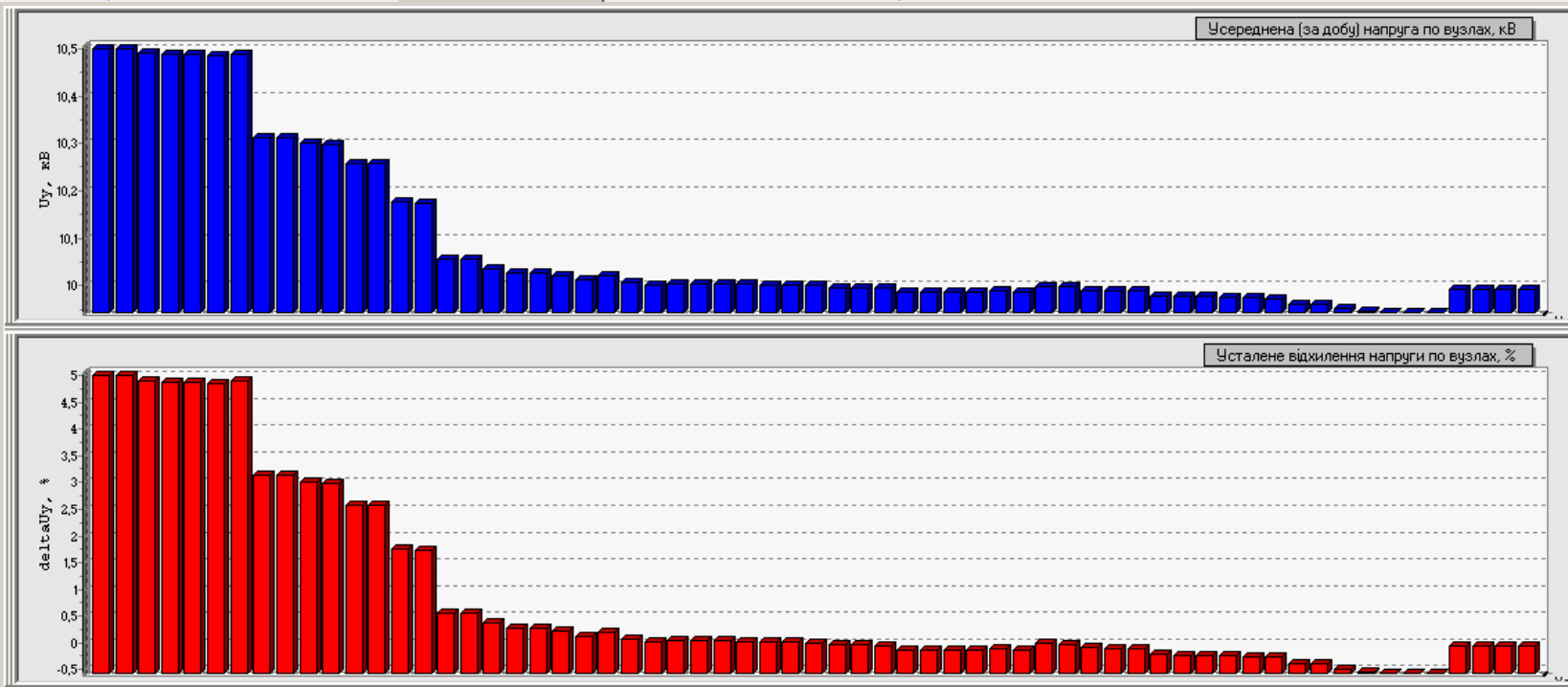

Iмовірність забезпечення нормативного відхилення напруги: 1.000000

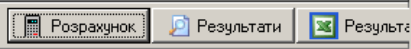

Figure 4.11 - Results of calculation of probability to provide normative voltage deviation of all feeder F-31 nodes

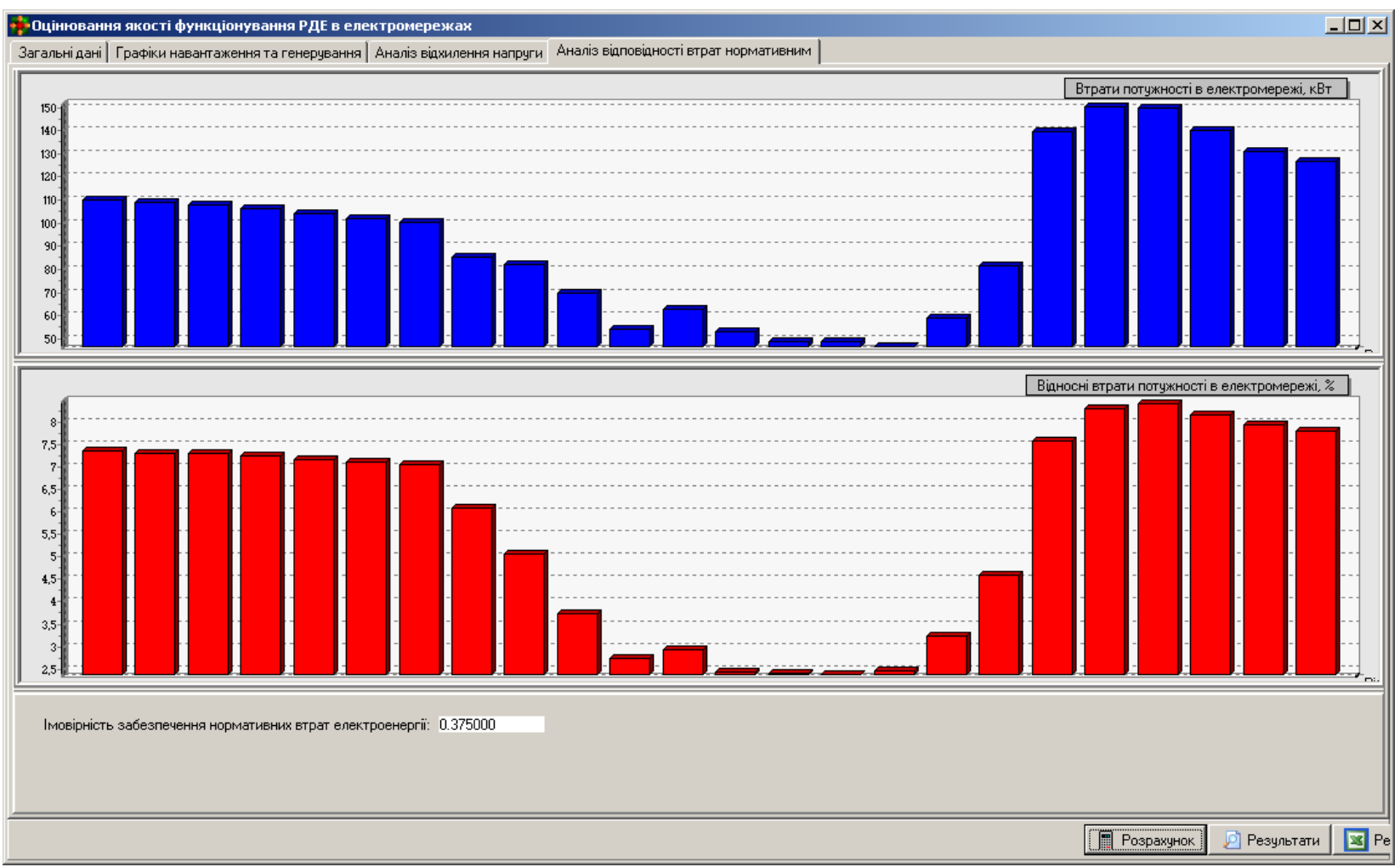

Figure 4.12 - Results of calculation of probability to provide probable normative electric power losses 
As it is seen from fig. 4.11, daily average value of voltage deviation for all LES nodes does not exceed $5 \%$. That's why according to expression (2.12), probability of providing normative voltage deviation is $\bar{P}(U \mathrm{a} v, T)=1$ r.u.

Analysis of power losses graphic in electric network (fig. 4.12) showed that relative value of power losses in rated LES exceeds previously adopted value to $5 \%$ during 15 hours a day (for each REN is rated separately). So, according to expression (2.19), probability of providing normative power losses deviation makes up:

$$
\bar{P}\left(\Delta W_{\text {allowable }}, T\right)=t_{\text {cyм }}\left(\Delta W_{\text {act }} \leq \Delta W_{\text {allowable }}\right) / T=9 / 24=0,375 \text { r.u. }
$$

To calculate numerical value of target function (2.2), tariffs to production of electric power by Tsekynivska SPP according to regulation of National Energy and Utilities Regulatory Commission № 1072 dated by 31.07.2014 «About establishment of «green» tariffs to electric power». Tariffs are shown in table 4.1.

Table 4.1 - «GREEN» tariffs to electric power produced by business entities on objects of power industry that use alternative energy sources

\begin{tabular}{|c|l|c|}
\hline № & \multicolumn{1}{|c|}{$\begin{array}{c}\text { Power generating companies } \\
\text { Tsekynivska SPP }\end{array}$} & $\begin{array}{c}\text { «Green» tariffs w/o VAT, } \\
\text { kop/kW·hour }\end{array}$ \\
\hline 1 & \multicolumn{1}{|c|}{2} & 3 \\
\hline 1 & Tsekynivska SPP № 1 & 731,95 \\
\hline 2 & Tsekynivska SPP № 2 (1-3 turns) & 731,95 \\
\hline 3 & Tsekynivska SPP № 2 (4-5 turns) & 533,71 \\
\hline 4 & Tsekynivska SPP № 3 & 533,71 \\
\hline
\end{tabular}

Numerical value of total revenue from exploitation Tsekynivska SPP № 1 for a day connected to parallel work in Yampilskyi PN may be written like next:

$$
C_{R E S}=\sum_{i=1}^{n} z_{i} \cdot P_{R E E_{i}} \cdot k_{f_{i}} \cdot T=731,95 / 100 \cdot 1430 \cdot 0,8 \cdot 24=200964 \mathrm{grn} .
$$


Target function of the problem for defining optimal established power of Tsekynivska SPP № 1 feeder № 31 SS 35/10 «Sloboda-Pidlisivska» will get such a numerical value:

$$
\begin{aligned}
C & =C_{R E S} \cdot e^{-k_{1} \cdot(1-\bar{P}(U \text { avallowable }, T))} \cdot e^{-k_{2} \cdot\left(1-\bar{P}\left(\Delta W_{\text {allowable }}, T\right)\right)}= \\
& =200964 e^{-0,288 \cdot(1-1)} \cdot e^{-0,163 \cdot(1-0,375)}=181647 \mathrm{grn} .
\end{aligned}
$$

So, inobservance of normative power losses reduces total revenue from exploitation of Tsekynivska SPP № 1 to $9 \%$.

The obtained value of total revenue may vary depending on values of weight factors $k_{1}$ and $k_{2}$. In subparagraph 2.1 .5 it is revealed analytically the expediency of establishing $k_{1}=0,288$ r.u. and $k_{2}=0,163$ r.u.

\subsubsection{Defining optimal established power of renewable energy sources by complex criterion in LES on example of Tsekynivska solar power plant № 1}

To define optimal established RES power by complex optimality criterion with consideration of electric power quality and minimum losses, the developed method (see subparagraph 2.1) on example of Tsekynivska SPP № 1 was used.

To calculate target function value, value of established power of Tsekynivska SPP № 1 has been increased according to algorithm fig. 3.1, by connecting part of generating powers from Tsekynivska SPP № 2 . According to re-distribution, graphic of load to feeder № 31 and feeder № 35 has been changed. Results of calculation are in the table 4.2.

Table 4.2 - Results of calculating optimal established power of first turn of Tsekynivska SPP by complex criterion

\begin{tabular}{|c|c|c|c|c|c|}
\hline $\begin{array}{c}\text { Tsekynivska } \\
\text { SPP № 1, kW }\end{array}$ & $\begin{array}{c}C_{R E E}, \\
\text { mln hrn/year }\end{array}$ & $\begin{array}{c}\bar{P}\left(U_{a v}, T\right), \\
\text { r.u. }\end{array}$ & $\begin{array}{c}\bar{P}\left(\Delta W_{l}, T\right), \\
\text { r.u. }\end{array}$ & $\begin{array}{c}\Delta W_{\text {act }} \\
\%\end{array}$ & $\begin{array}{c}\text { C, } \\
\text { mln hrn/year }\end{array}$ \\
\hline 1430 & 73,3 & 1 & 0,38 & 8,47 & 66,2 \\
\hline 1680 & 86,1 & 1 & 0,42 & 8,21 & 78,4 \\
\hline 2080 & 93,8 & 1 & 0,47 & 7,9 & 86,1 \\
\hline 2710 & 105,6 & 0,6 & 0,35 & 9,2 & 84,7 \\
\hline
\end{tabular}

As it is seen from research results, connection of power $2080 \mathrm{~kW}$ to feeder \#31 of Sloboda-Pidlisivska substation is optimal. Increase of established power leads to probable reduction of voltage quality that worsens conditions of local electric system functioning. 


\subsection{Results of studying efficiency of applying improved method for defining optimal places of connecting renewable energy sources in local electric systems}

To check adequacy of the suggested analytical conditions for electric power transportation schemes in LES (see subparagraph 2.3) by criterion of minimum power losses, and to prove efficiency of the improved method for defining optimal connection places of RES (see subparagraph 2.2), example of local electric system with RES of Sloboda-Bushanskyi complex with established power SPP $1881 \mathrm{~kW}$ and SH $250 \mathrm{~kW}$ (fig. 4.13) connected to SS 110/10 «Myhailivka» of Yampilskyi electric systems was used.

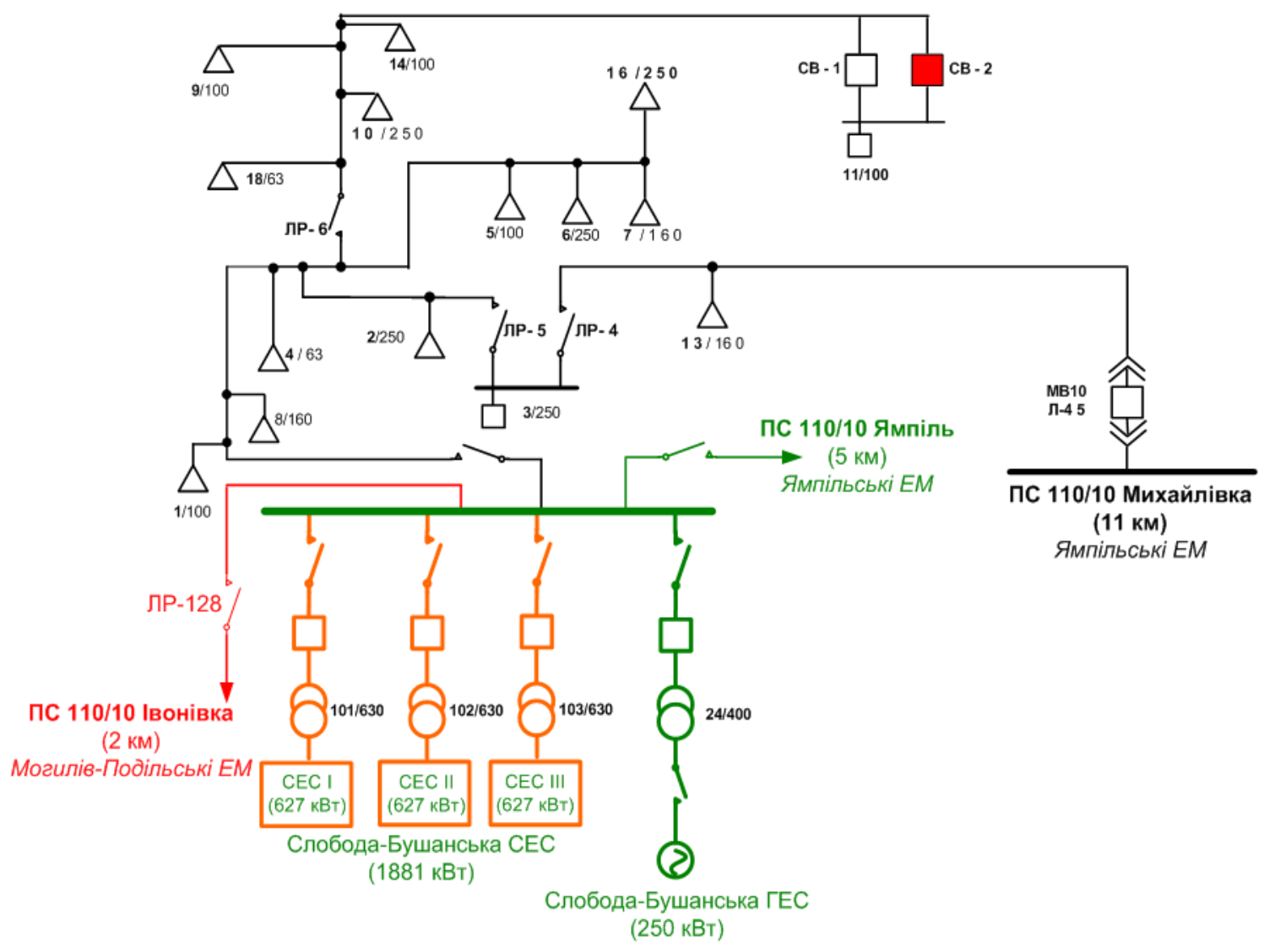

Figure 4.13 - Ways of connecting Sloboda-Bushanskyi RES complex to electric networks

During calculation process by algorithm (fig. 3.3) it was defined that established RES power exceeds optimal value. So, to define optimal connection place, it's reasonable to use generalized efficiency index $d P^{\prime}$ (2.51). 
A set of modes calculation at different values of power generation by Sloboda-Bushanska SPP was performed for the mentioned circuit in specified connection node and dependencies of generalized LES efficiency indexes (fig. 4.14) and mean-square voltage deviation on circuit's nodes from RES generation power were built (fig. 4.15).



Figure 4.14 - Dependencies of generalized LES efficiency indexes from power of Sloboda-Bushanskyi RES complex

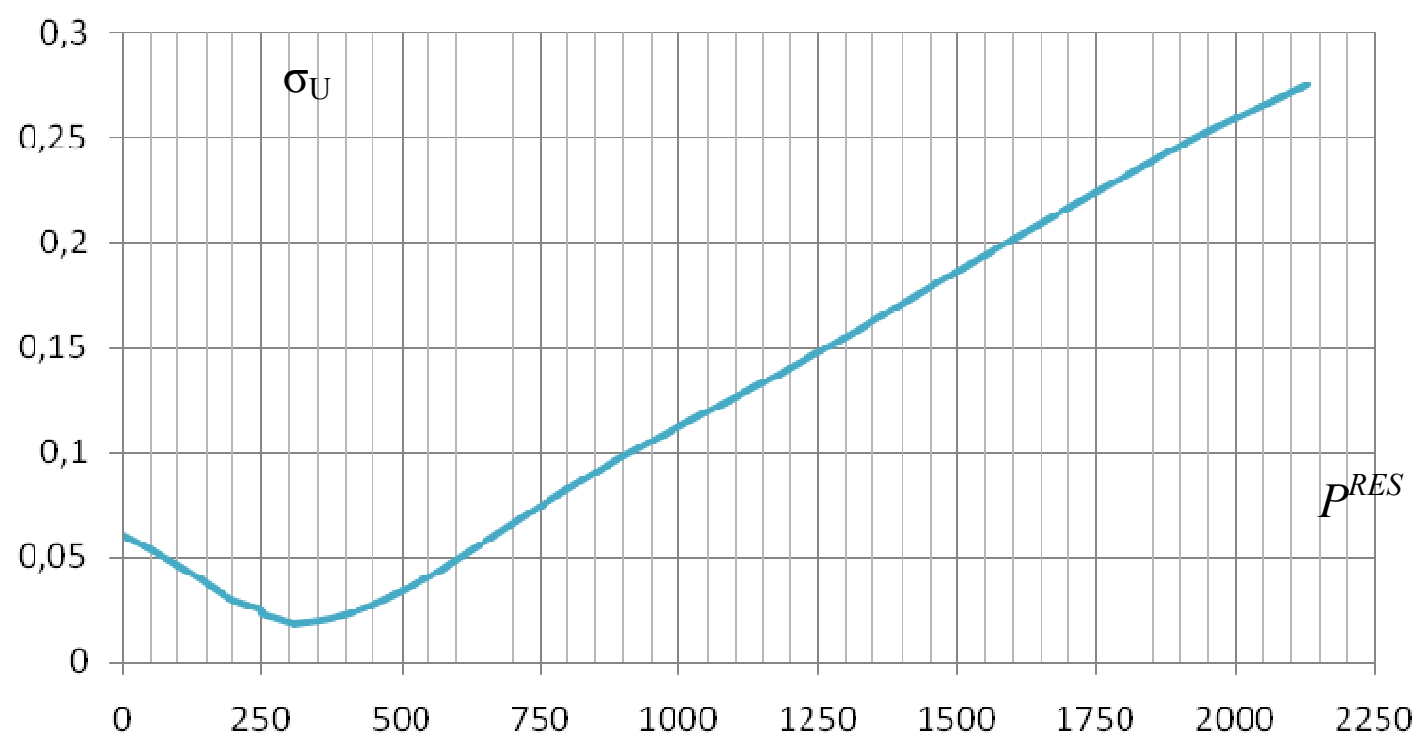

Figure 4.15 - Dependency of mean-square voltage deviation in a network from generation power of Sloboda-Bushanskyi RES complex 
Calculations of LES efficiency generalized indexes' dependencies $d P^{\prime}, d P^{\prime \prime}$ shown on fig. 4.14 were performed for invariable value of generating reactive power on RES and gradual increase of generating active power to established value.

From the analysis of dependencies it is seen that optimal mode of RES complex work that won't worsen LES functioning optimality criteria and perspective of further EN development will be the mode of power delivery $371 \mathrm{~kW}$. Increase of generation will lead to increase of power losses in LES and complications with further RES development in the studied local system. So, the range of RES powers worth to be connected to SS 110/10 "Mykhailivka" of Yampilskyi electric networks is about 400 $\mathrm{kW}$. Similar results with the use of method for defining equivalent resistances for RES connection nodes in electric networks were obtained in [3]. Transportation of maximum established power of Sloboda-Bushanskyi RES complex to power market with the use of analyzed electric networks, leads to increase of power losses, which is commensurable with generation by Sloboda-Bushanska HPP. Based from this, in the project of connecting the present RES complex, transportation of the great part of electric power by other electric networks to wires of SS 110/10 "Ivonivka" of MogylivPodilskyi EN $(2 \mathrm{~km})$ is foreseen.

Total dependency of generalized indexes $d P^{\prime}, d P^{\prime \prime}$ matches the form and minimum value of mean-square voltage deviation in the network from generation power of Sloboda-Bushanskyi RES complex (fig. 4.15). So, optimization of electric power delivery scheme with the use of generalized indexes $d P^{\prime}, d P^{\prime \prime}$ also allows to get solutions that provide abidance of conditions for providing electric power quality.

\subsection{Results of optimizing daily generation modes of renewable energy sources and power consumers in local electric systems on example of Tsekynivska solar power plant}

With the aim to check efficiency of applying the suggested method of correlation generation graphics for renewable energy sources and power consumers in local electric system (see subparagraph 3.3) and law of optimal control on means for reconfiguration of RES power delivery in local electric systems, daily functioning modes of Tsekynivska SPP in electric networks of Yampilskyi district are calculated.

Correlation of daily generation modes by Tsekynivska SPP (all turns together) and consumption of power in mode of maximum load to feeder \#31 SS «Sloboda Pidlisivska» is shown on fig. 4.16. 


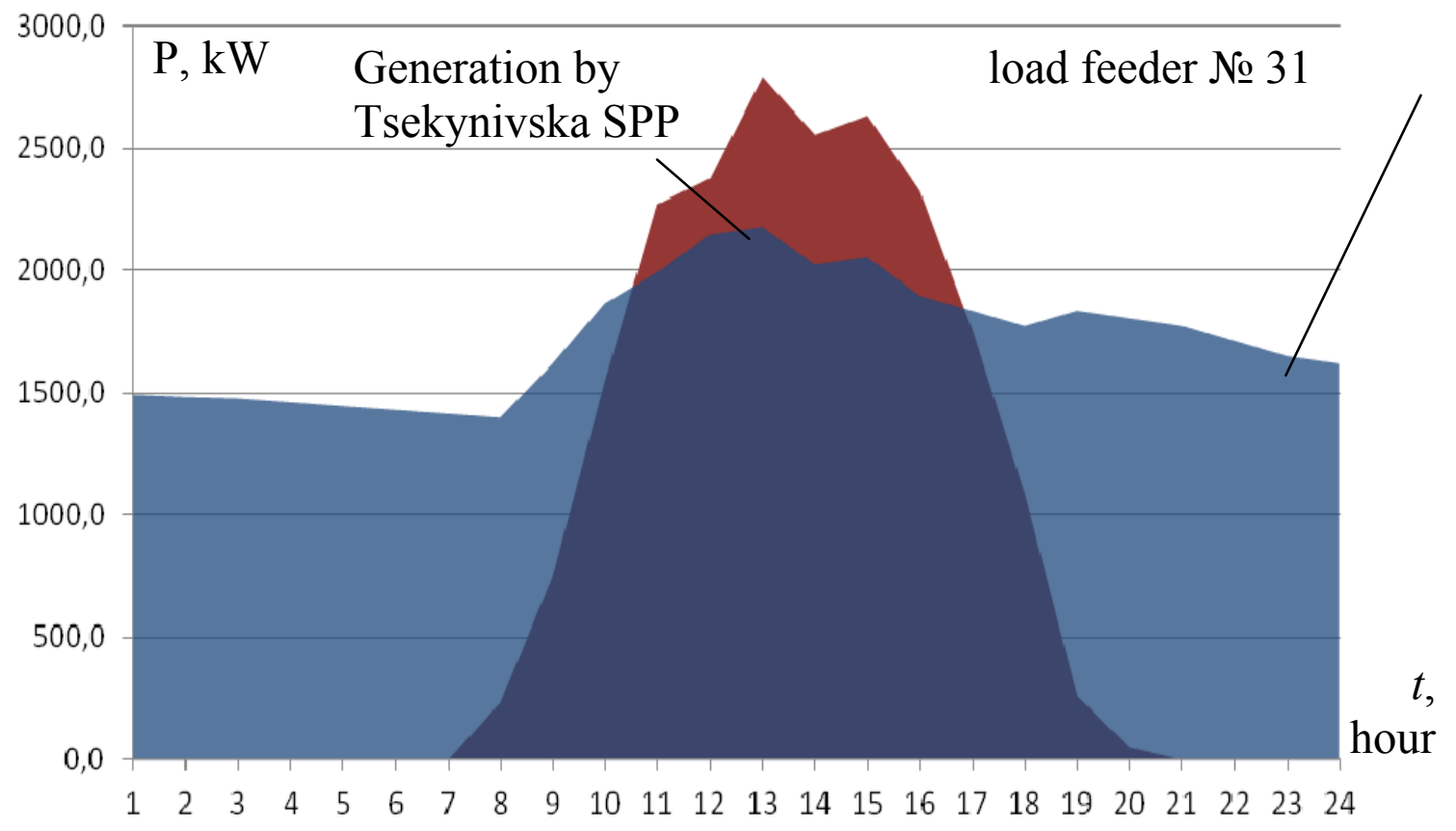

Figure 4.16 - Correlation of daily generation modes of Tsekynivska SPP and consumption of power in local electric system

A calculating experiment was carried out where generation power by Tsekynivska SPP (all turns together) is issued to supply center only by feeder № 31. Results of calculating power losses for mode of maximum load of feeder № 31 SS 35/10 "Sloboda Pidlisivska" functioning and graphic of covering consumption from supply center is shown on fig. 4.17.

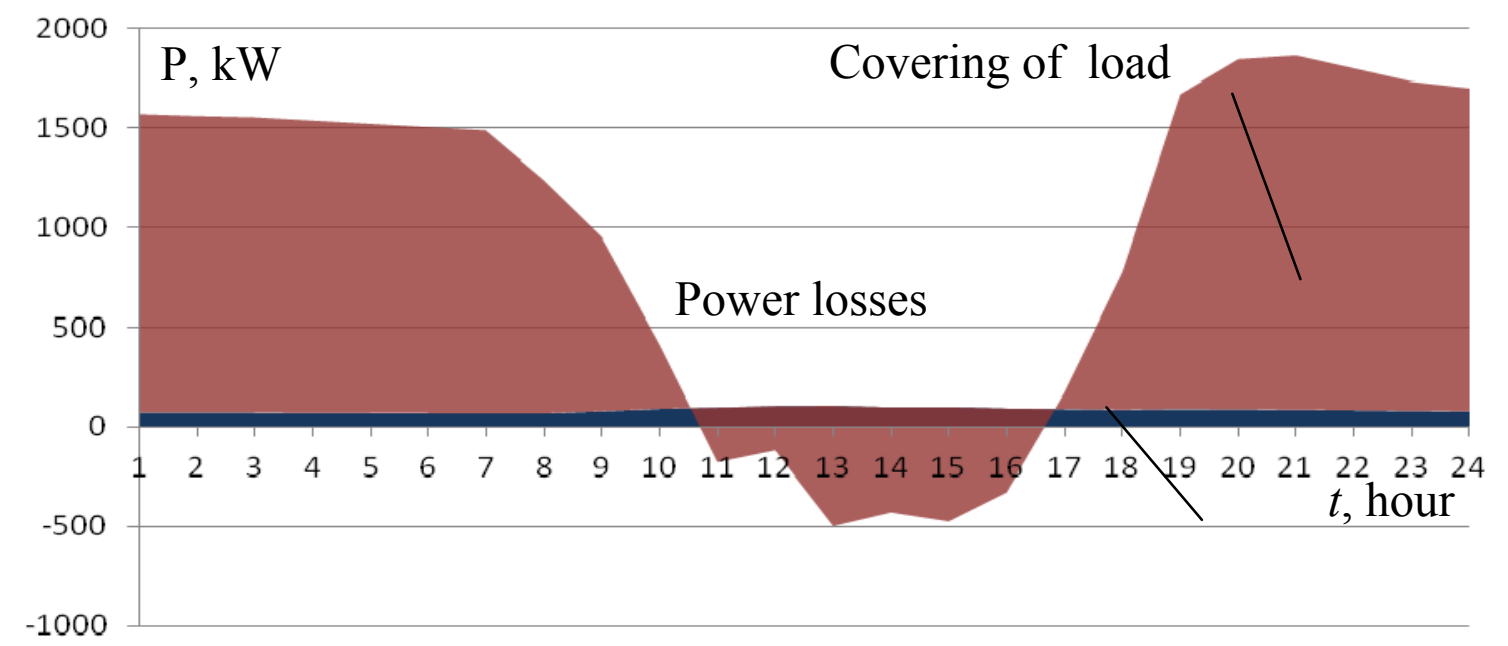

Figure 4.17 - Correlation of power losses F-31 and covering its load SS 35/10 «Sloboda Pidlisivska» 
Analyzing the dependencies shown on fig. 4.17 it is seen that mode when flows from Tsekynivska SPP (from 11.00 to 17.00) will be directed to supply centerб leads to increase of power losses in LES.

With the aim to check expediency of optimizing power flows by suggested method for correlating generation graphics of renewable energy sources and consumers of local electric systems, calculation of optimal controlling influences according to developed law of optimal control on means for reconfiguration of RES power delivery schemes in local electric systems (3.1).

Results of calculating optimal controlling influences are presented as a graphic of changing the number of inverters that may be switched on to regulated tires system (feeder F-31) during a day (fig. 4.18, a) and nonregulated tires system (feeder F-35) (fig. 4.18, b).



Figure 4.18 - Results of optimization of RES daily generation modes by Tsekynivska SPP and power consumers of SS 35/10

«Sloboda Pidlisivska»:

a) feeder № 31 b) feeder № 35 
By the results of calculating experiment, decrease of power losses in LES for typical modes (up to $10 \%$ ) was registered.

So, the method and algorithms for optimization of RES daily generation modes and power consumers in LES suggested in the paper may be used efficiently to decrease power losses in distributed networks, and in combination with local regulator they provide possibility to automate the process.

\subsection{Estimation of functional stability of subsystem for information exchange in local electric system}

Graph of the suggested subsystem for information exchange of ACS for scheme of RES power delivery in local electric system is presented on fig. 4.19, where on the top on graph are marked: 0 - industrial controller; 1 - system of local management and control; 2 - database server of calculating-dispatch center; 3 - router; 4,5 - reversers; 6,7 - intellectual counters; 8 - controller's WS; 9, 10 - contactors; and graph's edges connection lines between them. The indicated structure meets hardware realization of ACS for scheme of RES power delivery (fig. 3.8).

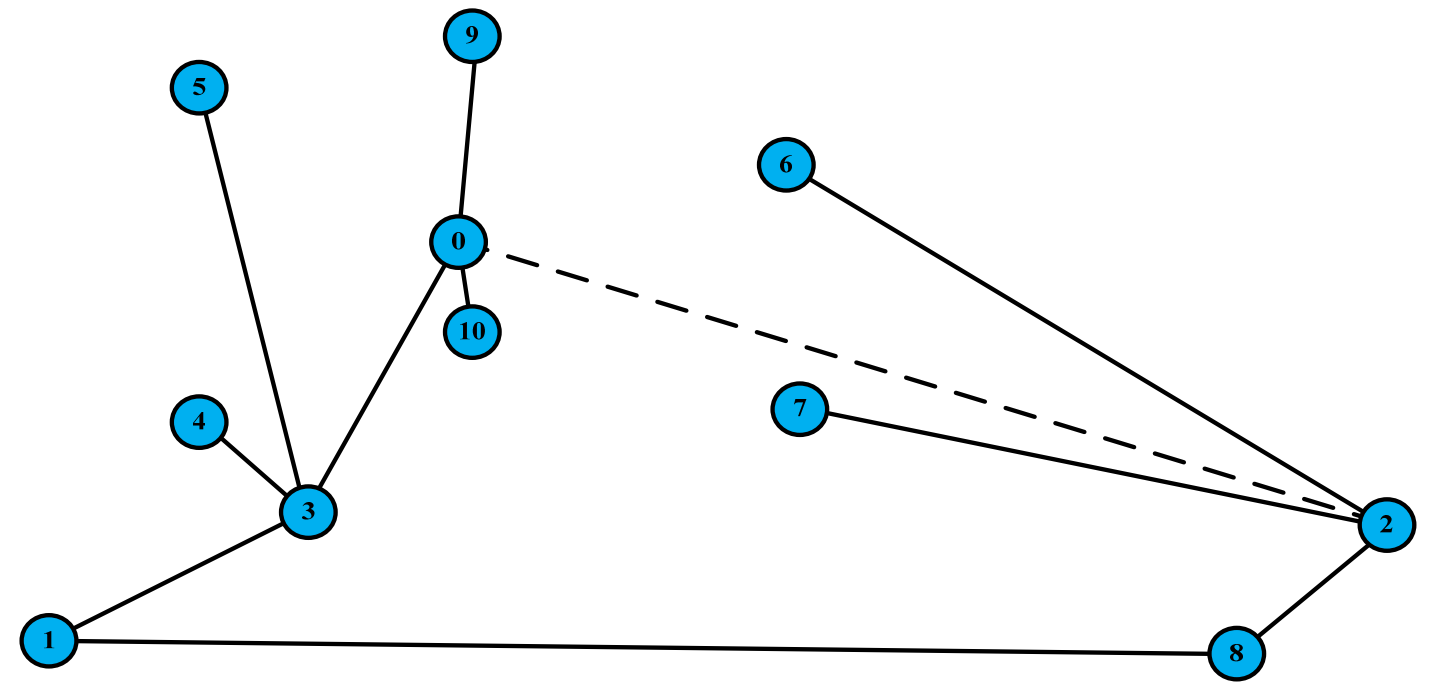

Figure 4.19 - Graph of the suggested subsystem for information exchange in LES

With the aim to research functional stability of subsystem for information exchange of the suggested ACS for RES power delivery scheme, method suggested in 3.4.2 was applied. Results of calculations are presented in attachment B.

The researched graph of ACS has $n=11$ connection lines and $m=11$ nodes. During calculation process supposition according to which the specified intensity of information transfer $\rho_{i j}$ between nodes directly 
connected by connection lines is considered equal to carrying capacity of single information transfer channel. Intensity of information transfer between nodes connected with several connection lines is considered to be equal to the smallest carrying capacity of a single channel on the way between nodes $v_{i}$ and $v_{j}$.

According to the suggestions, such intensity of information transfer over connection lines were adopted:

- lines $0-9$ and $0-10-$ double-wire connection lines $\rho=1 \mathrm{bit} / \mathrm{s}$;

- lines 0-3, 3-4, 3-5, 3-1, 8-2 - wire connection lines Ethernet 100BASE-T $\rho=100 \mathrm{Mbit} / \mathrm{s}$;

- line 1-8 - wireless connection line by networks of general use $3 \mathrm{G} \rho=3,2 \mathrm{Mbit} / \mathrm{s}$;

- lines 7-2, 6-2 - wireless connection lines by networks of general use GPRS $\rho=21,4 \mathrm{kbit} / \mathrm{s}$.

Mathematical expectation of the specified intensity of information transfer $\mathrm{M}[\rho]$ in system of ACS data transfer by scheme of RES power delivery is calculated by expression (3.5):

$$
\mathrm{M}[\rho]=\frac{1}{n(n-1)} \sum_{i=1}^{n} \sum_{j=1, j \neq i}^{n} \rho_{i j}=2,012 * 10^{7} \mathrm{kbit} / \mathrm{s} .
$$

According to calculated value $\mathrm{M}[\rho]$, weight indexes of connection lines (see subparagraph 3.4.2) that depend on indicated intensity of information transfer $\rho_{i j}$ between nodes $v_{i}$ and $v_{j}$.

Probability of connectivity $P_{i j}$ of bipolar graph with node-source $v_{i}$ and node-receiver $v_{j}$ was calculated basing on methods of reliability theory as series-parallel connection of elements where readiness coefficient of information transfer between nodes is $K_{\mathrm{r}}=0,997$ for systems of automated frequency and power regulation [105].

Value of generalized functionality index for subsystem of ACS information exchange by scheme of RES power delivery, calculated basing on matrix of probabilities connectivity with consideration of weight factors $w_{i j}$ defined according to (3.4) makes up:

$$
F_{A C S}=F\left(P_{c o n}\right)=\sum_{i=1}^{n} \sum_{j=1, j \neq i}^{n} w_{i j} \cdot P_{i j}=45,796 \text { r.u. }
$$

With the aim to estimate qualitative value of functional reliability of subsystem for information exchange, comparisons of the obtained result with value of functional stability of subsystem of ACS information exchange for ideal system $F_{A C S}^{p=1}=46$ r.u. with the index of information transfer readiness between nodes $\mathrm{K}_{\mathrm{r}}=1$ was performed: 


$$
F_{A C S}^{*}=F_{A C S} / F_{A C S}^{\mathrm{K}_{\mathrm{r}}=1}=0,9956 \text { r.u. }
$$

Considering the feature of index of functional reliability of connection channels failure and reserving the structure of information transfer, analysis of functional stability of the suggested subsystem of information exchange during the failure of connection lines was performed. Results of calculation are shown in table 4.3.

So, functional stability of the suggested subsystem of ACS information exchange does not meet stability requirements of information transfer between nodes as at such value of information transfer value over system will be smaller than normative value of readiness index 0,997 for systems of automated frequency and power regulation [105].

Table 4.3 - Sensitivity of functional stability index of the suggested subsystem for ACS information exchange of RES to connection lines failure

\begin{tabular}{|l|c|c|c|c|c|c|c|}
\hline \# of line & $0-3$ & $\begin{array}{c}0-10, \\
0-9\end{array}$ & $\begin{array}{c}3-5, \\
3-4\end{array}$ & $3-1$ & $1-8$ & $8-2$ & $\begin{array}{c}2-6, \\
2-7\end{array}$ \\
\hline$F_{A C S}$, r.u. & 29,88 & 45,298 & 33,856 & 29,88 & 41,814 & 39,82 & 44,799 \\
\hline$F_{A C S}^{*}$, r.u. & 0,649 & 0,985 & 0,736 & 0,649 & 0,909 & 0,866 & 0,974 \\
\hline
\end{tabular}

Increasing of functional stability index for subsystem of information exchange is possible in two ways:

1. Increasing of readiness to transfer information between nodes by mean of improving parameters of connection channels;

2. Reservation of connection lines of the suggested subsystem for information exchange in LES to provide excessiveness of information transfer.

With the aim to analyze possibility to provide functional stability of information transfer system by means of improving parameters of connection channels, sensitivity of functional stability of the suggested subsystem of ACS information exchange by scheme of RES power delivery to probability of information transfer between nodes was studied (fig. 4.20).

By the results of calculations it was established that $F_{A C S}^{*}>0,997$ r.u. for range of probability of information transfer $0,998<\mathrm{K}_{\mathrm{r}}<1$ by each single connection line. Cost of technical realization and servicing of such subsystem of information exchange will be much higher than cost of building a reserved scheme of information transfer. 


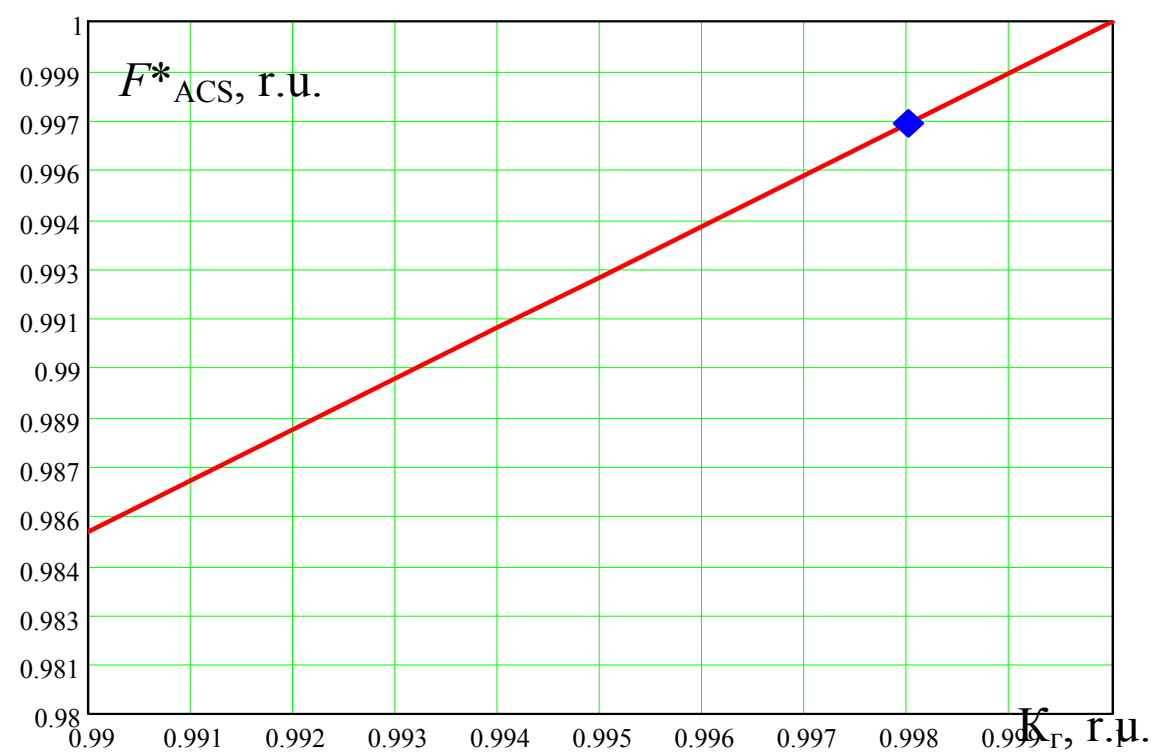

Figure 4.20 - Dependency of relative index of functional stability of the suggested subsystem of ACS information exchange by scheme of RES power delivery to factor of connection channels readiness

With the aim to check possibility of providing functional stability of system for information transfer by means of reserving connection lines, introduction of additional wireless connection line 0-2 was suggested, which connects industrial controller with data base server of calculationdispatch center and is shown on fig. 4.19 as a dashed line.

As the result of appearing parallel connection, value of generalized index of functional stability of ACS scheme for RES power delivery increased to $F_{A C S}=53,404$ r.u., that comparing to faultless system:

$$
F_{A C S}^{*}=F_{A C S} / F_{A C S}^{p=1}=53,404 / 53,5=0,9982 \text { r.u. }
$$

So, functional stability of subsystem of ACS information exchange with reserved connections, meets requirements of information transfer stability, and relative index of functional stability of the suggested subsystem in case of hardest connection line failure gets the value 0,92 r.u.

Peculiarities of hardware realization of ACS for RES delivery scheme with reserved channel are shown on fig. 4.21. The suggested subsystem of information exchange in ACS for RES power delivery scheme will provide stable functioning of RES equipped with means for local control automation that perform commands and realize laws of control from higher hierarchic levels, adapting them to local conditions. 


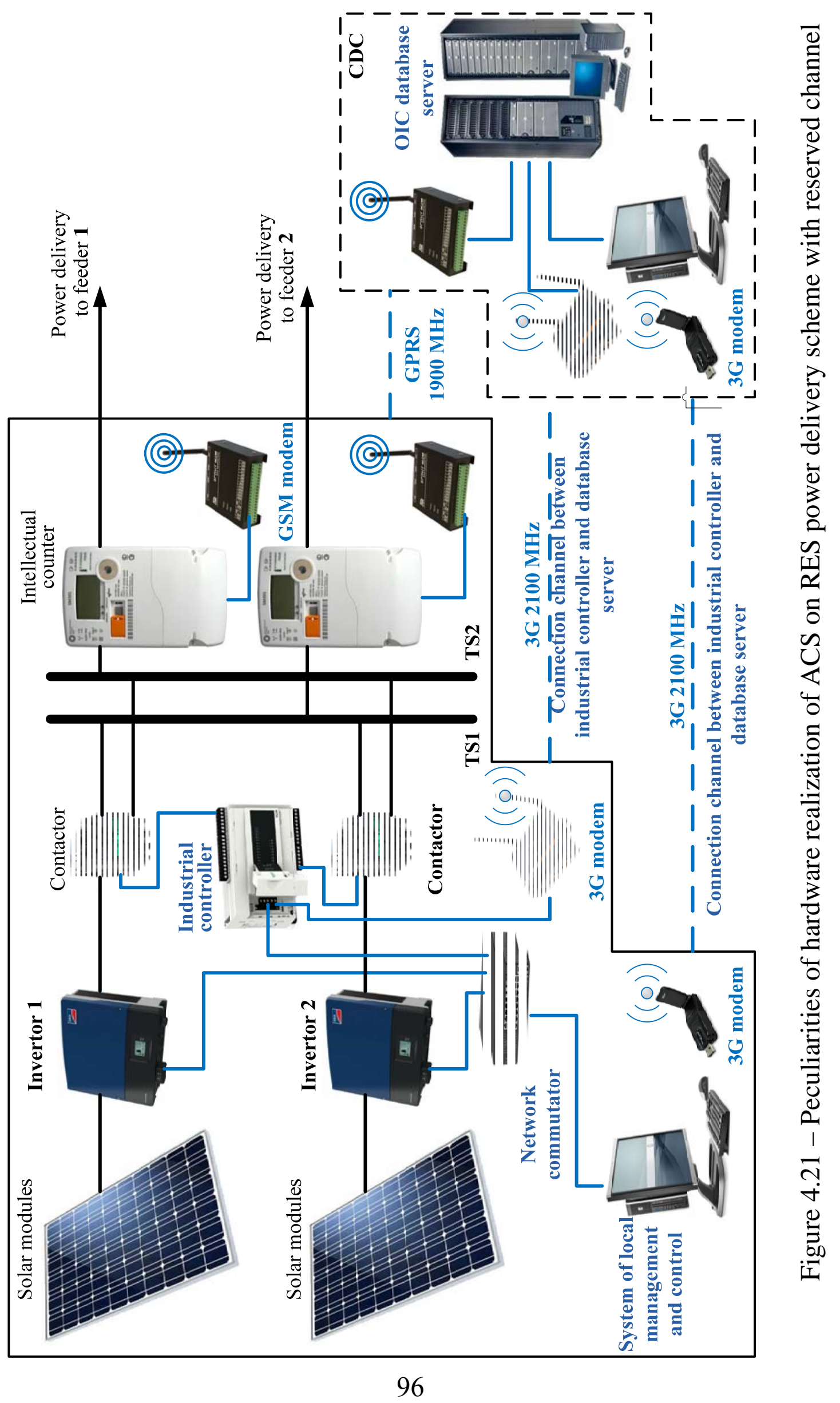




\section{Summary to chapter 4}

Calculation results showed that algorithms suggested in the paper used to define optimal established power of renewable energy sources in local electric system by complex criterion and defining optimal place of their connection may be efficiently used to optimize perspective plan of developing electric network. This is illustrated on example of real distribution electric networks.

Results of calculations of optimizing daily generation modes of renewable energy sources and power consumers in local electric systems on example of Tsekynivska solar power plant confirm working capacity and adequacy of developed models and algorithms. Results of calculations on imitations of introducing determined controlling influences proved sufficient efficiency of optimization measures.

Functional stability of the suggested subsystem for ACS information exchange by scheme of RES power delivery in local electric system is provided by means of reserving connection channels. The suggested subsystem will be functionally stable even at failure of connection channel with the biggest intensity of information transfer. 


\section{CONCLUSION}

New solution for actual problem of optimization of functioning local electric systems with renewable energy sources was obtained in the paper; it consists in selection of optimal schemes of their connection, as well as in automation of optimal control on their work within electric system and allows to reduce losses to transportation of electric power and improve their quality.

1. Capacities of RES complex application for modes optimization of local electric systems are systematized and studied. It was proved that in the quality of optimality criteria of LES modes it is expedient to use complex criterion of maximum revenue from realization of produced electric power by RES, considering their influence to EN work.

2. Application of developed methods for optimization of established power for specified RES connection place in local electric system and method of optimization daily functioning graphics of renewable energy sources allows to solve the problem of defining and supporting optimal power of conditionally-controlled renewable sources depending on the established goal on the stage of design and on the stage of exploitation with consideration of power quality indexes. Inobservance of the last mentioned puts away the obtained solution from the optimal one.

3. Method for defining generalized efficiency index of electric network by criterion of minimum active power losses was developed. It was proved that use of generalized efficiency indexes of electric network functioning allows to get qualitative scheme solutions on RES connection to electric networks. Considering interconnection between single optimality criteria of RES connection to electric networks, developed schemes, except reducing electric power losses, also provide leveling of voltage profile in EN.

4. Using the method of undetermined Lagrangian multipliers, analytical conditions of RES power transfer schemes by criterion of minimum losses were obtained. Basing on them, law and algorithm of operative control on means for connection schemes of renewable energy sources were developed. 
5. Way for coordination generation graphics of renewable energy sources and consumption of local electric systems that expects reconfiguration of power delivery scheme and increases efficiency of exploitation electric networks without worsening profitability of power generation companies was developed.

6. Algorithms for defining optimal established power for specified RES connection place in LES and defining optimal RES connection place with specified power by criterion of minimum losses was developed. The mentioned algorithms may be efficiently used to reduce electric power losses in distributed networks, and in combination with local regulator they provide possibility to automate this process.

7. Working capacity and efficiency of the methods and algorithms suggested in the paper is proved by calculation experiments on optimization and control on modes of renewable source that functions together with SPP. Developed programs were passed to enterprise OJSC «Vinnytsiaoblenergo» that performs exploitation of distributed electric networks with RES. Their introducing allowed to reach losses reduction in separate EN to 5-10 \%, as well as provide normative voltage deviations. 


\section{LITERATURE}

1. R. W. Wies, R. A. Johnson, J. Aspnes. DESIGN OF AN ENERGY EFFICIENT STANDALONE DISTRIBUTED GENERATION SYSTEM EMPLOYING RENEWABLE ENERGY SOURCES AND SMART GRID TECHNOLOGY // Proceedings of IEEE Power \& Energy Society General Meeting. - 2010. - P. 1-8.

2. Kyrylenko O. V., Trach I. V. The technical features of the power systems functioning with integrating sources of distributed generation / O. V. Kyrylenko, I. V. Trach // Pratsi instytutu elektrodynamiky NAN Ukrainy. - 2009. - Issue 24. - P. 3-7. - ISSN 1727-9895.

3. Tuhai Yu. I. Integration of renewable energy sources into distributive electric networks of rural regions / Yu. I. Tuhai, V. V. Kozyrskyi, O. V. Hai, V. M. Bodunov // Tekhnichna elektrodynamika.- 2011.- № 5. - P. 63-67.

4. Stognii B. S. Intellectual electrical networks of power systems and their technological support / B. S. Stognii, O. V. Kyrylenko, S. P. Denysiuk // Tech. electrodynamics.- 2010. - № 6. - P. 44-50.

5. NIST Releases Report on Smart Grid Development // National Institute of Standards and Technology (USA) - Recognized Standards for Inclusion In the Smart Grid Interoperability Standards Framework, Release 1.0 (електронний ресурс). Режим доступу: http://collaborate. nist.gov/twiki-sggrid/bin /view/_SmartGridInterimRoadmap/ Interim RoadmapFinal.

6. European Smart Grids Technology Platform // European Commission. Directorate-General for Research Sustainable Energy System, EUR 22040, 2006. - 44 p.

7. Sharat Ranjan. DECENTRALISED POWER GENERATION AND DISTRIBUTION // Proceedings of the Himalayan Small Hydropower Summit. - Dehradun, India. - 2006. - P. 147-155.

8. Taro Kondo, Jumpei Baba, Akihiko Yokoyama. VOLTAGE CONTROL OF DISTRIBUTION NETWORK WITH A LARGE PENETRATION OF PHOTOVOLTAIC GENERATIONS USING FACTS DEVICES // IEEE Transactions on Power and Energy. - 2006. - Vol. 126. - № 3. - P. 347-358.

9. B. Mahdad, K. Srairi and T. Bouktir. OPTIMAL COORDINATION AND PENETRATION OF DISTRIBUTED GENERATION WITH SHUNT FACTS USING GA/FUZZY RULES // Journal of Electrical Engineering \& Technology. - 2009. - Vol. 4. - № 1. P. 1-12. 
10. H. Hatta, S. Uemura and H. Kobayashi. COOPERATIVE CONTROL OF DISTRIBUTION SYSTEM WITH CUSTOMER EQUIPMENTS TO REDUCE REVERSE POWER FLOW FROM DISTRIBUTED GENERATION // Proceedings of IEEE Power\&Energy Society General Meeting. - 2010. - P. 1-6.

11. Kulyk V. V. Optimal control of distributed power sources with asynchronous generators with Smart Grid technology [Electronic resource] / V. V. Kulyk, T. Ye. Mahas, Yu.V. Malohulko // Naukovi pratsi VNTU. Enerhetyka ta elektrotekhnika. - 2011. - № 4. - P. 1-6. Rezhym dostupu: http://praci.vntu.edu.ua/article/view/1404/999. - ISSN 2307-5376.

12. Burykin O. B. Optimization of the local electrical systems mode with renewable energy sources [Text] / O. B. Burykin, Yu.V. Malohulko // Naukovi pratsi Donetskoho natsionalnoho tekhnichnoho universytetu. Series «Elektrotekhnika ta elektrotekhnolohii». - 2013. - № 2. S. 15 (338). - P. 42-46. - ISSN 2074-2630.

13. Kulyk V. V. Optimization of active and reactive power flows in power distribution systems by distributed generation [Text] / V. V. Kulyk, O. B. Burykin, Yu. V. Malohulko // Visnyk Vinnytskoho politekhnichnoho universytetu. Enerhetyka ta elektrotekhnika. - 2014. - № 1. - P. 90-93. ISSN: 1997-9274.

14. Rubanenko O. E. Improvement of mathematical support computer systems of local electrical systems modes optimization with renewable energy sources [Text] / O. E. Rubanenko, O.B. Burikin, Yu.V. Malogulko // Scientific Bulletin of Chernivtsi University. Series «Computer Systems and Components». - 2014. - No.2 (5). - P. 85-93. ISSN 2311-9276.

15. Lezhniuk P. D. Optimization of the distributed energy sources operation in local electrical systems. [Text] / P. D. Lezhniuk, O. Ie. Rubanenko, Yu.V. Malohulko // Visnyk Natsionalnoho tekhnichnoho universytetu «Kharkivskyi politekhnichnyi instytut». - 2014. - № 60 (1102). - P. 68-77. - ISSN 2079-4525.

16. Kulyk V. V. Exploration of the efficiency of joint operation of local electric networks with RES and centralized power supply systems [Text] / V. V. Kulyk, O. B. Burykin, Yu. V. Malohulko // Visnyk Natsionalnoho tekhnichnoho universytetu Ukrainy «Kyivskyi politekhnichnyi instytut». Seriia «Hirnytstvo». Elektryfikatsiia ta avtomatyzatsiia hirnychykh robit». - 2014. - S. 25. - P. 113-120.

17. Burykin O. B. Standardization of the local power systems functioning at their integration into centralized power supply systems based on the Smart Grid concept [Text] / O. B. Burykin, Yu. V. Tomashevskyi, 
Yu. V. Malohulko // Enerhetyka i elektryfikatsiia. - 2012. - № 12. P. 46-48. - ISSN 0424-9879.

18. Kulyk V. V. Optimal control of renewable electricity with Smart Grid / V. V. Kulyk, O. B. Burykin, Yu. V. Malohulko // Renewable energy of XXI century: XII international scientific and technical conference: conference materials. - AR Crimea: Renewable energy institute of the National academy of sciences in Ukraine, 2011.

19. Burykin O. B. Prospects for the integration of distributed energy sources into the local power grid based on the Smart Grid concept / O. B. Burykin, Yu. V. Malohulko // «Increased energy efficiency in electrical appliances and systems». IV international scientific and technical conference: conference materials. - Lutsk : RVV LNTU, 2012. - P. 37-40.

20. Burykin O. B. A method for reconciling the schedules for the solar power stations generation and energy consumers in local electrical systems / O. B. Burykin, Yu.V. Malohulko, O. V. Nikitorovych // Renewable energy of XXI century: XV international scientific and technical conference: conference materials. - Kyiv: Renewable energy institute of the National academy of sciences in Ukraine, 2014. - P. 52-55.

21. Malohulko Iu.V. Efficiency of joint operation of local electric networks with renewable energy sources / Yu.V. Malohulko // «Increased energy efficiency in electrical appliances and systems». $\mathrm{V}$ international scientific and technical conference: conference materials. - Lutsk: RVV LNTU, 2014. - P. 146-149.

22. European Smart Grid, 2011 [Online]. Available: http://www.smartgrids.eu/.

23. National Institute of Standards and Technology, Standards Identified for Inclusion in the Smart Grid Interoperability Standards Framework, Release 1.0, Sept. 2009, [Online]. Available: http://www.nist.gov/smartgrid/standards.html.

24. M. Uslar, S. Rohjans, R. Bleiker, J. González, M. Specht, T. Suding and T. Weidelt. SURVEY OF SMART GRID STANDARDIZATION STUDIES AND RECOMMENDATIONS // Proceedings of 2010 Innovative Smart Grid Technologies Conf. Europe (ISGT Europe), Gothenburg, Oct. 2010.

25. Electric Power Research Institute Tech. Rep. - THE SMART GRID INTEROPERABILITY STANDARDS ROADMAP. - Aug. 2009, [Online]. Available:ht tp://collaborate.nist.gov/twikisggrid/pub/Smart GridInterimRoadmap/InterimRoadmapFinal/Report_to_NISTl August10.pdf 26. Reed, G.F., Philip, P.A., Barchowsky, A., Lippert, C. J., Sparancino, A. - SAMPLE SURVEY OF SMART GRID APPROACHES 
AND TECHNOLOGY GAP ANALYSIS // Proceedings of 2010 Innovative Smart Grid Technologies Conf. Europe (ISGT Europe), pp. 1-8, Gothenburg, Oct. 2010.

27. IEC standard for Communication networks and systems for power utility automation - Part 90-1: Use of IEC 61850 for the communication between substations, IEC 61850-90-1, 1st ed., 2010.

28. IEC Standard for Instrument Transformers - Part 9: Digital Interface for Instrument Transformers, IEC 61869-9, Part 13: Standalone Merging Unit, IEC 61869-9. - 2012.

29. P. Schaub, J. Haywood, D. Ingram, A. Kenwrick, and G. Dusha, «Test and evaluation of non-conventional instrument transformers and sampled value process bus on Powerlink's transmission network», in Proceedings of 2011 South East Asia Protection and Control Conference (SEAPAC 2011), CIGRE, Doltone House, Sydney, NSW, 2011.

30. IEC standard for Industrial communication networks - High availability automation networks - Part 3: Parallel Redundancy Protocol (PRP) and High-availability Seamless Redundancy (HSR), IEC 62439-3 Ed.1.0, Feb. - 2010.

31. K. Martin, «Synchrophasor Standards Development - IEEE C37.118 \& IEC 61850», in Proceedings of the 44th Hawaii International Conference on System Sciences, Hawaii. - 2011.

32. IEEE Approved Draft Standard Profile for Use of IEEE Std. 1588 Precision Time Protocol in Power System Applications, IEEE C37.238, under construction. -2011

33. IEEE standard for Interconnecting Distributed Resources with Electric Power Systems, IEEE 1547. - 2003.

34. NERC Decree of 14.12.2005 № 1137 / Rules for connecting electrical installations to electrical networks // (electronic resource). Access mode: http://zakon5.rada.gov.ua/laws/show/z0042-06.

35. Technische Richtlinie Erzeugungsanlagenam Mittelspannungsnetz. Richtliniefur Anschlussund Parallelbetriebvon Erzeugungsanlagenam Mittelspannungsnetz. Ausgabe Juni 2008. BDEW.

36. Requirements for wind and solar photovoltaic power plants of $150 \mathrm{~kW}$ capacity for connection to external electrical networks. October 2011. Mercados, EMI.

37. State normative document 13109-97. Standards of quality of electric energy in general power supply systems.

38. P. Lezhniuk Optimal control of distributed sources of energy in the local electrical system / P. Lezhniuk, V. Kulyk, O. Kovalchuk // Proceedings of the Institute of Electrodynamics of NAS of Ukraine. 
Collected works. Special Issue. Part 1. - 2011.- P. 48-55. ISSN 1727-9895.

39. Walid El-Khattam, Kankar Bhattacharya, Yasser Hegazy and M. M. A. Salama, «Optimal Investment Planning for Distributed Generation in a Competitive Electricity Market», IEEE Transactions on Power Systems, vol. 19, no. 3, pp. 1674-1684, August 2004. Analytical Approaches for Optimal Placement of Distributed Generation Sources in Power Systems.

40. Andrew Keane, Mark O’Malley «Optimal Allocation of Embedded Generation on Distribution Networks», IEEE Transactions on Power Systems, vol. 20, no. 3, pp. 1640-1646, August 2005.

41. N. S. Rau and Y.-H. Wan, Optimum location of resources in distributed planning, IEEE Transactions on Power Systems, vol. 9, pp. 2014-2020, Nov. 1994.

42. Caisheng Wang, M. Hashem Nehrir «An Analytical Method for DG Placements Considering Reliability Improvements», IEEE Transactions on Power Systems, vol. 19, no. 4, pp. 2068-2076, November 2004.

43. Hamid Falaghi, Mahmood-Reza Haghifam «ACO Based Algorithm for Distributed Generation Sources Allocation and Sizing in Distribution Systems», PowerThech, pp. 555-560, 2007.

44. Víctor H. Méndez Quezada, Juan Rivier Abbad,and Tomás Gómez San Román «Assessment of Energy Distribution Losses for Increasing Penetration of Distributed Generation», IEEE Transactions on power systems, vol. 21, no. 2, pp.533-540, May 2006.

45. Seyed Mohammad Hossein Nabavi, Somayeh Hajforoosh, Mohammad A. S. Masoum, «Placement and Sizing of Distributed Generation Units for Congestion Management and Improvement of Voltage Profile using Particle Swarm Optimization», IEEE, 2011.

46. Andrew Keane, Luis (Nando) F. Ochoa, Eknath Vittal, Chris J. Dent, Gareth P. Harrison «Enhanced Utilization of Voltage Control Resources With Distributed Generation» IEEE Transactions on Power Systems, vol. 26, no. 1, pp. 252-260, February 2011.

47. Nikhil K. Ardeshna, Badrul H. Chowdhury, «Supporting Islanded Microgrid Operations in the Presence of Intermittent Wind Generation», IEEE, pp. 1-8, 2010.

48. C. L. T. Borges, and D. M. Falcao, Optimal distributed generation allocation for reliability, losses, and voltage improvement, International Journal of Power and Energy Systems, vol. 28, no. 6, pp. 413-420, July 2006. 
49. Y. Alinejad-Beromi, M. Sedighizadeh, M. Sadighi «A Particle Swarm Optimization for Sitting and Sizing of Distributed Generation in Distribution Network to Improve Voltage Profile and Reduce THD and Losses».

50. Lezhniuk P. D. Optimization of the distributive electric networks mode with distributed energy sources/ P. D. Lezhniuk, O. A. Kovalchuk, V. V. Kulyk // Naukovi pratsi Donetskoho natsionalnoho tekhnichnoho universytetu. Seriia «Elektrotekhnika i enerhetyka». - 2011. - S. 11 (186). - P. 250-254. $\neg$ ISSN 2074-2630.

51. Kozyrskyi V. V. Integration of renewable energy sources into distributive electric networks in rural regions / V. V. Kozyrskyi, Yu. I. Tuhai, V. M. Bodunov, O. V. Hai // Tekhnichna elektrodynamika. 2011. - № 5. - P. 63-67. - ISSN 0204-3599.

52. Nikitorovych O. V. Automation of small hydroelectric power stations and increase of their operation efficiency / Lezhniuk P.D., Nikitorovych O. V., Kulyk V. V.: mater. VIII Inter. conf. [Renewable energy of XXI century], (Crimea, 17-21 September 2007). - Crimea.: NAN Ukrainy, Renewable energy institute of the National academy of sciences in Ukraine, 2007. - P. 202-205.

53. Lezhniuk P. D. Optimal control of scattered energy sources in the local electrical system / P. D. Lezhniuk, V. V. Kulyk, O. A. Kovalchuk // Pratsi Instytutu elektrodynamiky NAN Ukrainy. Zbirnyk naukovykh prats. Spetsialnyi vypusk. Ch. 1. - 2011.- P. 48-55. - ISSN 1727-9895.

54. J.Z.Zhu Optimal reconfiguration of electrical distribution network / J. Z. Zhu / Optimization of power system operation // Institute of Electrical and Electronics Engineers. - 2009. - pp. 503-545.

55. Merlin and H. Back, «Search for minimum - Loss Operating Spanning Tree Configuration in an Urban Power Distribution System», Proc. 5th Power System Computation Conference, Cambridge, 1975 Paper 1.2/6

56. D. Shirmohammadi and H. W. Hong, «Reconfiguration of Electric Distribution Networks for Resistive Line Losses Reduction», IEEE Trans. PWRD, Vol. 4, No. 2, 1989, pp. 1492 - 1498.

57. C. H. Castro, J. B. Bunchand, and T. M. Topka, «Generalized Algorithms for distribution feeder deployment and sectionalizing», IEEE Transaction on Power Apparatus and Systems, Vol. 99. No. 2. March/April 1980, pp. 549-557.

58. C. H. Castro and A.L. M. Franca, «Automatic power distribution reconfiguration algorithm including operating constraints». IFAC 
Symposium on Planning and Operation of Electric Energy Systems, Rio de Janeiro 1985, pp. 181-86.

59. M. E. Baran and F. Wu, «Network Reconfiguration in distribution systems for loss reduction and load balancing». IEEE Transactions on Power Delivery, Vol. 4, No. 2, April 1989, pp. 1401-1407.

60. C. C. Liu, S. J. Lee, and S. S. Venkata, «An expert system operational aid for restoration and loss reduction of distribution systems», IEEE Transaction on Power Systems, Vol. 3, No. 2, May 1988, pp. 619-626.

61. Z.Zhu, X. F. Xiong, D. Hwang, and A. Sadjadpour, «A comprehensive method for reconfiguration of electrical distribution network», IEEE/PES 2007 General Meeting, Tampa, USA, June 24-28, 2007.

62. J. Z. Zhu, Application of Network Flow Techniques to Power Systems. First Edition, WA : Tianya Press, Technology, Dec. 2005.

63. D. Shirmohammadi and H. W. Hong, «Reconfiguration of Electric Distribution Networks for Resistive Line Losses Reduction», IEEE Trans. PWRD, Vol. 4, No. 2, 1989, pp. 1492-1498.

64. S. K. Goswami, «A New Algorithm for the Reconfiguration of Distribution Feeders for Loss Minimization», IEEE Trans. on Power Delivery, Vol. 17, No. 3, July, 1992, pp. 1484-149.

65. D. Shirmohammadi and H. W. Hong, «Reconfiguration of Electric Distribution Networks for Resistive Line Losses Reduction», IEEE Trans. PWRD, Vol. 4, No. 2, 198» A New Algorithm for the Reconfiguration of Distribution Feeders for Loss Minimization», IEEE Trans. on Power Delivery, Vol. 17, No. 3, July, 1992, pp. 1484-149.

66. Mohammadi, M. T. Arab Yar, Faramarzi, M. «PSO algorithm for sitting and sizing of distributed generation to improve voltage profile and decreasing power losses». - Electrical Power Distribution Networks (EPDC), 2012 p.p. 1-6.

67. Sharat Ranjan. DECENTRALISED POWER GENERATION AND DISTRIBUTION // Proceedings of the Himalayan Small Hydropower Summit. - Dehradun, India. - 2006. - P. 147-155.

68. Hordeiev, V. I. Adjustment of the maximum load of industrial electrical networks [Tekst] / V. I. Hordeiev. - Moskva : Enerhoatomyzdat, 1986. $-182 \mathrm{p}$.

69. Orlov, I. N. Electrotechnical reference book: in 3 p. P. 3 in 2 books. B. 1. Production and distribution of electric energy [Text] / I. N. Orlov. - M. : Enerhoatomyzdat, 1988. -880 p. 
70. Kulyk V. V. Identification of the coefficient of the form of the group load graph for determination of power losses in distribution networks [Text] / V. V. Kulyk, D. S. Pyskliarov // Visnyk Pryazovskoho derzhavnoho tekhnichnoho universytetu. - 2008. - S. № 18. - P. 92-95.

71. Hrytsiuk, I. V. Compensation of reactive power in a local electrical system [Tekst] / P. D. Lezhniuk, V. V. Kulyk, I. V. Hrytsiuk // Visnyk Kharkivskoho natsionalnoho tekhnichnoho universytetu silskoho hospodarstva im. Petra Vasylenka. - 2011. - № 3. - P. 32-33.

72. Rotshtein, A. P. Intelligent technologies: fuzzy sets, genetic algorithms, neural systems [Text] / A. P. Rotshtein. - Vynnytsa : UniversumVinnytsia, 1999. - $320 \mathrm{p}$.

73. Rotshtein, A. P. Fuzzy reliability of algorithmic processes [Text] / A. P. Rotshtein, S. D. Shtovba. - Vynnytsa : Kontynent-PRYM. - 1997. $141 \mathrm{p}$.

74. Besekerskyi V. A. Automatic control systems with microcomputer / V. A. Besekerskyi, V. V. Izrantsev. - M. : Nauka, 1987. - 320 p.

75. Lezhniuk P. D. An estimation of interplay of electric networks of power systems with transformer connections / P. D. Lezhniuk, V. V. Kulyk, O. B. Burykin // Tekhnichna elektrodynamika: tematychnyi vypusk: problemy suchasnoi elektrotekhniky, ch. 7. -2006. - P. 27-30.

76. Order of the Ministry of energy and coal Industry of Ukraine of 21.06.2013 N 399 / About Methodical recommendations for determination of technological losses of electric energy in transformers and transmission lines // (electronic resource). Access mode: http://www.leonorm.com/p/NL_DOC/UA/201301/Nak399.htm.

77. Hnatiienko H. M. Expert decision making technologies: monograph / H. M. Hnatiienko, V. Ye. Snytiuk. - K. - 2008. - 444 s.

78. Belov V. V. and oth. Graph Theory: A Textbook for universities. - M. : „Vysshaia shkola». - 1976. - 392 p.

79. Demydenko E. Z. Linear and nonlinear regressions. - M. : Finance and statistics. -1981.

80. Ferster Э., Rents B. Methods of correlation and regression analysis. - M. : Finance and statistics. -1983.

81. Litnarovych R. M. Construction and research of a mathematical model by sources of experimental data by regression analysis methods [Text] / Litnarovych R. M. // Navchalnyi posibnyk. - Rivne. - 2011. - 70 p.

82. State normative document from 31.07.1996. - N 28. / On approval of the rules for the use of electric energy // (electronic resource). Access mode: http://zakon0.rada.gov.ua/laws/show/z0417-96. 
83. State normative document dated September 28. 2000. - No 1038. / Procedure for determining the payment for the transportation of electricity of own production at the electricity supply at unregulated tariffs // (electronic resource). Access mode: http://www.uazakon.com. documents/dates_61/pg_gegwxw.htm.

84. Lezhniuk P. D. Optimization of modes of electric networks with small HPPs in the conditions of targeted power supply / P. D. Lezhniuk, V. V. Kulyk, O. B. Burykin, O. A. Kovalchuk // Tekhnichna elektrodynamika. Tematychnyi vypusk: Problemy suchasnoi elektrotekhniky. Ch. 3. - 2010. - P. 31-34. - ISSN 0204-3599.

85. Stohnii B. Determination of transit power losses in fragmented electrical networks of regional power supply companies / Stohnii B., Pavlovskyi V. // Energy policy of Ukraine. - 2004. - № 5. - P. 26-31.

86. Lezhniuk P. D. Mutual influence of electric networks and systems in the process of optimal control of their modes / P. D. Lezhniuk, V. V. Kulyk, O. B. Burykin: Monohrafiia. - Vinnytsia : UNIVERSUMVinnytsia, 2008. - 123 p.

87. Lezhniuk P. D. Analysis of the sensitivity of optimal solutions in complex systems by the criterion method: monogr. / Lezhniuk P. D. Vinnytsia : UNIVERSUM-Vinnytsia, 2003. - $131 \mathrm{~s}$.

88. Analysis of heterogeneities in electric power systems / [O. N. Voitov, N. Y. Voropai, A. Z. Hamm and oht.]. - Novosybyrsk: Nauka, 1999. $-250 \mathrm{p}$.

89. Lezhniuk P. D. Estimation of sensitivity of power losses in electric networks: monograph / P. D. Lezhniuk, V. A. Lesko. - Vinnitsa, VNTU, 2010. - $120 \mathrm{p}$.

90. Rozenvasser E. N. Sensitivity of control systems E. N. Rozenvasser, R. M. Yusupov. - M. : Nauka, 1981. - 464 p.

91. Donchev A. Optimal control systems: Perturbation perturbations and sensitivity analysis / Donchev A. - M. : Myr, 1987. - 156 p.

92. Designing of power supply systems of agroindustrial complex. Book 1. The modern concept: the manual. Kudriakov Aleksandr Heorhievich, Sazykin Vasilii Heorhievich. - Scientific magazine «Kontsep, 3 okt. 2014. -248 p.

93. Voevodin V. V. Matrytsy y vychyslenyya / V. V. Voevodin, Yu. A. Kuznetsov.- M. : Nauka, 1984.- 320 p.

94. Mokin B. I. Automatic regulators in electrical networks / B. I. Mokin, Yu. F. Vyhovskyi. - K. : Tekhnyka, 1985. - 104 p.

95. Rozenvasser E. N., Yusupov R. M. Sensitivity of control systems. - M. : Nauka, 1981. -464 p. 
96. Lezhniuk P. D., Kravtsov K. I., Vydmysh V. A. Analysis of sensitivity of mathematical models and distribution of tolerances on parameters by criterial method // Problems of creation of new machines and technologies.. (Nauchnye trudy Kremenchuhskoho hosudarstvennoho polytekhnycheskoho instituta). - 2000. - № 1(8) - P. 304-307.

97. Lezhniuk P. D., Ostraia N. V. The solution of the inverse problem of sensitivity and the distribution of tolerances on parameters by the criterial method // Visnyk Cherkaskoho derzhavnoho tekhnolohichnoho universytetu. - 2005. - № 3. - P. 34-36.

98. Methods for optimizing the modes of power systems / V. M. Hornshtein, B. P. Myroshnychenko, A. V. Ponomarev and oth. - M. : Enerhoizdat, 1981. - 336 p.

99. Tykhonov A. N., Arsenin V. Ya. Methods for solving ill-posed problems. - M. : Nauka, 1986. $-288 \mathrm{~s}$.

100. Lezhniuk P. D., Obolonskyi D. I., Al-Omari Zakariia, Kravtsov K. I. Aproximacies implicitly virazhenih criterias optimality of electricity systems by positom // Visnyk Vinnytskoho politekhn. in-tu. - 1994. - № 4. - P. 35-37.

101. Petro Lezhniuk, Eugene Didichenko, Konstantin Kravtsov. Optimal control of power flows in electric power systems using theory of similarity // Proceedings of the $5^{\text {th }}$ International Conference on «Development and application systems» (DAS - 2000). - Suceava, Romania: «MUSATINII», 2000. - P. 10-15.

102. Vorotnytskyi V. Ye., Lezhniuk P. D., Serova I. A. Methodology and program for assessing the effectiveness of the on-load tap-changer and ARPN in closed electrical networks // Electrical stations. - 1992. - № 1. P. 60-66.

103. Astakhov Yu.N., Lezhniuk P. D. Application of the criterial method in the electric power industry. - Kyiv: UMK VO. - 1989. - 137 p. J. Conejo, J. M. Arroyo, N. Alguacil, and A. L. Guijarro, «Transmission loss allocation: a comparison of different practical algorithms», Power Systems, IEEE Trans. Power Syst., vol. 17, P. 571-576, Aug. 2002.

104. S. M. Nedilko A system of indicators and criteria for formalizing the processes of ensuring the functional stability of air traffic control systems. Information technology management. - P. 102-105

105. State normative document 34.48.151-003 (Electronic resource). Access mode: http://eom.com.ua/index.php?action=downloads;sa=view; down $=2298$. 


\section{APPENDIX A}

\section{Analysis of the tasks of distributive electric networks of optimization}

\section{A.1 Distributed generation optimization model to reduce investment value of RES and reduce power losses}

The total value of RES is not only for investments in RES and construction costs, but also from the rest of the investment volume with deferred construction costs on the network. Accordingly, as a result, the objective function of the investment value of RES is as follows:

$$
\min F_{\text {invest }}=\min \sum_{j=1}^{N_{R E S}}(1-\beta) \cdot C_{j} \cdot P_{j R E S},
$$

where $N_{\text {RES }}$ - total number of nodes in which the RES can be set; $\beta-$ deferred investment factor for construction of RES; $C_{j}$ - the cost of the equipment and the cost of its installation in the $\mathrm{j}$ node, uah/KkW; $\mathrm{P}_{\mathrm{jRES}}-$ RES nominal power installed in the $\mathrm{j}$ node.

According to standard 1547-2003, which regulates the connection to the parallel work of RES and sets criteria and requirements for their connection to EPS, such sources are no longer forbidden to work in an excessive autonomous manner. Electricity supplier and consumers recommend switch-off LES from a network using technologies in line with energy efficiency goals.

When an emergency occurs in the power system, the critical load associated with the RES node can be sustained and therefore losses caused by a significant lack of load can be reduced to a certain value:

$$
\min F_{\text {island }}=\min \sum_{j=1}^{N_{R E S}} \lambda \cdot C_{i} \cdot\left(P_{\text {load }_{i}}-P_{R E S_{i}}\right),
$$

where $\lambda$ - coefficient taking into account the consumer category; $C_{i}-$ loss on disconnection of electric energy per unit time of electricity; $\mathrm{P}_{\text {loadi }}-$ full load capacity in the node $\mathrm{i}$; $\mathrm{P}_{\mathrm{RESi}-}$ the nominal power of the RES set in the i-th node.

When connecting RES to PN the direction of flow distribution in the individual list is changed. Accordingly, losses in the distribution network also change, which leads to a decrease in flow distribution in the branches in general. However, if the power input of the RES is too large, the change 
in flow distribution will lead to an increase in power losses in the PN. Therefore, the net loss amount is closely related to the size and location of the RES.

$$
\min F_{\text {loss }}=\min C_{2} \sum_{i=1}^{N_{\text {line }}} P_{\text {loss }_{i}},
$$

where $\mathrm{N}_{\text {line }}-$ total number of distribution lines of the line; $\mathrm{P}_{\text {loss } \mathrm{i}}-$ network losses in the $\mathrm{i}$ branch; $\mathrm{C}_{2}-$ the cost of losses «uah $/ \mathrm{kW} »$.

The integrated target function:

$$
\min F=\min \left(F_{\text {inv }}+F_{\text {island }}+F_{\text {loss }}\right) .
$$

The multipurpose optimization function can be transformed into a single optimization problem in order to obtain the minimum objective value of this equation. Limits of the complex target function can be, what form of equality, and in the form of inequalities. Conditions for constraints in the form of equality are presented in the form of line band equations. The equations for restrictions in the form of inequalities include:

1) Limit the bandwidth of the line:

$$
\left|S_{l}\right| \leq S_{l_{\max }}
$$

where $\mathrm{S}_{1}-$ this is a component of the power flow vector in the line $l ; \mathrm{S}_{\operatorname{lmax}}$ - maximum power flow limitation in the line $l$.

2) Limit of voltage on the buses RES:

$$
\mathrm{U}_{\text {mini }} \prec \mathrm{U}_{\mathrm{i}} \prec \mathrm{U}_{\text {maxi }}
$$

where $U_{\operatorname{maxi}}$ and $U_{\text {mini }}$ means respectively, the upper and lower limits in each node when integrating RES.

3) Total power of RES, connected to PN:

$$
\sum_{i=1}^{N_{R E S}} P_{R E S_{i}} \leq \delta P_{\text {load }}
$$

where $\mathrm{P}_{\text {RES } i}$ - rated power installed in the i node; $\mathrm{P}_{\text {loadi }}-$ load capacity; $\delta$ upper limit of proportion of total power of RES.

The output power of RES depends on such uncertain factors as wind speed, solar radiation and in some other degree. If the RES takes a large percentage of electricity in the distribution network, the quality of the power supply will deteriorate accordingly. Therefore, the task arises to manage the overall integrated capacity of RES. 
A2 Determination of the optimal place connection and installed capacity in distribution networks, taking into account the electricity quality

Improvement of the quality of electricity will be recorded in the form of a target function, taking into account the reduction of electricity losses, the improvement of the voltage profile, the reduction of the total harmonic distortion and the reduction of costs. The main objective of the proposed approach is to identify the best places to connect and the number of new RES by minimizing different functions.

The general target function with constrained restrictions is defined as follows:

$$
F_{\text {total }}=k_{1} \cdot f_{U}+k_{2} \cdot f_{C}
$$

where $k_{1}$ and $k_{2}-$ weight coefficients, $f_{v}$ defined as:

$$
\begin{gathered}
\min f_{U}=\sum_{i=1}^{n}\left|U_{i}-U_{i, \text { withoutRES }}\right|+\sum_{j=1}^{m} k_{1_{i}} \cdot \max \left(0,\left(T H D_{i}-T H D_{\max }\right)\right)+ \\
+\sum_{j=1}^{m} k_{j} \cdot \max \left(0,\left(P_{j}^{\text {withRES }}-P_{j}^{\text {withoutRES }}\right)\right)+\sum_{i=1}^{n} k_{2_{i}}\left[\max \left(0,\left(U_{i}^{\min }-U_{i}\right)\right)+\max \left(0, U_{i}-U_{i}^{\max }\right)\right],
\end{gathered}
$$

where $U_{i}$, ${ }^{\text {without RES }}$ - voltage on the i bus without RES; $U_{i}$ - voltage on the i bus with RES; $P_{j}^{\text {6without RES }}$ - loss of active power in $\mathrm{j}$ branch without RES; $P_{j}^{\text {withRES - }}$ loss of active power in $\mathrm{j}$ branch with RES; $T H D_{i}$ - total harmonic distortion in the $\mathrm{i}$ bus with REE; $T H D_{\max }$ - allowable total harmonic distortion in the i bus; $U_{i}^{\max }, U^{\text {min }}{ }_{i}-$ maximum and minimum allowable voltage in the $\mathrm{i}$ bus, respectively; $k_{i}, k_{j}$ - influential or penal factors; $n$ - the number of buses; $m$ - the numbers of branches.

$$
\min f_{C}=\sum_{i=1}^{n D G}\left[\left(k_{1} \cdot C_{P_{i}}+k_{2} \cdot C_{Q_{i}}\right)+k 3 \cdot C_{l_{i}}\right],
$$

where $C_{l i}$-purchase and cost of installment of i RES; $C_{P i}, C_{Q i}$ - the cost of active and reactive electricity for the i RES, respectively; $k_{1}, k_{2}, k_{3}$-weight coefficients; $P_{i}, Q_{i}$ - active and reactive power generated by i RES. 


\section{A3 Determination of the optimum place of RES installation in order to increase the LES reliability}

In order to increase the reliability and obtain advantages for the location of RES, an analytical method is used to take into account the location of RES and reliability increase. This method solves the problem of optimal placement of RES in terms of maximizing the usefulness of these sources. At the same time, it also establishes a method for assessing the reliability of distributed networks with RES, and uses linear interpolation to disable the consumer. The results of the tests showed that with the correct choice of the place of installation of RES, their use improves reliability, reduces the cost of consumer power interruptions and retains power losses, while at the same time, electric power companies can get maximum economic benefits.

Increased reliability, considered as the cost of electricity to the consumer, may be the cost of lack of electricity (CLE) or the peak of reducing the cost of the load. The target function based on the RES issue is the following:

$$
\begin{gathered}
\text { MaxF }=\text { Benefit }^{\text {RES }}=\frac{(1+\rho)^{N}}{(1+\rho)^{N}+1} \times \\
\times\left[K_{R E S} \cdot T_{\max } \cdot\left(\Delta P_{\text {loss }}^{R E S}+W_{R E S}\right)+\left(b^{0}-b^{R E S}\right)\right] \\
U^{\max } \leq U_{i} \leq U^{\max } ; \\
Q^{\max } \leq Q_{i} \leq Q^{\max },
\end{gathered}
$$

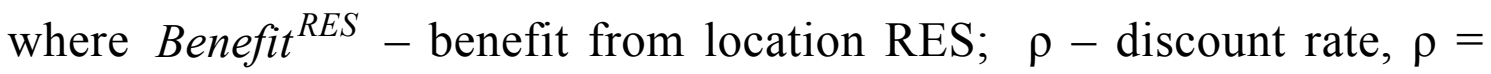
0,$9 ; \mathrm{N}$ - expected time investment, $\mathrm{N}=20 ; \mathrm{K}_{\mathrm{RES}}$ - profit from RES, (uah/kWh); $\mathrm{T}_{\text {мах }}$ - maximum usage time, (hours); $\Delta P_{\text {loss }}^{R E S}$ - the average loss of power annually by location of RES; $W_{R E S}$ - average RES generation per year; $b^{0}, b^{R E S}$ - the cost of underspending power energy without RES and RES. 


\section{A.4 Determining the RES optimal placement which considers of limit bandwidth constraints}

In the proposed target function for the placement and size of the RES, the following items are taken into account:

- $\quad$ investment value of RES;

- $\quad$ cost of operation and maintenance of RES;

- $\quad$ the cost of electricity losses.

Target function:

$$
\begin{gathered}
\operatorname{MinZ}=\sum_{y=1}^{n c d} C_{D S_{i}} \cdot K_{i D S}+\sum_{y=1}^{n y y} \sum_{i=1}^{n c d} \sum_{l=1}^{n l d} P W^{y} \cdot C_{i, l} \cdot K_{E D S} \cdot T_{l}+ \\
+\sum_{y=1}^{n y r} \sum_{j=1}^{n s s} \sum_{l=1}^{n l d} P W^{y} \cdot P_{S S_{j, l}} \cdot K_{S S_{l}} \cdot T_{l} \\
C_{D S_{i}}=\max _{l=1,2, \ldots, n l d}\left\{C_{i, l}\right\} \\
P W=\frac{1+\operatorname{InfR} R}{1+\operatorname{IntR}}
\end{gathered}
$$

where $\mathrm{Z}$ - value of the target function (uah); ncd - number of possible RES placements in the network; nld - number of load levels for the year; nss value $\mathrm{HV} / \mathrm{LV}$ of substations in the system; nyr - planned period (year); $\mathrm{C}_{\mathrm{DGi}}$ - the selected RES power for installation in the i node (MVA); $\mathrm{K}_{\mathrm{IDG}}-$ RES investment value (uah/ MVA); $K_{E D G}$ - the cost of RES functioning, including losses for its maintenance (uah/ MVA); $K_{S S l}$ - market price of power energy at load level 1 (uah/ MVA); $P_{S S j, l}$ - the power sent from substation $\mathrm{j}$ to the load level 1 , including network losses (MW); $C_{i, 1}-$ the power generated by the RES, which is installed in the $\mathrm{i}$ node and at the load level 1 (МВт); $P W$ - current value; Int $R$ - interest rate; Inf $R$ - inflation rate.

The objective function (1) is minimized, if such restrictions will be implemented:

- power section feeders. 
The power transmitted by each section of the feeder during the year should be equal to or less than the conductivity of its conductor.

$$
I_{i, l} \quad I_{i, \max }
$$

where $I_{i, l}$ and $I_{i, \max }$ - flow distribution and temperature limits of the i section.

A modified (forward / backward) distributed flow distribution algorithm is used to evaluate the behavior of the system. Once the nodal voltage has been calculated, the following expression is used to evaluate the relevant limitation:

$$
U_{\min } \leq U_{i, l} \leq U_{\max }
$$

where $\underline{U}_{i, 1}-$ the value of the voltage at the i node is calculated during the load level 1; $U_{\min }$ and $U_{\max }$ - minimum and maximum allowable working voltage.

- $\quad$ limit the total capacity of RES.

This restriction limits the total capacity of RES that is installed in the distribution system (due to any practical / financial constraints). Therefore:

$$
\sum_{i=1}^{n c d} C_{D G_{i}} \leq C_{D G_{\max }}
$$

where $C_{D G \mathrm{i}}$ - the selected RES power for installation in the i node. $C_{D G i-}$ this is the total allowable RES power, which can be connected to the system. 


\section{APPENDIX B \\ Results of calculations from the research of influence Sloboda- Buhanska SPP to the PN modes 10 kV F-45 substation «Mikhailivka»}

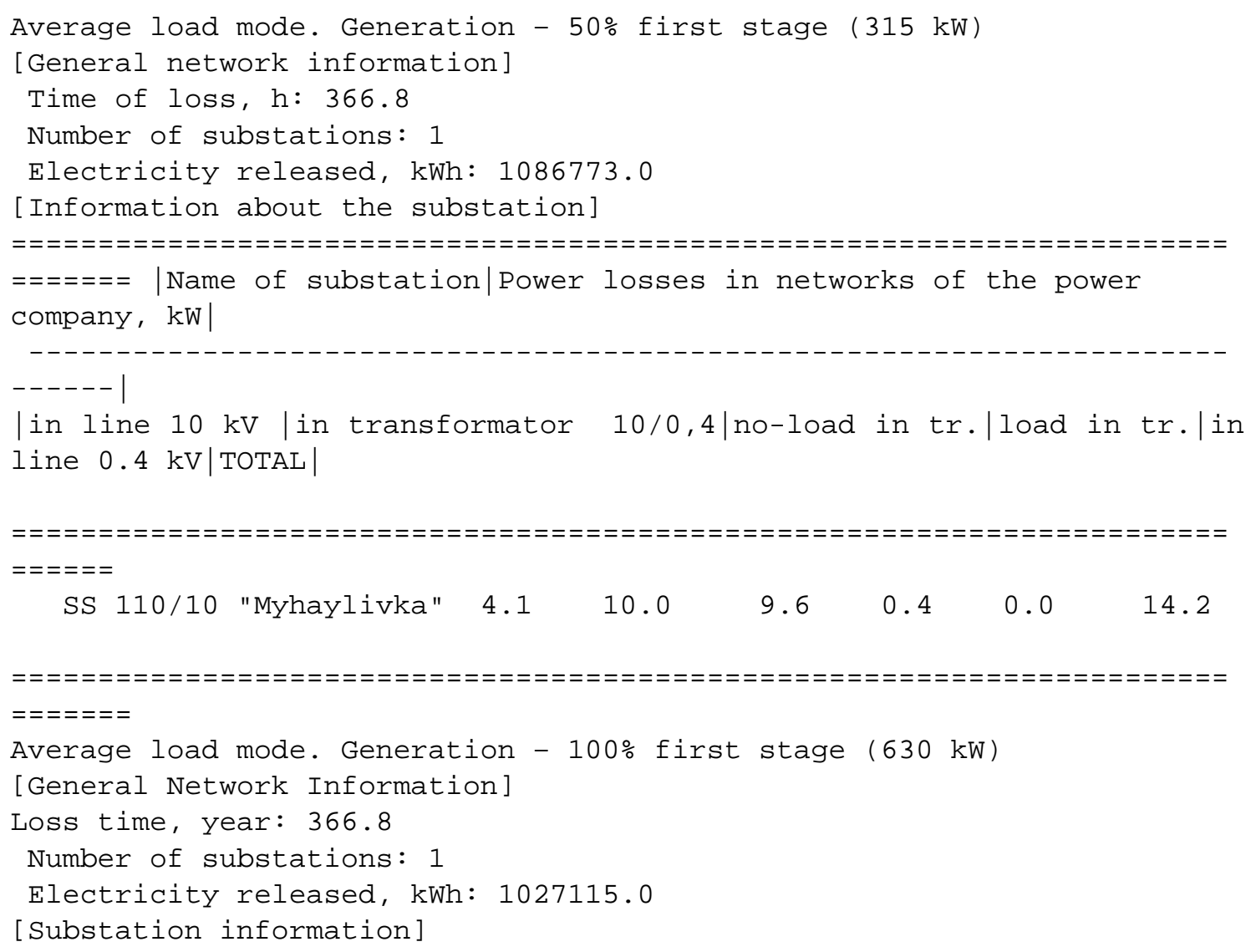





==ニ==ニ= | Name of substation|Power losses in networks of the power company, kW

$----1$

I in line $10 \mathrm{kV}$ |in transformator 10/0,4|no-load in $\mathrm{tr} . \mid$ load in $\mathrm{tr}$.| in line $0.4 \mathrm{kV}|\mathrm{TOTAL}|$

ニニニニニニ
ニニニニニ


78.4

Average load mode. Generation - 100\% first, second and third stages $(1700 \mathrm{~kW})$

[General Network Information]

Loss time, year: 366.8

Number of substations: 1

Electricity released, kWh: 1371700.4

[Substation information]

- - - -

Iin line $10 \mathrm{kV}$ |in transformator 10/0,4|no-load in tr.|load in tr.|in line $0.4 \mathrm{kV} \mid \mathrm{TOTAL}$

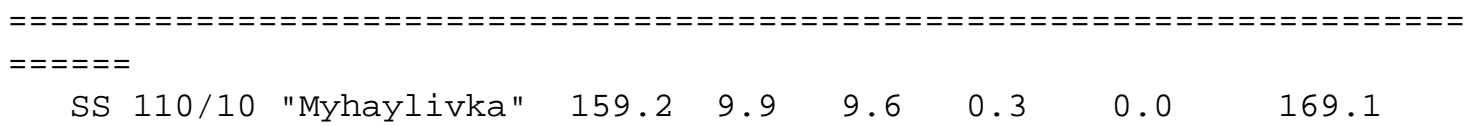

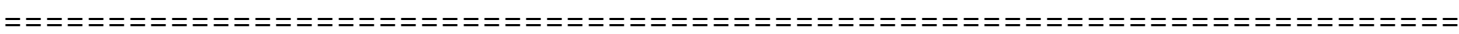
ニニニニニニニ 


\section{APPENDIX C \\ Output file for calculating the F-31 mode of the $110 / 10 \mathrm{kV}$ substation Sloboda-Pidlisivska}

\begin{tabular}{|c|c|c|c|c|}
\hline \multicolumn{4}{|c|}{ Substation: } & SI.Pidlisivska \\
\hline \multicolumn{4}{|c|}{$\mathrm{N}$ buses } & 3000 \\
\hline \multicolumn{4}{|l|}{$U=$} & 10.500 \\
\hline \multicolumn{4}{|c|}{$\operatorname{Cos} \mathrm{Fi}=$} & 0.824 \\
\hline \multicolumn{4}{|c|}{ Time $=$} & 24.000 \\
\hline \multicolumn{4}{|c|}{ Numbers of fider } & 3 \\
\hline \multicolumn{4}{|c|}{ CalcSS $=$} & TRUE \\
\hline \multicolumn{4}{|c|}{ Load's schedule. Number of steps } & 0 \\
\hline \multicolumn{5}{|l|}{ P: } \\
\hline \multicolumn{5}{|l|}{ Q: } \\
\hline \multicolumn{5}{|c|}{ Ncom: } \\
\hline \multicolumn{3}{|l|}{ Fider: } & & ф.№ 31 \\
\hline \multicolumn{3}{|l|}{$\mathrm{I}=$} & & 140.643 \\
\hline \multicolumn{3}{|c|}{ Number of branches } & & 63 \\
\hline \multicolumn{3}{|c|}{ Number of nodes } & & 63 \\
\hline \multicolumn{3}{|l|}{ Calc $=$} & & TRUE \\
\hline \multicolumn{5}{|c|}{$\begin{array}{l}\text { Inf about } \\
\text { nodes }\end{array}$} \\
\hline $\mathrm{N}$ & Name & $\mathrm{S}, \mathrm{KBT}$ & $\mathrm{dPx}, \mathrm{KBT}$ & $\mathrm{dPk}, \mathrm{kBT}$ \\
\hline 3000 & & 0 & 0 & 0 \\
\hline 3201 & & 0 & 0 & 0 \\
\hline 3202 & & 0 & 0 & 0 \\
\hline 3203 & & 0 & 0 & 0 \\
\hline 3204 & & 0 & 0 & 0 \\
\hline 461 & TM-40/10 & 40 & 0,18 & 0,88 \\
\hline 447 & TM-30/10 & 30 & 0,13 & 0,6 \\
\hline 3205 & & 0 & 0 & 0 \\
\hline 3206 & & 0 & 0 & 0 \\
\hline 3207 & & 0 & 0 & 0 \\
\hline 451 & TM-160/10 & 160 & 0,54 & 2,65 \\
\hline 3208 & & 0 & 0 & 0 \\
\hline 3209 & & 0 & 0 & 0 \\
\hline 3210 & & 0 & 0 & 0 \\
\hline 452 & TM-160/10 & 160 & 0,54 & 2,65 \\
\hline 3211 & & 0 & 0 & 0 \\
\hline 453 & TM-160/10 & 160 & 0,54 & 2,65 \\
\hline 3212 & & 0 & 0 & 0 \\
\hline 3213 & & 0 & 0 & 0 \\
\hline 3214 & & 0 & 0 & 0 \\
\hline 3215 & & 0 & 0 & 0 \\
\hline 457 & TM-100/10 & 100 & 0,36 & 1,97 \\
\hline 454 & TM-250/10 & 250 & 1,05 & 3,7 \\
\hline 3216 & & 0 & 0 & 0 \\
\hline 456 & TM-250/10 & 250 & 1,05 & 3,7 \\
\hline 3217 & & 0 & 0 & 0 \\
\hline 3218 & & 0 & 0 & 0 \\
\hline 3219 & & 0 & 0 & 0 \\
\hline 3220 & & 0 & 0 & 0 \\
\hline 3221 & & 0 & 0 & 0 \\
\hline 455 & TM-250/10 & 250 & 1,05 & 3,7 \\
\hline 3227 & & 0 & 0 & 0 \\
\hline 3222 & & 0 & 0 & 0 \\
\hline 3223 & & 0 & 0 & 0 \\
\hline 459 & TM-400/10 & 400 & 1,08 & 5,5 \\
\hline 3224 & & 0 & 0 & 0 \\
\hline 3225 & & 0 & 0 & 0 \\
\hline 3226 & & 0 & 0 & 0 \\
\hline 3240 & & 0 & 0 & 0 \\
\hline 3231 & & 0 & 0 & 0 \\
\hline 3232 & & 0 & 0 & 0 \\
\hline 3228 & & 0 & 0 & 0 \\
\hline
\end{tabular}

\begin{tabular}{|c|c|c|c|c|c|}
\hline $\mathrm{KzV}$ & $\mathrm{Kz}$ & $\mathrm{Pg}, \mathrm{kBT}$ & Qg,кВар & $\mathrm{P}, \mathrm{KBT}$ & Q,кBap \\
\hline 0 & 0 & 0 & 0 & 0 & 0 \\
\hline 0 & 0 & 0 & 0 & 0 & 0 \\
\hline 0 & 0 & 0 & 0 & 0 & 0 \\
\hline 0 & 0 & 0 & 0 & 0 & 0 \\
\hline 0 & 0 & 0 & 0 & 0 & 0 \\
\hline 0 & 0,891 & 0 & 0 & 32,806 & 13,922 \\
\hline 0 & 0,891 & 0 & 0 & 24,595 & 10,498 \\
\hline 0 & 0 & 0 & 0 & 0 & 0 \\
\hline 0 & 0 & 0 & 0 & 0 & 0 \\
\hline 0 & 0 & 0 & 0 & 0 & 0 \\
\hline 0 & 0,888 & 0 & 0 & 131,053 & 54,789 \\
\hline 0 & 0 & 0 & 0 & 0 & 0 \\
\hline 0 & 0 & 0 & 0 & 0 & 0 \\
\hline 0 & 0 & 0 & 0 & 0 & 0 \\
\hline 0 & 0,888 & 0 & 0 & 131,053 & 54,789 \\
\hline 0 & 0 & 0 & 0 & 0 & 0 \\
\hline 0 & 0,888 & 0 & 0 & 131,053 & 54,789 \\
\hline 0 & 0 & 0 & 0 & 0 & 0 \\
\hline 0 & 0 & 0 & 0 & 0 & 0 \\
\hline 0 & 0 & 0 & 0 & 0 & 0 \\
\hline 0 & 0 & 0 & 0 & 0 & 0 \\
\hline 0 & 0,889 & 0 & 0 & 81,934 & 34,43 \\
\hline 0 & 0,893 & 0 & 0 & 204,965 & 88,65 \\
\hline 0 & 0 & 0 & 0 & 0 & 0 \\
\hline 0 & 0,893 & 0 & 0 & 204,965 & 88,65 \\
\hline 0 & 0 & 0 & 0 & 0 & 0 \\
\hline 0 & 0 & 0 & 0 & 0 & 0 \\
\hline 0 & 0 & 0 & 0 & 0 & 0 \\
\hline 0 & 0 & 0 & 0 & 0 & 0 \\
\hline 0 & 0 & 0 & 0 & 0 & 0 \\
\hline 0 & 0,893 & 0 & 0 & 204,965 & 88,65 \\
\hline 0 & 0 & 0 & 0 & 0 & 0 \\
\hline 0 & 0 & 0 & 0 & 0 & 0 \\
\hline 0 & 0 & 0 & 0 & 0 & 0 \\
\hline 0 & 0,886 & 0 & 0 & 327,377 & 135,848 \\
\hline 0 & 0 & 0 & 0 & 0 & 0 \\
\hline 0 & 0 & 0 & 0 & 0 & 0 \\
\hline 0 & 0 & 0 & 0 & 0 & 0 \\
\hline 0 & 0 & 0 & 0 & 0 & 0 \\
\hline 0 & 0 & 0 & 0 & 0 & 0 \\
\hline 0 & 0 & 0 & 0 & 0 & 0 \\
\hline 0 & 0 & 0 & 0 & 0 & 0 \\
\hline
\end{tabular}




\begin{tabular}{|c|c|c|c|c|c|c|c|c|c|c|}
\hline 458 & TM-100/10 & 100 & 0,36 & 1,97 & 0 & 0,889 & 0 & 0 & 81,934 & 34,43 \\
\hline 3229 & & 0 & 0 & 0 & 0 & 0 & 0 & 0 & 0 & 0 \\
\hline 460 & TM-40/10 & 40 & 0,18 & 0,88 & 0 & 0,891 & 0 & 0 & 32,806 & 13,922 \\
\hline 3230 & & 0 & 0 & 0 & 0 & 0 & 0 & 0 & 0 & 0 \\
\hline 3233 & & 0 & 0 & 0 & 0 & 0 & 0 & 0 & 0 & 0 \\
\hline 3234 & & 0 & 0 & 0 & 0 & 0 & 0 & 0 & 0 & 0 \\
\hline 3235 & & 0 & 0 & 0 & 0 & 0 & 0 & 0 & 0 & 0 \\
\hline 3236 & & 0 & 0 & 0 & 0 & 0 & 0 & 0 & 0 & 0 \\
\hline 465 & TM-100/10 & 100 & 0,36 & 1,97 & 0 & 0,889 & 0 & 0 & 81,934 & 34,43 \\
\hline 466 & TM-100/10 & 100 & 0,36 & 1,97 & 0 & 0,889 & 0 & 0 & 81,934 & 34,43 \\
\hline 3237 & & 0 & 0 & 0 & 0 & 0 & 0 & 0 & 0 & 0 \\
\hline 462 & TM-250/10 & 250 & 1,05 & 3,7 & 0 & 0,893 & 0 & 0 & 204,965 & 88,65 \\
\hline 3238 & & 0 & 0 & 0 & 0 & 0 & 0 & 0 & 0 & 0 \\
\hline 464 & TM-100/10 & 100 & 0,36 & 1,97 & 0 & 0,889 & 0 & 0 & 81,934 & 34,43 \\
\hline 3239 & & 0 & 0 & 0 & 0 & 0 & 0 & 0 & 0 & 0 \\
\hline 463 & TM-160/10 & 160 & 0,54 & 2,65 & 0 & 0,888 & 0 & 0 & 131,053 & 54,789 \\
\hline 467 & TM-160/10 & 160 & 0,54 & 2,65 & 0 & 0,888 & 0 & 0 & 131,053 & 54,789 \\
\hline 9971 & TM-400/10 & 400 & 1,08 & 5,5 & 0,8 & 0,764 & 400 & 0 & $-118,206$ & 117,972 \\
\hline 9972 & TM-400/10 & 400 & 1,08 & 5,5 & 0,8 & 0,764 & 400 & 0 & $-118,206$ & 117,972 \\
\hline 9973 & TM-630/10 & 630 & 1,68 & 7,6 & 0,8 & 0,763 & 630 & 0 & $-186,195$ & 185,216 \\
\hline 997 & & 0 & 0 & 0 & 0 & 0 & 0 & 0 & 0 & 0 \\
\hline
\end{tabular}

\begin{tabular}{|c|c|c|c|c|c|c|c|c|}
\hline $\mathrm{Nn}$ & $\mathrm{Nk}$ & Type & Name & $\mathrm{L}, \mathrm{KM}$ & Ro,oм/км & Хо,ом/км & $R, O M$ & X,om \\
\hline 3000 & 3201 & 2 & & 1 & 0 & 0 & 0 & 0 \\
\hline 3201 & 3202 & 1 & $A C-50$ & 0,1 & 0,63 & 0,374 & 0,063 & 0,037 \\
\hline 3202 & 447 & 1 & $A C-50$ & 0,63 & 0,63 & 0,374 & 0,397 & 0,236 \\
\hline 3202 & 3203 & 1 & $A C-50$ & 1,7 & 0,63 & 0,374 & 1,071 & 0,636 \\
\hline 3203 & 3204 & 2 & & 1 & 0 & 0 & 0 & 0 \\
\hline 3204 & 461 & 1 & $A C-50$ & 1,12 & 0,63 & 0,374 & 0,706 & 0,419 \\
\hline 3202 & 3205 & 1 & $A C-35$ & 1,4 & 0,91 & 0,385 & 1,274 & 0,539 \\
\hline 3205 & 3206 & 2 & & 1 & 0 & 0 & 0 & 0 \\
\hline 3206 & 3207 & 1 & AC-35 & 0,1 & 0,91 & 0,385 & 0,091 & 0,039 \\
\hline 3207 & 451 & 1 & $A C-35$ & 0,1 & 0,91 & 0,385 & 0,091 & 0,039 \\
\hline 3207 & 3208 & 1 & AC-35 & 0,35 & 0,91 & 0,385 & 0,319 & 0,135 \\
\hline 3208 & 3209 & 2 & & 1 & 0 & 0 & 0 & 0 \\
\hline 3209 & 3210 & 1 & $A C-35$ & 0,7 & 0,91 & 0,385 & 0,637 & 0,269 \\
\hline 3210 & 452 & 1 & $A C-35$ & 0,22 & 0,91 & 0,385 & 0,2 & 0,085 \\
\hline 3210 & 3211 & 1 & $A C-50$ & 1,5 & 0,63 & 0,374 & 0,945 & 0,561 \\
\hline 3211 & 453 & 1 & $A C-35$ & 0,22 & 0,91 & 0,385 & 0,2 & 0,085 \\
\hline 3211 & 3212 & 1 & $A C-50$ & 0,28 & 0,63 & 0,374 & 0,176 & 0,105 \\
\hline 3212 & 3213 & 1 & AC-35 & 0,1 & 0,91 & 0,385 & 0,091 & 0,039 \\
\hline 3213 & 3214 & 2 & & 1 & 0 & 0 & 0 & 0 \\
\hline 3214 & 3215 & 1 & $A C-35$ & 0,1 & 0,91 & 0,385 & 0,091 & 0,039 \\
\hline 3215 & 457 & 1 & $A C-35$ & 1,6 & 0,91 & 0,385 & 1,456 & 0,616 \\
\hline 3215 & 454 & 1 & $A C-35$ & 0,1 & 0,91 & 0,385 & 0,091 & 0,039 \\
\hline 3215 & 3216 & 1 & $A C-35$ & 0,5 & 0,91 & 0,385 & 0,455 & 0,193 \\
\hline 3216 & 456 & 1 & AC-25 & 0,2 & 1,38 & 0,391 & 0,276 & 0,078 \\
\hline 3216 & 3217 & 1 & AC-35 & 0,1 & 0,91 & 0,385 & 0,091 & 0,039 \\
\hline 3217 & 3218 & 2 & & 1 & 0 & 0 & 0 & 0 \\
\hline 3218 & 3219 & 1 & AC-35 & 0,1 & 0,91 & 0,385 & 0,091 & 0,039 \\
\hline 3219 & 3220 & 1 & ААБ-3X50 & 0,1 & 0,589 & 0,09 & 0,059 & 0,009 \\
\hline 3220 & 455 & 1 & $A C-50$ & 0,1 & 0,63 & 0,374 & 0,063 & 0,037 \\
\hline 3213 & 3221 & 1 & $A C-50$ & 0,7 & 0,63 & 0,374 & 0,441 & 0,262 \\
\hline 3221 & 3227 & 1 & $A C-50$ & 0,1 & 0,63 & 0,374 & 0,063 & 0,037 \\
\hline 3227 & 3222 & 1 & ААБ-3X50 & 0,25 & 0,589 & 0,09 & 0,147 & 0,023 \\
\hline 3222 & 3223 & 2 & & 1 & 0 & 0 & 0 & 0 \\
\hline 3223 & 459 & 1 & $A C-50$ & 0,1 & 0,63 & 0,374 & 0,063 & 0,037 \\
\hline 3221 & 3228 & 1 & $A C-50$ & 0,2 & 0,63 & 0,374 & 0,126 & 0,075 \\
\hline 3228 & 458 & 1 & $A C-50$ & 0,1 & 0,63 & 0,374 & 0,063 & 0,037 \\
\hline 3228 & 3229 & 1 & $A C-50$ & 0,56 & 0,63 & 0,374 & 0,353 & 0,209 \\
\hline 3229 & 460 & 1 & $A C-50$ & 0,1 & 0,63 & 0,374 & 0,063 & 0,037 \\
\hline 3229 & 3230 & 1 & $A C-50$ & 0,1 & 0,63 & 0,374 & 0,063 & 0,037 \\
\hline 3230 & 3231 & 2 & & 1 & 0 & 0 & 0 & 0 \\
\hline 3231 & 3232 & 1 & $A C-50$ & 0,1 & 0,63 & 0,374 & 0,063 & 0,037 \\
\hline 3232 & 3240 & 1 & $A C-50$ & 0,56 & 0,63 & 0,374 & 0,353 & 0,209 \\
\hline 3240 & 3226 & 1 & $A C-50$ & 1,8 & 0,63 & 0,374 & 1,134 & 0,673 \\
\hline 3226 & 3225 & 1 & $A C-50$ & 1,05 & 0,63 & 0,374 & 0,662 & 0,393 \\
\hline 3225 & 3224 & 1 & ААБ-3X50 & 0,21 & 0,589 & 0,09 & 0,124 & 0,019 \\
\hline
\end{tabular}




\section{APPENDIX D}

\section{Estimation of functional stability of the subsystem of information exchange in local electrical systems}

Calculation of the functional stability of the subsystem of information exchange ACS:

$$
\begin{aligned}
& \rho_{2 \text { пров }}=1 \\
& \rho_{\text {пров }}=10010^{6} \\
& \rho_{\text {gprs }}=21.410^{3} \\
& \rho_{\text {edge }}=474: 610^{3} \\
& \rho_{3 G}=3: 210^{6} \\
& \rho_{\text {orr }}=1.010^{9} \\
& \mathrm{r}=11
\end{aligned}
$$

Basic mode

Bandwidth matrix of communication channels:



$$
\begin{aligned}
& \begin{array}{llllllllll}
0 & 0 & \rho_{3 G} & P_{\text {пров }} P_{\text {пров }} P_{\text {пров }} 0 & 0 & \rho_{3 G} & 0 & 0
\end{array}
\end{aligned}
$$

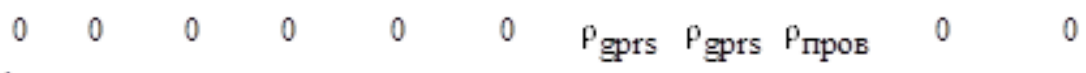

$$
\begin{aligned}
& \begin{array}{llllllllll}
0 & 0 & 0 & 0 & P_{\text {пров }} P_{\text {пров }} & 0 & 0 & 0 & 0 & 0
\end{array} \\
& p^{t}=\begin{array}{lllllllllll}
0 & 0 & 0 & 0 & 0 & 0 & 0 & 0 & 0 & 0 & 0 \\
0 & 0 & 0 & 0 & 0 & 0 & 0 & 0 & 0 & 0 & 0
\end{array}
\end{aligned}
$$

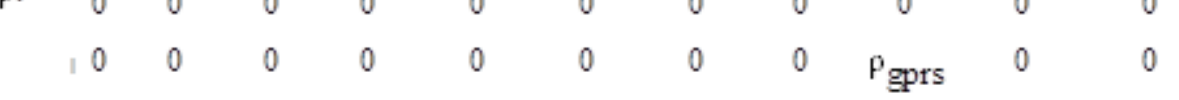

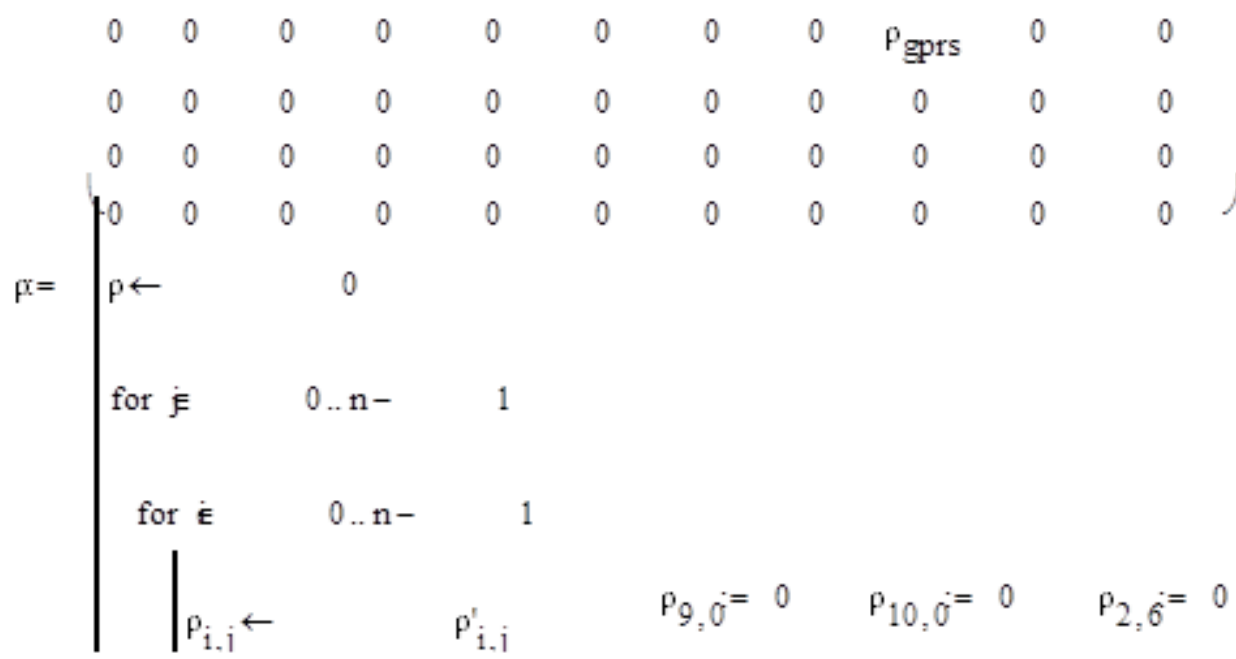

Calculation of the functional stability of the subsystem of information exchange ACS: 


$$
\begin{aligned}
& P_{2 \text { пров }}=1 \\
& P_{\text {пров }}=10010^{6} \\
& P_{\text {gprs }}=21: 410^{3} \\
& P_{\text {edge }}=474: 610^{3} \\
& P_{3 G}=3: 210^{6} \\
& P_{\text {orr }}=1.010^{9} \\
& \mathrm{rr}=11
\end{aligned}
$$

Mathematical expectation of the intensity of information transmission:

$$
M_{\rho}:=\frac{1}{n \cdot(n-1)} \cdot \sum_{i=0}^{n-1} \sum_{j=0}^{n-1} \rho_{i, j}=2.012 \times 10^{7}
$$

Formation of the matrix of weighting coefficients of communication lines:



The probability of transmitting information to the base line communication lines

$$
\mathrm{p}:=0.998 \quad \mathrm{q}:=1-\mathrm{p} \quad \mathrm{q}=0.002
$$

Determination of the association matrix of ACS:

$$
\mathrm{p}_{\mathrm{N}}:=\left(\begin{array}{lllllllllll}
0 & 0 & 0 & \mathrm{p} & 0 & 0 & 0 & 0 & 0 & \mathrm{p} & \mathrm{p} \\
0 & 0 & 0 & \mathrm{p} & 0 & 0 & 0 & 0 & \mathrm{p} & 0 & 0 \\
0 & 0 & 0 & 0 & 0 & 0 & 0 & \mathrm{p} & \mathrm{p} & 0 & 0 \\
\mathrm{p} & \mathrm{p} & 0 & 0 & \mathrm{p} & \mathrm{p} & 0 & 0 & 0 & 0 & 0 \\
0 & 0 & 0 & \mathrm{p} & 0 & 0 & 0 & 0 & 0 & 0 & 0 \\
0 & 0 & 0 & \mathrm{p} & 0 & 0 & 0 & 0 & 0 & 0 & 0 \\
0 & 0 & \mathrm{p} & 0 & 0 & 0 & 0 & 0 & 0 & 0 & 0 \\
0 & 0 & \mathrm{p} & 0 & 0 & 0 & 0 & 0 & 0 & 0 & 0 \\
0 & \mathrm{p} & \mathrm{p} & 0 & 0 & 0 & 0 & 0 & 0 & 0 & 0 \\
0 & 0 & 0 & 0 & 0 & 0 & 0 & 0 & 0 & 0 & 0 \\
0 & 0 & 0 & 0 & 0 & 0 & 0 & 0 & 0 & 0 & 0
\end{array}\right)
$$




$$
\begin{aligned}
& \mathbf{P}_{0,1}=\mathbf{P}_{0,3}-\mathbf{P}_{3,1} \quad \mathbf{P}_{1,0}=\mathbf{P}_{1,3}-\mathbf{P}_{3,0}
\end{aligned}
$$

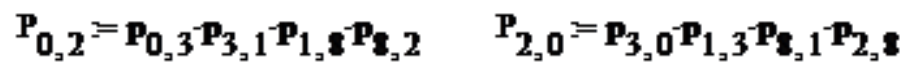

$$
\begin{aligned}
& \mathbf{P}_{\mathbf{0}_{3},}=\mathbf{P}_{0,3} \quad \mathbf{P}_{3,0}=\mathbf{P}_{3,0} \\
& \mathbf{P}_{0,4}=\mathbf{P}_{0,3}-\mathbf{P}_{3,4} \quad \mathbf{P}_{4,0}=\mathbf{P}_{3,0} \mathbf{P}_{4,3} \\
& \mathbf{P}_{0,5}=\mathbf{P}_{0,3}-\mathbf{P}_{3,5} \quad \mathbf{P}_{5,0}=\mathbf{P}_{3,0}-\mathbf{P}_{5,3} \\
& P_{0,6}=0 \\
& \mathbf{P}_{6,0}=\mathrm{p}_{6,0} \\
& P_{0,8}=0 \\
& \mathrm{P}_{\mathrm{g}, 0}=\mathrm{p}_{8,1} \mathrm{p}_{1,3} \mathrm{p}_{3, \mathrm{C}} \\
& P_{0,9}=P_{0,9} \\
& \mathbf{P}_{9,0}=0 \\
& \mathrm{P}_{0,10}=\mathrm{P}_{0,10} \\
& \mathrm{P}_{10,0}=0 \\
& \mathrm{P}_{1,2}=\mathrm{p}_{1 ; \mathrm{s}} \mathrm{p}_{\mathrm{g}, 2} \\
& \mathbb{P}_{2,1}:=p_{2 ; 8} p_{8,1} \\
& \mathrm{P}_{1,3}=\mathrm{P}_{1,3} \\
& \mathrm{P}_{3,1}:=\mathrm{p}_{3,1} \\
& \mathrm{P}_{1,4}=\mathrm{P}_{1,3} \mathrm{P}_{3,4} \\
& \mathbf{P}_{4,1}:=\mathrm{p}_{3,1} \mathrm{p}_{4,3} \\
& \mathrm{P}_{1,5}=\mathrm{P}_{1,3} \mathrm{P}_{3,5} \\
& \mathbf{P}_{5,1}=\mathrm{p}_{3,1} \mathrm{p}_{5,3} \\
& \mathrm{P}_{1, \dot{\mathrm{S}}}=\mathrm{P}_{1, \mathrm{~S}} \\
& \mathrm{P}_{8,1}:=\mathrm{p}_{8,1} \\
& \mathrm{P}_{1,9}=\mathrm{p}_{1,3} \mathbf{p}_{3,0} \mathrm{P}_{0,9} \\
& \mathbf{P}_{9,1}:=0 \\
& \mathrm{P}_{1,10}=\mathrm{p}_{1,3} \mathrm{p}_{3,0} \mathrm{p}_{0,9} \\
& \mathbf{P}_{10,1}=0 \\
& \mathrm{P}_{2,6}=0 \\
& \mathrm{P}_{6,2}=\mathrm{p}_{6,2} \\
& \mathrm{P}_{2,7}=0 \\
& \mathrm{P}_{7,2}=\mathrm{P}_{6,2} \\
& \mathrm{P}_{2, \dot{\mathrm{S}}}=\mathrm{P}_{2, \mathrm{~S}} \\
& \mathrm{P}_{8,2}=\mathrm{p}_{8,2} \\
& \mathrm{P}_{3,4}=\mathrm{P}_{3,4} \\
& \mathrm{P}_{4,3}=\mathrm{P}_{4,3} \\
& \mathrm{P}_{3,5}=\mathrm{P}_{3,5} \\
& \mathrm{P}_{5,3}=\mathrm{P}_{5,3} \\
& \mathrm{P}_{3, \dot{8}}=\mathrm{p}_{3,1} \mathrm{p}_{1,8} \\
& \mathrm{P}_{8,3}=\mathrm{p}_{1,3} \mathrm{p}_{8,1} \\
& \mathrm{P}_{3,9}=\mathrm{P}_{3,0} \mathrm{P}_{0,9} \\
& \mathbf{P}_{9,3}=0 \\
& \mathrm{P}_{3,10}=\mathrm{P}_{3,0} \mathrm{P}_{0,9} \\
& \mathrm{P}_{10,3}=0
\end{aligned}
$$

A generalized index of functional stability:

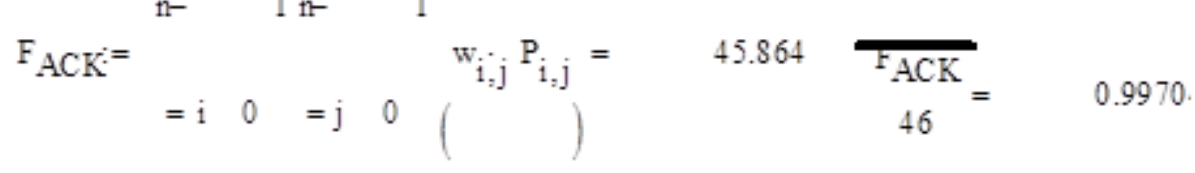


УДК 621.311.24+621.311.1

O-66

Автори:

О. Б. Бурикін, П. Д. Лежнюк, В. В. Кулик, О. Є. Рубаненко, Ю. В. Малогулко

Рецензенти:

М. С. Сегеда, доктор технічних наук, професор

В. М. Кутін, доктор технічних наук, професор

Рекомендовано до друку Вченою радою Вінницького національного технічного університету Міністерства освіти і науки України (протокол № 4 від 30.11.2017 р.)

Оптимізація функціонування локальних електричних O-66 систем 3 відновлюваними джерелами енергії: монографія / О. Б. Бурикін， П. Д. Лежнюк， В.В.Кулик та ін. - Вінниця : ВНТУ, 2018. - $124 \mathrm{c}$.

ISBN 978-966-641-719-3

В монографії розглядається проблема функціонування локальних енергосистем 3 різнотипними відновлюваними джерелами енергії (ВДЕ) в електромережах за рахунок оптимізації схем ї приєднання, а також автоматизації частини функцій керування, а саме оптимального керування режимами ВДЕ з урахуванням особливостей перетворення ними первинної енергії та електричних зв'язків. Монографія розрахована на фахівців в галузі математичного моделювання та оптимізації роботи відновлюваних джерел енергії в розподільних електричних мережах, а також може бути корисною студентам і аспірантам відповідного спрямування.

УДК 621.311.24+621.311.1

ISBN 978-966-641-719-3

(C) О. Бурикін, П. Лежнюк, В. Кулик, О. Рубаненко, Ю. Малогулко, 2018 


\author{
Бурикін Олександр Борисович \\ ЛежнюкПетро Дем'янович \\ КуликВолодимир Володимирович \\ Рубаненко Олександр Євгенійович \\ Малогулко Юлія Володимирівна
}

\title{
ОПТИМІЗАЦІЯ ФУНКЦІОНУВАННЯ ЛОКАЛЬНИХ ЕЛЕКТРИЧНИХ СИСТЕМ 3 ВІДНОВЛЮВАНИМИ ДЖЕРЕЛАМИ ЕНЕРГІЇ
}

\author{
Монографія \\ Редактор С. Малішевська \\ Оригінал-макет підготовлено Ю. Малогулко
}

Підписано до друку 12.01.2018 р.

Формат 29,7×421/4. Папір офсетний.

Гарнітура Times New Roman.

Друк різографічний. Ум. др. арк. 7,16.

Наклад 300 (1-й запуск 1-75) пр. Зам № В2018-01

Вінницький національний технічний університет,

ІРВЦ ВНТУ,

21021, м. Вінниця, Хмельницьке шосе, 95,

ВНТУ, ГНК, к. 114.

Тел. (0432) 65-18-06.

press.vntu.edu.ua; email: kivc.vntu@gmail.com.

Свідоцтво суб' єкта видавничої справи серія ДК № 3516 від 01.07.2009 р.

Віддруковано ФОП Барановська Т. П. 21021, м. Вінниця, вул. Порика, 7.

Свідоцтво суб' єкта видавничої справи серія ДК № 4377 від 31.07.2012 p. 